\title{
On the Macro-drivers of Realized Volatility: the destabilizing impact of UK Policy Uncertainty across Europe.
}

\author{
M. Karanasos ${ }^{\dagger}$, S. Yfanti ${ }^{\ddagger}, *$ \\ ${ }^{\dagger}$ Brunel University London, UK; ${ }^{\ddagger}$ Loughborough University, UK
}

January 2020

\begin{abstract}
This paper studies the bivariate HEAVY system of daily and intra-daily volatility equations and its macro-augmented asymmetric power extension. We focus on economic drivers that exacerbate stock market volatility and can be proved to be major threats for financial stability. Our study proves the inflammatory effects of UK Policy Uncertainty alongside global credit and commodity factors that spread across European financial markets. This UK-led spillover phenomenon should be considered by world market participants and recognized, monitored and mitigated by policymakers amid the Brexit fears and the associated highly probable harm for Europe. Other findings are as follows. First, once we allow for power transformations, asymmetries, and macro-effects in the benchmark specification, it is found that both powered conditional variances are significantly affected by the powers of squared negative returns and realized measure, further improving the HEAVY framework's forecasting accuracy. Second, the structural breaks applied to the bivariate system capture the time-varying behavior of the parameters, in particular during the global financial crisis of 2007/08. Third, higher UK uncertainty levels increase the leverage and global macro-effects from credit and commodity markets on all European stock markets' realized volatilities.
\end{abstract}

Keywords: macro-financial linkages, HEAVY model, UK economic policy uncertainty, highfrequency data, realized variance, asymmetries, power transformations, financial crisis, structural breaks, risk management.

JEL classification: C22, C58, D80, E44, G01, G15

*Address for correspondence: Stavroula Yfanti, School of Business and Economics, Loughborough University, Epinal Way, Loughborough, Leicestershire, LE11 3TU, UK; email: stavyfan@gmail.com, tel: +44 (0)1509 227091. 


\section{Introduction}

The volatility of financial returns constitutes a pivotal part of empirical finance and econometrics research, with crucial implications for financial risk management practices, and financial stability oversight. Robust modeling and reliable forecasting the volatility trajectory of financial instruments has been the main task and objective of financial economics applications for business operations, given that volatility constitutes one of the fundamental input variables in estimations and decision processes of any corporation on derivatives pricing, portfolio optimization, investment diversification, firm valuation, and funding choices. Financial volatility is also closely inspected by policymakers since it entails critical destabilizing threats for the financial system.

Intriguingly, the financial econometrics literature on realized volatility dynamics mostly ignores important macro-factors that affect the volatility pattern in the high-frequency domain. In this vein, we examine the role of uncertainty, besides other macro-proxies, in volatility modeling using the news-based Economic Policy Uncertainty Index, the sole uncertainty metric provided in daily frequency by Baker et al. (2016) for the United States and the United Kingdom and considered as the most comprehensive one, including both economic and policy-related constituents of uncertainty. Our motivation to explore the uncertainty effects on financial volatility derives from the recent resurgence of research interest in uncertainty, partly stimulated by the global crisis of 2008 and primarily reflected in the definition and measurement debate of this 'amorphous' concept by economists (Bloom, 2014). Following the Knightian definition (Knight, 1921) and the early studies on uncertainty by Bernanke (1983) and Dixit and Pindyck (1994), academics and practitioners have attempted to objectively quantify this latent variable to reflect the prevailing uncertainty in the process of decision making by economic agents. Consumers' spending and saving behavior, firms' hiring, financing and investment choices, investors' asset allocation, central banks, and government policy decisions are heavily affected by their 'inability to forecast the likelihood of events happening' according to Frank Knight (Bloom, 2014). In principle, the prevailing uncertainty is evidenced to elicit potent disruptions in the real economy through financial and credit markets, dampening the general confidence and discouraging market participants from doing business. Undoubtedly, in times of elevated uncertainty, households tend to reduce consumption and increase precautionary savings and firms postpone investments ('wait and see' tactics) and refrain from hiring. Similarly, investors in financial markets concerned with uncertainty react, evoking the progressive slowdown or often the steep fall of asset price returns (either through the discount rate or the cash flow channel) and synchronously driving volatility to jump (Pastor and Veronesi, 2013). Simultaneously, in the credit markets uncertainty commands a risk premium in the cost of capital, foreshadowing the possible meteoric rise of the financing cost for firms (Alessandri and Mumtaz, 2019) and undermining general trust in the financial system. 
This paper examines the HEAVY model of Shephard and Sheppard (2010), which jointly estimates conditional variances based on both daily (squared returns) and intra-daily (realized variance) data, by enriching the bivariate system, firstly, with asymmetries and power transformations, through the structure of Ding et al. (1993). Motivated by the widely-recognized merits of the APARCH framework, which considerably improves Bollerslev's GARCH process by adding leverage and power effects (see, for example, Karanasos and Kim, 2006), we similarly extend the HEAVY system with these two main features of asymmetries and power transformations to prove its superiority over the benchmark specification. The optimal estimation of the power term and the asymmetric response to positive and negative shocks embedded in the time-varying volatility pattern have already proved to be one of the most pivotal innovations in the GARCH family of models (see, for example, Brooks et al., 2000). Among others, Pérez et al. (2009, see the references therein for more details) show that the presence of an asymmetric response of volatility to positive and negative returns shows up in non-zero cross-correlations between original returns and future powers of absolute returns. One of our main findings is that each of the two powered conditional variances is significantly affected by the first lags of both power transformed variables, that is, squared negative returns, and realized variance (or, for the latter, its negative signed values). Secondly, we extend the asymmetric power specification with macro-effects from Economic Policy Uncertainty, Bond and Commodity market benchmarks, providing a competing framework of volatility modeling to the well-established practice of financial instruments trading and risk measuring based on economic fundamentals.

We analyze the macro-augmented Asymmetric Power HEAVY model in depth and we investigate its performance over eleven European stock indices, considering common volatility effects from UK Economic Policy Uncertainty and global bond and commodity market factors. The UK Economic Policy Uncertainty is the only daily uncertainty metric provided for European economies and should lie in the epicenter of academics' and practitioners' interest in European macro-financial linkages. Since it nowadays reflects the major Brexit fear effects on agents' expectations among other issues related directly to the AngloSaxon and the European and global economy, as well, we anticipate that its effect on financial markets can be proved a critical destabilizing factor across the whole continent. The asymmetric power model for the returns equation pools information across both low- and high-frequency based volatility indicators. Similarly, the more richly parametrized HEAVY process for the realized variance equation is bolstered with low-frequency information as well since the lagged value of the powered squared negative returns improves the forecasting performance of the model. The realized measure also receives significant positive impact from all macro-variables included, that is uncertainty, bond and commodity market conditions with further improvement of the model's forecasting performance. Moreover, in the presence of structural breaks, which are apparent in the two power transformed volatility measures, we re-estimate the bivariate 
system including dummy variables, and we present the time-varying behavior of the parameters. Focusing on the recent global financial crisis, we observe that their values increase significantly after the crisis. Finally, we examine not only the direct destabilizing effect of uncertainty on realized volatility, by using it as a regressor to the HEAVY process, but also the impact on each parameter of the system, proving that higher uncertainty levels inflate the leverage and macro-effects from credit and commodity markets on the realized measure.

In the advent of the crisis, when volatilities increased sharply and persistently with crucial systemic risk externalities, we witnessed a reigniting interest of regulators and academics in meaningful volatility estimates, while, at the same time, practitioners remained alert to improving the relevant volatility frameworks on a day-to-day basis. Financial economics scholars focused on volatility as a potent catalyst of systemic risk build-up, which policymakers tried to limit. To the best of our knowledge, we are the first to extend the benchmark HEAVY model with asymmetries, power transformations and macroeffects, providing a well-defined framework that adequately fits the volatility process. Our framework contributes to two main strands of empirical macro-finance literature: the research on volatility modeling and the macro-financial linkages with the investigation of the crucial uncertainty effects on financial market stability. The bivariate system of the two volatility equations, we establish, is ready-to-use not only on stock market returns but also on further asset classes or financial instruments (e.g. exchange rate, cryptocurrency, commodity, real estate, and bond returns, associating them with alternative macroproxies besides uncertainty) and multiple financial economics applications of business operations, such as bonds investing, foreign exchange trading and commodities hedging, core daily functions in the treasuries of most financial and non-financial corporations.

Overall, our proposed volatility modeling framework improves the HEAVY model, with major implications for market practitioners and policymakers on forecasting the financial returns' second moment. Volatility modeling and forecasting are essential for asset allocation, pricing and risk management hedging strategies. A reliable volatility forecast, exploiting in full the high-frequency domain and the macrofinancial linkages, is the input variable of paramount importance for the processes of derivatives pricing, effective cross-hedging, Value-at-Risk measurement, investment allocation and portfolio optimization with different asset classes and financial instruments. Moreover, the robust volatility modeling approach we introduce provides a useful tool not only for market players but also for policymakers. Policymaking includes continuous oversight duties and prudential regulation practices. In this vein, it is imperative for the authorities to account for the volatility of financial markets across every aspect of the financial system's policy responses, both post-crisis through stabilization policy reactions and pre-crisis through proactive assessment of financial risks. Focusing, here, on the UK uncertainty effect across the European stock markets is crucial due to the close inspection by policymakers and the huge concern by market 
players of the financial disruption risks contingent on the final Brexit outcome and the prevailing Brexit uncertainty since the 2016 referendum.

The paper proceeds as follows. In Section 2, we detail the HEAVY formulation with our extended specification, which allows for asymmetries, power transformations, and macro-effects. Section 3 describes the data and Section 4 presents the estimation results for i) the benchmark process, ii) the macro-augmented asymmetric power models, iii) the multiple-step-ahead forecasts that measure the out-of-sample performance of the various specifications, and iv) the asymmetric power formulations with structural breaks. Section 5 focuses on the UK uncertainty effects across the parameters of the HEAVY specifications and Section 6 discusses the policy implications of our findings. Finally, Section 7 concludes the analysis.

\section{The HEAVY Framework}

There are several studies introducing non-parametric estimators of realized volatility using high-frequency market data. Andersen and Bollerslev (1998), Andersen et al. (2001) and Barndorff-Nielsen and Shephard (2002) were the first that econometrically formalized the realized variance with quadratic variation-like measures, while Barndorff-Nielsen et al. (2008, 2009) focused on the realized kernel estimation as a realized measure which is more robust to noise. Consequently, a large body of empirical research focuses on modeling and forecasting the realized volatility. Various studies combine it with the conditional variance of returns. Engle (2002b) proposed the GARCH-X process, where the former is included as an exogenous variable in the equation of the latter. Corsi et al. (2008) suggested the HAR-GARCH formulation for modeling the volatility of realized volatility. Hansen et al. (2012) introduced the Realized GARCH model that corresponds more closely to the HEAVY framework of Shephard and Sheppard (2010), which jointly estimates conditional variances based on both daily (squared returns) and intra-daily (it uses the realized measure - kernel and variance - as a measure of ex-post volatility) data, so that the system of equations adopts to information arrival more rapidly than the classic daily GARCH process. One of its advantages is the robustness to certain forms of structural breaks, especially during crisis periods, since the mean reversion and short-run momentum effects result in higher quality performance in volatility level shifts and more reliable forecasts. Borovkova and Mahakena (2015) employed a HEAVY specification with a skewed-t error distribution, while Huang et al. (2016) incorporated the HAR structure of the realized measure in the GARCH conditional variance specification in order to capture the long memory of the volatility dynamics.

The HEAVY model of Shephard and Sheppard (2010) can be extended in many directions. We allow for power transformations, leverage and macroeconomic effects in the conditional variance process. We run the estimated benchmark specification, enriched with the three key features to improve volatility 
modeling and forecasting further.

\subsection{The Benchmark Model}

The HEAVY model uses two variables: the close-to-close stock returns $\left(r_{t}\right)$ and the realized measure of variation based on high-frequency data, $R M_{t}$. We first form the signed square rooted (SSR) realized measure as follows: $\widetilde{R M_{t}}=\operatorname{sign}\left(r_{t}\right) \sqrt{R M_{t}}$, where $\operatorname{sign}\left(r_{t}\right)=1$, if $r_{t} \geqslant 0$ and $\operatorname{sign}\left(r_{t}\right)=-1$, if $r_{t}<0$.

We assume that the returns and the SSR realized measure are characterized by the following relations:

$$
r_{t}=e_{r t} \sigma_{r t}, \widetilde{R M_{t}}=e_{R t} \sigma_{R t},
$$

where the stochastic term $e_{i t}$ is independent and identically distributed (i.i.d), $i=r, R$; $\sigma_{i t}$ is positive with probability one for all $t$ and it is a measurable function of $\mathcal{F}_{t-1}^{(X F)}$, that is the filtration generated by all available information through time $t-1$. We will use $\mathcal{F}_{t-1}^{(H F)}(X=H)$ for the high-frequency past data, i.e., for the case of the realized measure, or $\mathcal{F}_{t-1}^{(L o F)}(X=L o)$ for the low-frequency past data, i.e., for the case of the close-to-close returns. Hereafter, for notational convenience, we will drop the superscript $X F$.

In the HEAVY/GARCH model $e_{i t}$ has zero mean and unit variance. Therefore, the two series have zero conditional means, and their conditional variances are given by

$$
\mathbb{E}\left(r_{t}^{2} \mid \mathcal{F}_{t-1}\right)=\sigma_{r t}^{2}, \text { and } \mathbb{E}\left({\widetilde{R M_{t}}}^{2} \mid \mathcal{F}_{t-1}\right)=\mathbb{E}\left(R M_{t} \mid \mathcal{F}_{t-1}\right)=\sigma_{R t}^{2}
$$

where $E(\cdot)$ denotes the expectation operator. The returns equation is called HEAVY- $r$ and, similarly, the realized measure equation is denoted as HEAVY- $R$.

\subsection{The Macro-augmented Asymmetric Power Specification}

The asymmetric power (AP) specification for the $\operatorname{HEAVY}(1,1)$ model consists of the following equations (in what follows, for notational simplicity, we will drop the order of the model if it is $(1,1)$ ):

$$
\left(1-\beta_{i} L\right)\left(\sigma_{i t}^{2}\right)^{\frac{\delta_{i}}{2}}=\omega_{i}+\left(\alpha_{i r}+\gamma_{i r} s_{t-1}\right) L\left(r_{t}^{2}\right)^{\frac{\delta_{r}}{2}}+\left(\alpha_{i R}+\gamma_{i R} s_{t-1}\right) L\left(R M_{t}\right)^{\frac{\delta_{R}}{2}},
$$

where $L$ is the lag operator, $\delta_{i} \in \mathbb{R}_{>0}$ (the set of the positive real numbers), for $i=r, R$, are the power parameters, and $s_{t}=0.5\left[1-\operatorname{sign}\left(r_{t}\right)\right]$, that is, $s_{t}=1$ if $r_{t}<0$ and 0 otherwise; $\gamma_{i i}, \gamma_{i j}(i \neq j)$ are the own and cross leverage parameters, respectively ${ }^{1}$; positive $\gamma_{i i}, \gamma_{i j}$ means a larger contribution of negative 'shocks' in the volatility process. In this specification the powered conditional variance, $\left(\sigma_{i t}^{2}\right)^{\delta_{i} / 2}$, is a linear function of the lagged values of the powered transformed squared returns and realized measure.

\footnotetext{
${ }^{1}$ This type of asymmetry was introduced by Glosten et. al. (1993).
} 
We will distinguish between three different asymmetric cases: the double one (DA: $\gamma_{i j} \neq 0$ for all $i$ and $j$ ) and two more, own asymmetry (OA: $\gamma_{i j}=0$ for $i \neq j$ only) and cross asymmetry $\left(\mathrm{CA}: \gamma_{i i}=0\right)$.

The $\alpha_{i R}$ and $\gamma_{i R}$ are called the (four) Heavy parameters (own when $i=R$ and cross when $i \neq R$ ). These parameters capture the impact of the realized measure on the two conditional variances. Similarly, the $\alpha_{i r}$ and $\gamma_{i r}$ (four in total) are called the Arch parameters (own when $i=r$ and cross for $i \neq r$ ). They depict the influence of the squared returns on the two conditional variances.

The asymmetric power model is equivalent to a bivariate AP-GARCH process for the returns and the SSR realized measure (see, for example, Conrad and Karanasos, 2010). If all four Arch parameters are zero, then we have the AP version of the benchmark HEAVY specification, where the only unconditional regressor is the first lag of the powered $R M_{t}$.

Next, we provide a comparison between the benchmark HEAVY system and the more general AP specification. Their difference is captured by the matrix $C$ (see eq. (B.6) of the Supplementary Appendix). We will examine the bivariate case, which is when $N=2$. For the more general DAP specification, $C$ is a full matrix with: i) diagonal elements given by $\beta_{i}+\left(\alpha_{i i}+\gamma_{i i} / 2\right) z_{i}, i=r, R$, where $z_{i}=E\left(\left|e_{i t}\right|^{\delta_{i}}\right.$, and ii) off-diagonal elements given by $\left(\alpha_{i j}+\gamma_{i j}\right) z_{j}, i, j=r, R$, for $i \neq j$. For the benchmark model, since $\gamma_{i j}=0, z_{i}=1$, for all $i, j=r, R$, and $\alpha_{R i}=0, C$ is restricted to being an upper diagonal matrix. That is, we have

$$
\begin{array}{ll}
\text { DAP Specification: } & \mathbf{C}=\left[\begin{array}{ll}
\beta_{r}+\left(\alpha_{r r}+\gamma_{r r} / 2\right) z_{r} & \left(\alpha_{r R}+\gamma_{r R} / 2\right) z_{R} \\
\left(\alpha_{R r}+\gamma_{R r} / 2\right) z_{r} & \beta_{R}+\left(\alpha_{R R}+\gamma_{R R} / 2\right) z_{R}
\end{array}\right] \\
\text { Benchmark HEAVY }: \quad \mathbf{C}=\left[\begin{array}{ll}
\beta_{r} & \alpha_{r R} \\
0 & \beta_{R}+\alpha_{R R}
\end{array}\right] .
\end{array}
$$

Figure 1 presents the comparison of the benchmark and DAP-HEAVY models' forecasting performance (see also Section 4.3). We apply the optimal predictor $\left|\mathbf{r}_{t}\right|^{\wedge \boldsymbol{\delta}}$ (under Proposition 3 of the Supplementary Appendix) on FTSE 100 returns and realized variance data and calculate 50-step ahead forecasts. The more general specification produces forecasts significantly closer to the actual values for both returns (Fig.1, a \& b) and realized measure (Fig.1, c \& d). Most importantly, its forecasts are more accurate in peaks of returns and realized variance actual values. The benchmark model remains behind our proposed asymmetric power extension in predicting low- and high-frequency volatility indicators. It produces, mostly, lower volatility forecasts (dotted lines) in comparison with DAP (dashed lines) and actual (solid lines) values. Therefore, our main contribution, that is the asymmetric power extension, provides a significant improvement to the HEAVY system of Shephard and Sheppard (2010).

[Figure 1 here] 
Furthermore, we should mention that all the parameters in this bivariate system should take nonnegative values (see, for example, Conrad and Karanasos, 2010). Therefore, we extend the realized measure equation of the model with the non-negative macro-proxies: the UK Economic Policy Uncertainty, $E P U_{t}$, the Bonds (the Merrill Lynch MOVE 1 month treasury bonds implied volatility index, the Moody's AAA \& BAA corporate bonds yields or the Moody's BAA over AAA corporate bonds spreads), $B O_{t}$, and the Commodities (the S\&P GSCI index or the Crude oil WTI prices), $C O_{t}$, market benchmark indices. The macro-augmented (m-) AP-HEAVY system is characterized by the following equation for the realized measure:

$$
\begin{aligned}
\left(1-\beta_{R} L\right)\left(\sigma_{R t}^{2}\right)^{\frac{\delta_{R}}{2}}= & \omega_{R}+\left(\alpha_{R r}+\gamma_{R r} s_{t-1}\right) L\left(r_{t}^{2}\right)^{\frac{\delta_{r}}{2}}+\left(\alpha_{R R}+\gamma_{R R} s_{t-1}\right) L\left(R M_{t}\right)^{\frac{\delta_{R}}{2}} \\
& +\phi_{R} E P U_{t-1}+\zeta_{R} B O_{t-1}+\vartheta_{R} C O_{t-1}
\end{aligned}
$$

Eq. (4) incorporates three Macro parameters, $\phi_{R}, \zeta_{R}$, and $\vartheta_{R}$, which capture the macro-effects on the power transformed realized measure. The returns equation remains the same as in the non-augmented specification, without the direct effect from the macro-variables $\left(\phi_{r}, \zeta_{r}, \vartheta_{r}=0\right)$.

To sum up, the benchmark model (eq. (2)) is characterized by two conditional variance equations, the $\operatorname{GARCH}(1,0)-\mathrm{X}$ formulation for returns and the $\operatorname{GARCH}(1,1)$ formulation for the SSR realized measure:

$$
\begin{aligned}
& \text { HEAVY- } r:\left(1-\beta_{r} L\right) \sigma_{r t}^{2}=\omega_{r}+\alpha_{r R} L\left(R M_{t}\right), \\
& \text { HEAVY-R: }\left(1-\beta_{R} L\right) \sigma_{R t}^{2}=\omega_{R}+\alpha_{R R} L\left(R M_{t}\right)
\end{aligned}
$$

Eq. (4) gives the general formulation of our macro-augmented extension for $R M_{t}$, which adds asymmetries and power transformations to the benchmark specification (see also the Supplementary Appendix for our theoretical considerations). We also use the existing Gaussian quasi-likelihood estimators and multistepahead predictors already applied (Ding et al., 1993) in the APARCH framework (see, for example, He and Teräsvirta 1999, Laurent, 2004, Karanasos and Kim, 2006). We will first estimate both conditional variance equations in the general form with all Heavy, Arch and Asymmetry parameters given by eq. (4) and in case a parameter is insignificant, we will exclude it and this will result in a reduced form which is statistically preferred for each volatility process. For example, in the returns and realized measure conditional variances estimation, the own and cross Arch parameters ( $\alpha_{r r}$ and $\alpha_{R r}$ respectively) prove to be insignificant and are, therefore, excluded (see Section 4.2, Tables 3A and 3B) since this is the way to reach the returns and realized measure formulations that are statistically preferred. 


\section{Data Description}

The HEAVY framework is estimated for eleven European stock indices returns and realized volatilities. According to the analysis in Shephard and Sheppard (2010), the HEAVY formulation improves the volatility modeling considerably by allowing momentum and mean reversion effects and adjusting quickly to the structural breaks in volatility. We extend the benchmark specification in Shephard and Sheppard (2010), by adding the features of power transformed conditional variances, leverage, and macro-effects in the volatility process. Moreover, in order to identify the possible recent global financial crisis effects on the volatility process and to take into account the structural breaks in the two powered series (squared returns and realized measure), in Section 4.4, we incorporate dummies in our empirical investigation.

\subsection{Oxford-Man Institute's Library}

We use daily data for eleven European stock market indices extracted from the Oxford-Man Institute's (OMI) realized library version 0.3 (Heber et al., 2009): FTSE 100 (FTSE) from the UK, EURO STOXX 50 (EU) from the Eurozone, DAX 30 (DAX) from Germany, CAC 40 (CAC) from France, AEX from the Netherlands, Bell 20 (BELL) from Belgium, IBEX 35 (IBEX) from Spain, the Swiss Stock Market Index (SSMI), the OMX Copenhagen 20 index (OMXC) from Denmark, the OMX Stockholm All Share index (OMXS) from Sweden and the Oslo Exchange All Share index (OSE) from Norway. Our sample covers the period from 2001 to 2019 for most indices. For OMXC and OMXS, the data start from 2005. The OMI's realized library includes daily stock market returns and several realized volatility measures calculated on high-frequency data from the Reuters DataScope Tick History database. The data are first cleaned and then used in the realized measures calculations. According to the library's documentation, the data cleaning consists of deleting records outside the time interval that the stock exchange is open. Some minor manual changes are also needed when results are ineligible due to the re-basing of indices. We use the daily closing prices, $P_{t}^{C}$, to form the daily returns as follows: $r_{t}=\left[\ln \left(P_{t}^{C}\right)-\ln \left(P_{t-1}^{C}\right)\right] \times 100$, and two realized measures as drawn from the library: the 5-minute realized variance and the realized kernel. The estimation results using the two alternative measures are very similar, so we present only the ones with the realized variance (the results for the realized kernel are available upon request).

\subsection{Realized Measures}

The library's realized measures are calculated in the way described in Shephard and Sheppard (2010). The realized kernel, which we use as an alternative to the realized variance (results are not reported but they are available upon request), is calculated using a Parzen weight function as follows: $R K_{t}=$ $\sum_{k=-H}^{H} k(h /(H+1)) \gamma_{h}$, where $k(x)$ is the Parzen kernel function with $\gamma_{h}=\sum_{j=|h|+1}^{n} x_{j, t} x_{j-|h|, t} ; x_{j t}=$ 
$X_{t_{j, t}}-X_{t_{j-1, t}}$ are the 5 -minute intra-daily returns where $X_{t_{j, t}}$ are the intra-daily log-prices and $t_{j, t}$ are the times of trades on the $t$-th day. Shephard and Sheppard (2010) declared that they selected the bandwidth of $H$ as in Barndorff-Nielsen et al. (2009).

The 5 -minute realized variance, $R V_{t}$, which we choose to present here, is calculated with the formula: $R V_{t}=\sum x_{j, t}^{2}$. Heber et al. (2009) additionally implement a subsampling procedure from the data to the most feasible level in order to eliminate the stock market noise effects. The subsampling involves averaging across many realized variance estimations from different data subsets (see also the references in Shephard and Sheppard, 2010 for realized measures surveys, noise effects and subsampling procedures).

Table 1 presents the eleven stock indices extracted from the database and provides volatility estimations for each one's squared returns and realized variances time series for the respective sample period (see also the FTSE series graphs in Appendix A.2, Figures A.1 - A.2). We calculate the standard deviation of the series and the annualized volatility. Annualized volatility is the square rooted mean of 252 times the squared return or the realized variance. The standard deviations are always lower than the annualized volatilities. The realized variances have lower annualized volatilities and standard deviations than the squared returns since they ignore the overnight effects and are affected by less noise. The returns represent the close-to-close yield and the realized variances the open-to-close variation. The annualized volatility of the realized measure is between $15 \%$ and $20 \%$, while the squared returns show figures from $18 \%$ to $23 \%$.

[Table 1 here]

Next, we examine the sample autocorrelations of the power transformed absolute returns $\left|r_{t}\right|^{\delta_{r}}$ and signed square rooted realized variance $\left|S S R_{-} R M_{t}\right|^{\delta_{R}}$ for various values of $\delta_{i}$. Figures 2 and 3 show the autocorrelograms of the FTSE 100 index from lag 1 to 120 for $\delta_{r}=1.5,1.7,2.0$ and $\delta_{R}=1.3,1.6,2.0$ (similar autocorrelograms for the other ten indices available upon request). The sample autocorrelations for $\left|r_{t}\right|^{1.5}$ are greater than the sample autocorrelations of $\left|r_{t}\right|^{\delta_{r}}$ for $\delta_{r}=1.7,2.0$ at every lag up to at least 120 lags. In other words, the most interesting finding from the autocorrelogram is that $\left|r_{t}\right|^{\delta_{r}}$ has the strongest and slowest decaying autocorrelation when $\delta_{r}=1.5$. Similarly, for the realized measure, the power with the strongest autocorrelation function is $\delta_{R}=1.3$. Furthermore, Figures 4 and 5 present the sample autocorrelations of $\left|r_{t}\right|^{\delta_{r}}$ and $\left|S S R_{-} R M_{t}\right|^{\delta_{R}}$ as a function of $\delta_{i}$ for lags 1,12,36,72 and 96. For example, for lag 12, the highest autocorrelation values of power transformed absolute returns and signed square rooted realized variance are calculated closer to the power of 1.5 and 1.0, respectively. These figures explain our motivation to extend the benchmark HEAVY through the APARCH framework of Ding et al. (1993) and confirm the power choice of our econometric models, which is $\delta_{r}=1.5$ for returns and $\delta_{R}=1.3$ for the realized measure (see Section 4.2). 
[Figure 2 here] [Figure 3 here]

[Figure 4 here] [Figure 5 here]

\subsection{Macroeconomic Proxies}

In order to shed light on the macro-financial linkages, we augment the financial volatility HEAVY process with non-negative macro-proxies of daily frequency. The extant literature on the economic sources of stock market volatility mainly uses lower frequency economic variables (monthly or quarterly). From Schwert (1989) and Hamilton and Lin (1996), who were among the pioneers that related monthly stock market volatility to the business cycle, until Engle and Rangel (2008) and Engle et al. (2013), who applied a mixed frequency approach (Spline- and MIDAS-GARCH), the research focus has remained on lower than daily frequency macro-factors to explain the time-varying behavior of financial volatility. Corradi et al. (2013) further investigated the macroeconomic environment contribution to monthly stock returns, volatilities, and volatility risk-premia, while Conrad and Loch (2015) explained S\&P 500 daily conditional variance with quarterly economic variables. The principal common finding across the volatility determinants studies is the counter-cyclical pattern of volatility for several economic activity variables.

Research on the economic drivers of financial volatility lacks evidence on daily macro-factors of the daily or intra-daily stock index volatility pattern. Motivated by this literature gap, we augment the HEAVY model of both daily and intra-daily volatility with daily macro-variables that proxy the business cycle conditions used in the existing monthly or quarterly studies of volatility determinants. In line with Conrad and Loch (2015), we proxy the macroeconomic environment through economic activity, monetary and business conditions, and sentiment daily variables that could explain European stock index realized variance. Since GDP, industrial production, unemployment, inflation, consumer sentiment or any available activity, monetary base, and sentiment index is not measured on a daily frequency, we turn to relevant daily variables. The Economic Policy Uncertainty index is directly related to the business cycle with significant contractive effects on investment and employment (Baker et al., 2016). It is used here in place of the activity variables included in all prior studies. We expect the opposite sign effect from the sign previously observed for economic activity variables since uncertainty is negatively correlated to activity and higher uncertainty is strongly associated with recessions. The uncertainty index applied is also considered as an alternative to financial uncertainty (VIX index in Corradi et al., 2013), sentiment, and macroeconomic volatility (Conrad and Loch, 2015). Daily credit conditions variables are chosen to account for the business and monetary conditions' impact on financial volatility, following Schwert (1989), who uses financial leverage variables, interest rate and corporate bond returns volatility. Lastly, we use daily commodity price indices motivated by the fact that commodity price increases and 
oil, in particular, are often associated with recessions in the macroeconomy (Barsky and Kilian, 2004). Therefore, we expect a significant surge in stock market volatility following a rise in commodity prices, which has been proved to be harmful for real economic activity.

Our first macro-variable is the news-based Economic Policy Uncertainty Index (EPU), established by Baker et al. (2016) and retrieved from http://www.policyuncertainty.com/. The site, maintained by Baker, Bloom, and Davis, provides daily EPU data for the UK starting from 2001. The EPU index effectively captures the broad 'amorphous' concept of economic uncertainty (Bloom, 2014). The 2008 global financial crisis has brought the previously overlooked notion of economic uncertainty to the frontline of academics', policymakers' and practitioners' interest. We are now witnessing an extensive burgeoning literature having uncertainty as its principal topic and exploring the widely-recognized countercyclical uncertainty effects on macroeconomic and financial indicators across the business cycle. In particular, for unique crisis events and long-lasting recession periods, academics try to scrutinize all possible factors from their arsenal of indicators, which could prove to be forces behind the poor economic performance. Uncertainty in the agents' thoughts has been recently verified as a crucial factor deciphering a substantial part of economic fluctuations. Our motivation and recognition of the relative merits of the news-based EPU metric over several other uncertainty measures are further discussed in the analysis of the EPU effects on realized volatility (Section 5).

Moving to the credit market conditions, we use four alternative Bond market global benchmarks: the Merrill Lynch MOVE 1 month Index (MOVE), the Moody's AAA and BAA Corporate Bonds Yields (AAA \& BAA) and the spread of the BAA over the AAA yields (BAA_AAA). The MOVE Index is an estimate of the Option Implied Volatility of US Treasury bonds. It is the Treasury counterpart of the 'fear' index (VIX) for S\&P 500 and captures the sovereign credit market stance. Higher sovereign bond volatility denotes higher turbulence in the credit channel for sovereigns with direct spillovers to financial and non-financial corporations' credit conditions. The Moody's indices provide daily averages of global triple-A and BAA corporate bond yields (higher yields and spreads denote higher cost of financing and credit risk pricing for corporations) and are used as alternatives to the MOVE index for the credit channel. Moreover, the Commodities market conditions are proxied by two alternative global factors: the S\&P GSCI Index (GSCI) and the Crude Oil Prices per barrel (WTI). Both capture the cost of production for firms in the economy, where rising commodity values can lead to production and investment deterioration due to increased cost effects on economic activity. On the one hand, the S\&P Goldman Sachs Commodity Index is the widely-recognized commodity markets performance benchmark. On the other hand, crude oil is the most important commodity as an energy source across all economies. The crude oil dollar prices per barrel (crude stream: West Texas Intermediate - WTI) are used as our alternative macro-regressor to the GSCI, where, besides oil, most liquid commodities are incorporated. The four bonds and commodities 
variables are retrieved from Thomson Reuters Datastream and FRED economic database of the St. Louis Federal Reserve Bank.

All daily macro-regressors, except for the Moody's BAA minus AAA spreads, are log-transformed (see graphs in Appendix A.2, Figures A.3 - A.9) and included in the realized measure equation where they are proved to be significant ${ }^{2}$. In the macro-augmentation of the HEAVY model, we are restricted to using only non-negative variables with estimated coefficients of positive sign due to the GARCH positivity constraints. Consequently, we focused our analysis of the macro-financial linkages on the EPU index for uncertainty and the six bonds and commodities variables, which are characterized by non-negative values only and exert an inflating impact on realized volatility. Increased uncertainty, bond yields and volatility, and commodity prices, all contribute to financial volatility heightening, apparent especially during economic downturns. Figures 6-8 clearly show that higher realized volatility is observed in times of elevated uncertainty, credit market turbulence and commodity prices boost.

[Figure 6 here]

[Figure 7 here]

[Figure 8 here]

Beyond imposing the GARCH constraints, we initially tested an additional non-negative proxy of the real estate market (the log-transformed Dow Jones [DJ] REIT index). This proved to be highly significant but we should exclude it since the negative sign of the relevant coefficient violates our econometric framework constraints ${ }^{3}$. Better performance of the real estate sector is associated with higher REIT's level mostly in economic growth periods and is consistently negatively related to financial volatility. Finally, the realized variance receives sound negative impact from two economic activity indicators with values not bounded to the positive territory of real numbers and, therefore, have been excluded. We used the Aruoba-Diebold-Scotti (ADS) Business Conditions Index (Aruoba et al., 2009) and the Yield Curve slope, which are among the unique economic activity indicators available on a daily frequency. The ADS index tracks daily real business conditions based on economic data releases and the Yield Curve slope, as calculated by the difference of the 10-year minus the 3-month Treasury bond yields, has proved to be a powerful predictor of future economic activity (Estrella and Hardouvelis, 1991). Financial volatility receives a significant negative effect from both variables, as expected since lower ADS and term structure slope values indicate economic worsening associated with higher stock market volatility. This opens

\footnotetext{
${ }^{2}$ The log-transformed series are always positive because all series' values are higher than one. Since the lower bound of our macro-regressors' series is not one but zero, we, alternatively, included the regressors divided by 100 (EPU, MOVE, WTI), 10000 (GSCI) and 10 (AAA, BAA). This resulted in similar estimated coefficients in terms of level and significance within the HEAVY framework (results available upon request).

${ }^{3}$ Further research could consider an exponential HEAVY specification to address the non-negativity limitations.
} 
several paths for future research on macro-financial linkages in the high-frequency domain to connect the three variables (DJ REIT, ADS, Yield Curve slope), excluded here, with realized variation measures in the absence of positivity constraints of the econometric framework applied.

\section{Estimation Results}

\subsection{The Benchmark HEAVY Model}

Building upon the introduction of the GARCH-X process by Engle (2002b) to include realized measures as exogenous regressors in the conditional variance equation, Han and Kristensen (2014) and Han (2015) studied the asymptotic properties of this new specification with a fractionally integrated (nonstationary) process included as covariate. Moreover, Pedersen and Rahbek (2019) developed likelihood-ratio tests on the significance of the nonstationary covariate in the above-mentioned model, while Halunga and Orme (2009) provided some asymmetry and nonlinearity tests. Lastly, Nakatani and Terasvirta (2009) and Pedersen (2017) focused on the multivariate case, the so-called extended constant conditional correlation, which allows for volatility spillovers and they developed inference and testing for the quasi-maximum likelihood estimator (QMLE) parameters (see also Ling and McAleer, 2003 for the asymptotic theory of vector ARMA-GARCH processes). For the extended HEAVY models, we employ the existing Gaussian quasi-likelihood estimators and multistep-ahead predictors applied in the APARCH framework (see, for example, He and Teräsvirta 1999, Laurent, 2004, Karanasos and Kim, 2006).

Within the HEAVY framework, we first estimate the benchmark formulation as in Shephard and Sheppard (2010), that is, without asymmetries, power transformations, and macro-effects, obtaining very similar results (Table 2). The only unconditional regressor in both equations is the first lag of the $R M_{t}$. In other words, the chosen returns equation is a $\mathrm{GARCH}(1,0)-\mathrm{X}$ process dropping out the own Arch effect, $\alpha_{r r}$, from lagged squared returns since it becomes insignificant when we add the cross effect of the lagged realized measure as regressor, with a Heavy coefficient, $\alpha_{r R}$, high in value and significance across all indices. The momentum parameter, $\beta_{r}$, is estimated around 0.39 to 0.75 . For the SSR realized variance, the best-chosen model is the $\operatorname{GARCH}(1,1)$ without the cross effect from lagged squared returns.

The Heavy term, $\alpha_{R R}$, is estimated between 0.33 and 0.52 and the momentum, $\beta_{R}$, is around 0.47 to 0.66. The benchmark HEAVY system of equations chosen (three alternative GARCH models are tested for each dependent variable with order: $(1,1),(1,0)-\mathrm{X}$, and the most general one, that is, $(1,1)-\mathrm{X})$ is the same as in Shephard and Sheppard (2010) with similar parameter values and the identical conclusion that the realized measure of variation does all the work at moving around the conditional variances of stock returns and the SSR realized variance. The benchmark's conclusion, as we show in this study, does not 
hold for the more richly parametrized macro-augmented asymmetric power model. More importantly, according to the Sign Bias test (SBT) of Engle and Ng (1993), the asymmetric effect is obviously omitted from the benchmark specification with the sign coefficient always significant (SBT p-values lower than $0.09)$.

[Table 2 here]

\subsection{The Macro-augmented Asymmetric Power HEAVY Model}

Moving to our proposed extension of the benchmark HEAVY system, Table 3 presents the estimation results for the chosen macro-augmented asymmetric power specifications. For both returns and realized variance, we statistically prefer the double asymmetric power (DAP) specification since both power transformed conditional variances are significantly affected by own and cross asymmetries. We estimate the power terms separately with a two-stage procedure, as follows: We, firstly, estimate univariate asymmetric power specifications for the returns and the realized measure. The Wald tests for the estimated power terms (available upon request) reject the hypotheses of $\delta_{i}=1$ and $\delta_{i}=2$ in most cases. In the second stage, we use the estimated powers, $\delta_{r}$ and $\delta_{R}$, from the first step to power transform each series' conditional variance and incorporate them into the bivariate DAP model. The sequential procedure produces the fixed power term values, which are the same for both specifications $\left(\delta_{r}\right.$ and $\delta_{R}$ are common for Panels A and B).

For the returns (see Table 3, Panel A), the estimated power, $\delta_{r}$, lies between 1.40 and 1.70. The Heavy asymmetry parameter, $\gamma_{r R}$, is significant and around 0.09 (min. value) to 0.18 (max. value). Although $\alpha_{r r}$ is insignificant and excluded in all cases, the own asymmetry parameter $\left(\gamma_{r r}\right)$ is significant

with $\gamma_{r r} \in[0.07,0.12]$. In other words, the lagged values of both powered variables, that is, the negative signed realized measure and the squared negative returns, drive the model of the power transformed conditional variance of the returns. Moreover, the momentum parameter, $\beta_{r}$, is estimated to be around 0.86 to 0.90 . All eleven indices generated very similar DAP specifications without macro-effects since we statistically prefer to include the macro-regressors in the realized measure equation.

[Table 3, Panel A here]

Similarly, for the realized measure the most preferred specification is the m-DAP one. The power, $\delta_{R}$, is estimated from 1.00 to 1.40 and is consistently lower than the returns power term (see Table 3, Panel B). Both Heavy parameters, $\alpha_{R R}$ and $\gamma_{R R}$, are significant: $\alpha_{R R}$ is around 0.13 (min. value) to 0.27 (max. value), while the own asymmetry, $\gamma_{R R}$, is between 0.02 and 0.04 . Only in the OMXC 
case, the own asymmetry parameter, $\gamma_{R R}$, is insignificant and, therefore, excluded. Moreover, the cross asymmetry Arch parameter is always significant with $\gamma_{R r} \in[0.04,0.09]$. This means that the power transformed conditional variance of $\widetilde{R M}_{t}$ is significantly affected by the lagged values of both powered variables: squared negative returns and realized measure. Further, the momentum parameter, $\beta_{R}$, is estimated to be around 0.64 to 0.77 . Table A.1 (in Appendix A.1) provides additional results for the realized measure equation before including the macro-effects. We, firstly, estimated the DAP extension before resulting in our final chosen model, that is extending it with all three macro-factors (see also Appendix A.1, Table A.2, where we statistically prefer MOVE and WTI for the FTSE according to the Akaike Information Criterion - AIC).

Lastly, the lagged macro-effects are highly significant with the expected positive sign in all cases. The power transformed realized variance receives the boosting impact from higher UK EPU levels, $\phi_{R} \in[0.01,0.03]$, in line with Pastor and Veronesi (2013), who were the first to associate stock market volatilities with EPU, resulting in a positive link. The uncertainty effect also confirms the finding of Conrad and Loch (2015), among others, on the negative effect of consumer confidence (University of Michigan Consumer Sentiment Index), which is the opposite sentiment to uncertainty and is estimated here with the expected opposite sign, as well. The Norwegian index volatility is the sole case without direct impact from the UK uncertainty. However, for this index, the EPU effect on Heavy, Arch, and bond factors is significant (see Section 5, Table 9). Regarding the bond and commodity markets, we prefer to use common global proxies for all European indices. Bond market conditions are better captured by the MOVE index in most cases except for DAX and OMXC, where we prefer the Moody's triple-A yields, OMXS with BAA yields and OSE with the spread between BAA and AAA bonds. Increased US treasury implied volatility or elevated international corporate bond yields and spreads raise realized volatility in stock markets $\left(\zeta_{R} \in[0.03,0.15]\right)$, as expected since the turbulence in the credit markets always gives significant volatility spillover effects to stock markets. Hereby, we confirm, among others, Engle and Rangel (2008), who estimate a positive effect of short-term government bond interest rate volatility on stock market volatility through the Spline-GARCH specification. Turning to commodities, the realized measure equations of BELL and OMXC do not include the direct impact from a significant commodities proxy, while for the remaining indices we either prefer the GSCI index or the WTI crude oil prices $\left(\vartheta_{R} \in[0.01,0.02]\right)$. In Section 5 (see again Table 9), we prove that BELL receives the commodity price effect when multiplied by the EPU variable. The same applies in the cases where the commodities parameters are not jointly significant with bond coefficients. Section 5, Table 9 includes estimations where commodities are estimated jointly significant with bonds when considering the EPU effect on either commodities or bonds. Lower commodity prices mean decreased cost of supplies for firms in the economy, propelling productivity, investment and, more generally, economic growth and, at the same time, 
reducing stock market volatilities. Given that increased oil prices are mostly coincident with recession periods (Barsky and Kilian, 2004), the positive link of realized variance and commodity prices, captured by $\vartheta_{R}$, proves the negative association of economic activity with stock market volatility, in accordance with the existing literature. All prior volatility determinant studies have provided sound evidence on the negative sign effect of economic activity proxies on stock market volatility (see, for example, the GDP growth coefficients in Engle and Rangel, 2008).

Overall, our results show strong Heavy effects (captured by the $\gamma_{r R}, \alpha_{R R}$, and $\gamma_{R R}$ parameters), as well as asymmetric Arch influences (the estimated $\gamma_{r r}$ and $\gamma_{R r}$ are always significant) and macroimpact (measured by $\phi_{R}, \zeta_{R}$, and $\left.\vartheta_{R}\right)$. According to the $\log$-likelihood $(\ln L)$ values reported, the $\log$ likelihood is always higher for the m-DAP specifications compared to the benchmark one, that is without asymmetries, powers, and macro-effects, proving the superiority of our model's in-sample estimation (see also the comparison of the two models in terms of the FTSE standardized residuals graphs in Appendix A.2, Figure A.10). The SBT statistics further show that the asymmetric effect is not omitted any more since the sign coefficients are insignificant with p-values consistently higher than 0.16.

From an economic point of view, the macro-effects on European stock markets volatility observed through the m-DAP-HEAVY framework confirm prior studies on the upward volatility trajectory during economic downturns. This counter-cyclical behavior has been mainly proved by the negative sign effect of economic activity leading or coincident indicators on a monthly or quarterly frequency (Engle and Rangel, 2008). Turning to the high-frequency domain of the macro-financial linkages, the monthly activity variables should be replaced by possible daily proxies of economic activity to be included as explanatory variables in the realized variance equation. Given the non-negativity restriction, we could not use, among others, the daily term spread, a reliable predictor of GDP (Estrella and Hardouvelis, 1991) and significant in the monthly context as evidenced by Conrad and Loch (2015). Based on the rich empirical evidence of the adverse uncertainty effects on economic activity (Caggiano et al. 2017, Colombo, 2013, Jones and Olson, 2013), we select the daily EPU index to associate stock market volatility with a variable directly linked to economic activity contractive forces. The positive sign consistently estimated here across all specifications for the UK EPU variable is in accordance with prior findings on the positive sign given to macroeconomic uncertainty (Schwert, 1989) and unemployment, and the negative sign of the real GDP, industrial production, and consumer sentiment growth (Conrad and Loch, 2015). All forces associated with a positive real economic impact exert a negative influence on stock market fluctuations, while the depressive forces exacerbate volatility and are estimated with a positive sign irrespective of the specification chosen by the different scholars. Therefore, it is economically plausible for the daily economic uncertainty to drive financial volatility higher, at the same time weakening the prevailing macroeconomic conditions. 
Against this backdrop, we also selected the sovereign bond yield volatility (or, alternately, the corporate bond yield level and default spread) to identify the credit channel effect on stock markets. Increased volatility in the sovereign bond market (Engle and Rangel, 2008) or corporate debt yields and default spreads are reasonably correlated with macroeconomic turbulence since they increase the cost of financing for firms and investors and, consequently, reduce activity. Accordingly, the global bond factor coefficients are consistently estimated with positive signs across all stock market volatility models (see also Asgharian et al., 2013). Finally, the commodity price index or, alternately, the oil price are included as a third volatility determinant, which is found positive and highly significant in most cases. Motivated by the widespread discussion and empirical evidence about the commodity price effects on the macroeconomy in Kilian's research works (see, for example, Barsky and Kilian, 2004), we complement the volatility macro-determinants literature by enriching the set of significant macro-variables for the volatility pattern with commodities and observe the destabilizing impact of higher daily commodity prices, mostly associated with economic downturns, on stock market realized variance. Increased commodity cost for firms' production supplies impairs economic activity and exacerbates equities' volatility.

Hence, apart from contributing to the realized variance modeling research through the asymmetric, power, and macro-augmentation of the benchmark HEAVY specification, we also contribute to the economic sources of volatility by exploring the macro-financial linkages in the high-frequency domain with daily macro-proxies. All three daily economic variables that exacerbate stock market volatility are associated with weak economic conditions: higher economic uncertainty, tighter credit conditions, and increased commodity prices. Moreover, we bridge the macro-finance literature with the high-frequency volatility studies by using, for the first time, the sole economic uncertainty index computed daily. The daily UK EPU is applied in the present European study to reveal the uncertainty spillovers from the UK across the whole continent's stock markets. The UK-led spillover is crucial nowadays given its direct connection to the Brexit fears which trigger agents' uncertainty feelings spread over the whole union.

[Table 3, Panel B here]

\subsection{Forecasting Performance}

Following the estimation of the m-DAP extension to the HEAVY framework of equations, we perform multistep-ahead out-of-sample forecasting in order to compare the forecasting accuracy of the enriched specification proposed in this study with the benchmark model introduced by Shephard and Sheppard (2010). We compute 1-, 5-, 10-, and 20-step-ahead forecasted (power transformed) conditional variances for the benchmark model, the DAP and its macro-augmented extension. We apply a rolling window in-sample estimation using 3000 observations (the initial in-sample estimation period for FTSE spans 
from 2/1/2001 until 28/11/2012). Each model is re-estimated daily based on the 3000-day rolling sample so that the out-of-sample forecasts of each specification calculated for FTSE are as follows: 1581 onestep-ahead, 1577 five-step-ahead, 1572 ten-step-ahead, and 1562 twenty-step-ahead forecasted variances. We then use the time series of the forecasted values to compute the Mean Square Error (MSE) and the QLIKE Loss Function (Patton, 2011) of each point forecast compared to the respective actual value. For each formulation and each forecast horizon, we calculate the time series average MSE and QLIKE to build the ratio of the forecast losses for each extended HEAVY specification to the loss of the benchmark one. A ratio lower than the unity indicates the forecasting superiority of the proposed models relative to the benchmark one. The lowest ratio means lowest forecast losses, that is the model with the best forecasting performance. The implications of volatility prediction concern traders, investors, risk managers, and regulators. Traders are mostly involved in short-term forecasting while regulators need longer-term predictions. Investors and risk managers can have both short- and long-term interests.

The results, presented in Table 4 for FTSE (similar forecasting results for the other ten indices are available upon request), clearly show the preference for our macro-augmented asymmetric power extensions over the benchmark models across all time horizons. For the returns equations (see Table 4, Panel A), the m-DAP formulation dominates the alternative benchmark one with the lowest MSE and QLIKE in all forecasting periods. In the realized measure equation (see Table 4, Panel B), we get the best forecasting performance in the m-DAP specification either with all three macro-factors $(5-, 10-$, and 20-day periods) or the EPU regressor only without Bonds and Commodities (1-day horizon). Overall, the more general extension proposed in our study performs significantly better than the benchmark one in the short- and long-term horizons. Considering the stepwise estimation of the final m-DAP model, we evidence, firstly, the significant improvement in forecasting results with the double asymmetric power over the benchmark specification, and, secondly, its further enhancement with macro-effects. Investors, traders and risk managers can benefit from the superior short-term macro-informed forecasts for one up to ten days, while policymakers should focus on the longer-term forecasting performance to predict 'safely' the one-month financial volatility given the significant macro-determinants.

[Table 4 here]

\subsection{Structural Breaks}

Following the analysis of the superiority of our macro-augmented DAP extension for the HEAVY system, in this Section we investigate the impact of structural changes (detected in the two power transformed time series used as dependent variables) on the Heavy, Arch and Macro estimated parameters. The time-varying behavior of these parameters can be significant, specifically around a financial crisis break, 
indicative of the crisis effects on the volatility pattern. The structural breaks of the two volatility series are identified, focusing mainly on the recent global financial crisis, and we study their impact on the HEAVY framework. The methodology in Bai and Perron $(1998,2003 a, b)$ is employed to test for structural breaks. They address the problem of testing for multiple structural changes in a least squares context and under very general conditions on the data and the errors. In addition to testing for the presence of breaks, these statistics identify the number and location of multiple breaks. So, we identify the structural breaks in the two powered series (power transformations of squared returns and realized measure) with the Bai and Perron methodology (see Table 5 and Figures 9-10 for FTSE). We use the breaks identified in order to build the slope dummies for the various parameters. One break date for the recent financial crisis of 2007/08 is detected, so we can focus on the crisis effect. We also detect one break date before and one after the crisis.

[Table 5 here]

[Figure 9 here]

[Figure 10 here]

We focus on the crisis period effect and present the estimation results for FTSE in Table 6 (similar results for the other ten indices available upon request). We choose to use the break dates of the power transformed realized measure series: (1) 01/10/2003: pre-crisis break, (2) 24/07/2007: crisis break and (3) 21/07/2010: post-crisis break. The crisis dummy variable multiplied by the respective Heavy, Arch and Macro variables (to construct the slope dummies) is defined as follows: $D_{2, t}=1$, if $T_{(2)} \leq t<T_{(3)}$ and $D_{2, t}=0$, if $t \geqslant T_{(3)}$ and $t<T_{(2)}$. We, firstly, apply the slope dummies in the Heavy and Arch coefficients of the m-DAP-HEAVY-r equation (see Table 6, Panel A). In the returns equation, we estimate two different specifications with the crisis break: the first $(I)$ with the slope dummy on the own asymmetry (Arch) parameter, $\gamma_{r r}$, and the second $(I I)$ with the slope dummy on the cross asymmetry (Heavy) parameter, $\gamma_{r R}$. Both asymmetries' coefficients increase with the crisis break. Regarding the realized measure equation (see Table 6, Panel B), the Heavy impact, as captured by the Heavy parameter $\alpha_{R R}$, and the own asymmetry $\gamma_{R R}$, and the Arch asymmetric influence (captured by $\gamma_{R r}$ ) all rise with the crisis break (Panel B specifications: $I, I I, I I I)$. Following the DAP model with crisis structural break on the Heavy and Arch coefficients, we further focus on the macro-augmented DAP equation of the realized variance, in order to estimate the slope dummies on the Macro parameters (Panel B specifications: $I V$, $V, V I)$. The first macro-augmented specification $(I V)$ presents the equation with the EPU regressor only, where we observe the positive increment on the EPU coefficient from the crisis break. Lastly, the augmented equations with Bonds $(V)$ and Commodities $(V I)$ illustrate once more the positive crisis effect on each macro-factor. 
[Table 6 here]

Overall, we evidence consistently the same signs of the dummies' coefficients across all specifications with Heavy, Arch, and Macro parameters. The crisis break dummies always increase the relevant coefficients, magnifying the macro-effects that destabilize the stock markets during the crisis. The destabilizing impact of the crisis stance on financial volatility either directly through the Heavy and Arch effects or through the uncertainty, credit market and commodity prices influences should raise the concern of policymakers about the imminent and highly probable Brexit harm to the whole European financial system.

\section{The Uncertainty Effect on Realized Volatility}

Following the augmentation of the benchmark HEAVY system with asymmetries, power transformations, and macroeconomic effects, we investigate the drastic influence of UK uncertainty on European financial markets volatility. We, first, review the uncertainty measurement approaches in order to discuss the relative merits of the Economic Policy Uncertainty index and briefly present the relevant empirical evidence. Lastly, and most importantly, we prove the significant UK EPU effect on the Heavy, Arch, Bonds, and Commodities impact on the European stock markets realized variance.

\subsection{Uncertainty Measurement and the EPU Index}

Since economic uncertainty constitutes one of the most debated factors to explain the recent crisis with the ensuing persistent slowdown and the unexpectedly sluggish recovery, eminent scholars responded to the challenge of quantifying such an unobservable variable in order to test its influence on economic activity. They employed a wide variety of econometric forecasting techniques and some more novel text-mining and machine-learning methods on time series data of economic variables, survey data, news stories, Google search volumes or even internet-clicks data to compute tangible measures of uncertainty. Beyond the acknowledged consensus on the use of financial markets implied volatility (e.g. VIX) as a reliable proxy of uncertainty in macro-financial modeling (Bloom, 2009, Bekaert et al., 2013), another rather traditional approach to gauge uncertainty has been the second moment of the time series of a macroeconomic or financial indicator (e.g. GARCH conditional variance in Fountas and Karanasos, 2007). More recently, under the pure econometrics approach, academics have addressed the quantification problem by formalizing economic uncertainty measures with sophisticated large-scale structural models on macroeconomic and financial datasets (Mumtaz and Theodoridis, 2018, Jurado et al., 2015, Carriero et al., 2018). A further strand of the well-established uncertainty literature has produced survey-based uncertainty measures, using among others the Surveys of Professional Forecasters (Scotti, 2016, Rossi 
and Sekhposyan, 2015, Jo and Sekkel, 2017).

In light of the seminal paper of Baker et al. (2016), a considerable number of studies have developed news-based uncertainty measures, which are gaining enormous popularity. Baker et al. (2016) were among the first scholars that applied textual analysis to construct the Economic Policy Uncertainty Index by calculating the frequency of references to uncertainty concerning economic policy in leading newspapers (count of keywords like uncertainty and economic policy). The EPU Index is computed nowadays for many countries (see the indices publicly available by the majority of EPU authors on http://www.policyuncertainty.com/) on a monthly frequency (daily EPUs are constructed only for US and UK) and extended to several categorical subindices (i.e. uncertainty on fiscal, monetary, trade policy, etc.). The motivation behind the news-based indicators lies in the consideration that the press is a reliable and timely mirror of the agents' expectations and economic sentiment. Common knowledge suggests that newspapers should outline the economic reality according to readers' information demand, interests and expectations in order to maintain their audience. Baker et al. (2016) opened up a new strand of research with a growing body of bibliography which markedly focused on textual search and machine learning methods to construct similar news-based Policy Uncertainty indices with the mounting interest of many scholars in improving such methodologies (Brogaard and Detzel, 2015, Larsen and Thorsrud, 2018). In line with the news-based uncertainty measures extracted through text mining algorithms on newspaper articles, there are two more approaches in this bibliography part: the sophisticated and ready-to-use news indicators provided by news agencies like Bloomberg and Thomson Reuters (see, for example, Caporale et al., 2018) and the internet search engines volume metrics (Google trends in Castelnuovo and Tran, 2017, Wikipedia searches in Vlastakis and Markellos, 2012, and Bitly click data in Benamar et al., 2018). Several uncertainty indices are derived from internet search intensity of keywords related to uncertainty or to an economic term, event or variable, indicating that such terms attract the attention of the general public due to uncertainty.

Within the long stream of literature on news-based indices, the key conceptual difference between the two main approaches, the news coverage, and the internet search engines or clicks, lies in the information perspective they employ. The former is applied to the information supply side, while the latter is on the demand side. We strongly believe that the supply side is more reliable for quantifying uncertainty. On the one hand, it is commonplace that newspapers as information providers should reflect the general mood in order to attract and maintain their audience. Thus, the media content is of immense value for gauging uncertainty. On the other hand, the demand side, directly connected to economic psychology, is measured by internet queries and news clicks intensity. Thus, it may create bias on the real uncertainty level since the clicks volume also depends on people's free time and internet access, apart from implying attention or information search as a response to uncertainty. Consistent with our view that news-based 
indices constructed on the information supply side are more appealing, in this paper, we focus on Economic Policy Uncertainty. The intuition behind our preference to use the novel news-based EPU index is straightforward given the numerous attractive features, suggestive of its usefulness. The merits of the EPU index are summarized as follows: i) the insights derived from real-time news coverage, ii) the timeliness of news arrival with their sound signaling potential, iii) the availability for major economies, iv) the policy-sensitive feature included in the uncertainty measurement, and v) the consistency as substantiated in the ample empirical support of its explanatory and predictive power in macro-financial models. Given the facts that i) EPU relies on daily news, ii) political news dominates the markets, and iii) the construction of the index includes policy-related concerns apart from economic terms alone, we regard it as a number that fits all, both macroeconomic and financial reality, in a timely manner. The model- and survey-based uncertainty proxies cannot be as up-to-date as EPU due to their reliance on the history of economic variables or the non-real-time survey responses by forecasters, whose disagreement or forecast error dispersion do not necessarily suggest the omnipresence of uncertainty in the economy. Newspapers can be thought of as the best illustration of the general public's (households, corporations, investors and governments) feeling in terms of uncertainty, although they are occasionally criticized in relation to their objectivity, that they may create news instead of simply transmitting it. In this case, the use of wide-ranging sources to construct the EPU indices eliminates the possibility of one or more newspapers attempting to inflate or conceal the ubiquitous uncertainty.

\subsection{Economic Policy Uncertainty and Realized Volatility}

It is important to note here that news textual analysis is used broadly in various scientific fields to quantify societal trends and public opinion. Nowadays, this novel strategy has inevitably come to the aid of economic science for measuring variables not directly observable, such as uncertainty, leading to the lengthy catalogue of the renowned EPU indices. These indices have gained remarkable popularity in numerous applications in economics and finance. Interestingly, they have recently started showing up even in media reports and investment recommendations. A voluminous literature has mushroomed over three axes of research: connecting EPU with macro-aggregates, microeconomic data, and financial variables. The large bulk of EPU literature investigates the explanatory or the predictive power of EPU on business cycles (with the leading macro-variables included: unemployment in Caggiano et al., 2017, output and inflation in Colombo, 2013, Jones and Olson, 2013, Karaman and Yildirim-Karaman, 2019, economic development in Scheffel, 2016, monetary dynamics in Aastveit et al., 2017, Tarassow, 2019, yield curve slope in Connolly et al., 2018, foreign exchange rates in Kido, 2016, bank credit and bailouts in Bordo et al., 2016, Caliendo et al., 2018), on asset prices, returns, volatilities and correlations (equities 
in Pastor and Veronesi, 2012, Kelly et al., 2016, Dakhlaoui and Aloui, 2016, bonds in Bernal et al., 2016, stock-bond correlation in Li et al., 2015, commodities in Andreasson et al., 2016, Bakas and Triantafyllou, 2019, real estate in Christou et al., 2017, sovereign credit ratings in Boumparis et al., 2017, CDS spreads in Wisniewski and Lambe, 2015, cryptocurrencies in Fang et al., 2019), and at the micro-level on corporate accounting numbers (Gulen and Ion, 2015, Pham, 2019, Zhong et al., 2019), firm and household decisions (Nagar et al., 2018, Ben-David et al., 2018). Granger causality tests, Structural VARs, Diebold-Yilmaz (DY) dynamic interconnectedness (Diebold and Yilmaz, 2009), Quantile regressions, GARCH models with MIDAS specifications in many cases, when variables of mixed frequencies are involved, and with Dynamic Conditional Correlations (Engle, 2002a), when the dynamic nature of correlations is considered, are among the most common modeling approaches adopted in the EPU empirical evidence studies.

Despite the substantial advances in the EPU research, proving the adverse EPU impact on economic activity and its contractive effect on financial variables and the functioning of the financial system, the literature on the realized volatility dynamics of high-frequency financial variables associated with uncertainty is still in its infancy. Reviewing the few commendable attempts to explain the behavior of stock market volatility with EPU, we can trace back this link to Pastor and Veronesi (2013), who were the first to connect stock markets with monthly EPU using simple OLS regressions of monthly stock returns, volatilities and correlations (unconditional) on the EPU index, whose coefficient sign was consistently positive for correlations and volatilities and negative for returns. Antonakakis et al. (2013) further compute the Dynamic Conditional Correlations between EPU, S\&P 500 Stock Index returns and implied volatility (VIX) pairwise on a monthly frequency. The EPU-VIX correlation is positive and the EPU-returns negative, as expected, since elevated uncertainty depresses stock market performance and goes alongside higher stock market volatility. More recently, Fang et al. (2018) have related daily gold futures volatility with the monthly Global EPU index through the GARCH-MIDAS framework. They evidence the strong positive effect of uncertainty on gold volatility and its power in forecasting the monthly realized volatility of gold futures. Finally, Cho et al. (2018) highlight the fact that high exchange rate volatility is linked with elevated EPU leading to carry trade losses.

Despite the rapidly growing EPU literature, it appears that the empirical work on the realized volatility dynamics driven by EPU is limited, with evidence still scant. Consequently, the present study fills a notable gap in the extant EPU literature. We elucidate whether EPU exerts considerable influence on the HEAVY volatility modeling framework and on specific parameters of the macro-augmented asymmetric power specification. Our work differs from the existing literature in the use of the daily EPU index as a daily realized volatility determinant, with major implications for macro-informed trading in financial markets and policymakers' financial stability concerns and systemic risk oversight. Obviously, the particular EPU-volatility link has not yet been assessed. 
Against this backdrop, we have already highlighted the direct positive effect, in line with Pastor and Veronesi (2013), and forecasting power of daily EPU on realized volatility within the m-DAP-HEAVY framework in Section 4. In this Section, we first investigate the UK EPU effect on the benchmark realized volatility equation enriched with the lagged bonds and commodities variables. Table 7 presents the macro-augmented benchmark equation of FTSE with the EPU effect on the Heavy coefficient, bonds, and commodities. The equation is estimated using ten restricted forms to examine all combinations of jointly significant macro-factors and each EPU effect separately with the following three interaction terms: i) $\alpha_{R R}^{e p u}$ is the parameter of the lagged EPU multiplied with the lagged realized variance, capturing the EPU effect on the Heavy coefficient $\left(\alpha_{R R}\right)$, ii) $\zeta_{R}^{e p u}$ and iii) $\vartheta_{R}^{e p u}$ measure the EPU effect on the bonds' and commodities' proxies, respectively.

All interaction terms are estimated with highly significant positive signed coefficients. Intriguingly, within the macro-enriched benchmark specification, we prove that higher uncertainty means a stronger effect of credit (specifications: (5), (8), (9) and (10)) and commodity (specifications: (6) and (7)) market conditions on the realized measure. Since it is widely evidenced that higher uncertainty is associated with economic worsening, we further deduce the link of tighter credit conditions and elevated commodity prices during the business cycle's downturns with higher financial volatility heavily affected by the uncertainty channel. It is also remarkable that a significant part of the realized measure arch effect, the Heavy coefficient $\left(\alpha_{R R} \in[0.17,0.23]\right)$, is explained by EPU with $\alpha_{R R}^{e p u}$ estimated between 0.06 and 0.09 (specifications: (1)-(4)). Lastly, EPU partly absorbs the macro-effects from bonds and commodities, with parameter values $\zeta_{R}^{e p u} \in[0.02,0.04]$ and $\vartheta_{R}^{e p u}$ equal to 0.01 , respectively. We also observe that although the commodities effect $\left(\vartheta_{R}\right)$ in the benchmark model is not significant, when it is multiplied by EPU $\left(\vartheta_{R}^{e p u}\right)$ it becomes highly significant jointly with the MOVE index (specifications: (6) and (7)).

[Table 7 here]

After proving the EPU effect on the benchmark specification's parameters, we proceed with the DAP extension. Table 8 reports the alternative restricted forms for FTSE with bonds, commodities and five interaction terms of EPU with the two Heavy and one Arch coefficients and the other two Macro parameters. The interaction terms are all positive, signifying the amplifying EPU impact on each parameter. Heavy effects and cross Arch asymmetries receive a considerable increasing influence from higher uncertainty. Consistently with the macro-augmented benchmark model, the macro-effects are also significantly inflated with elevated uncertainty levels. Within the uncertainty literature, the link between credit conditions tightening and uncertainty has recently been investigated by Alessandri and Mumtaz (2019), who associate the rising financing costs for firms with credit markets uncertainty, while the commodities-uncertainty relation is widely explored by Antonakakis et al. (2014), Aloui et al. 
(2016) and Fang et al. (2018) among others. Most notably, Antonakakis et al. (2017) focus on the oil prices-stock market volatility link. According to our review of the flourishing research on uncertainty effects, academics have not yet covered the EPU, credit and commodities macro-effects on intra-daily financial volatility and the EPU amplifying role on the credit and production cost channel impact, which is plainly visible here through the HEAVY framework.

[Table 8 here]

The UK uncertainty effect is clear not only in the local stock market (FTSE 100) but across all European stock indices considered in this study, as well. Central, Southern, and Northern European and Scandinavian financial markets are destabilized by higher policy uncertainty in the Anglo-Saxon economy directly and indirectly. The direct effect on Europe is already evidenced through the $\phi_{R}$ coefficient of the m-DAP equation (Section 4, Table 3, Panel B), and the interaction terms on the Heavy, $\alpha_{R R}^{e p u}$ and $\gamma_{R R}^{e p u}$, and Arch, $\gamma_{R r}^{e p u}$, parameters for FTSE in Tables 7 and 8. The indirect uncertainty effect is estimated with the positive and significant bonds and commodities interaction terms, $\zeta_{R}^{e p u}$ and $\vartheta_{R}^{e p u}$. Table 9 , summarizes the EPU effects on realized volatility of the ten European indices beyond the aforementioned local (UK) index analysis. We present the uncertainty effect on each Heavy, Arch and Macro parameter of the model as estimated through alternative restricted forms of the volatility equation including each EPU effect separately (see also Appendix A.1, Table A.3, where we bring together the EPU effects on each coefficient of the macro-augmented benchmark equation for the ten European index volatilities).

All indices in the asymmetric power specification receive considerable direct and indirect uncertainty effects, which is not the case for Copenhagen's OMX index in the benchmark specification (Appendix A.1, Table A.3). Interestingly, we observe that for the Norwegian index, the commodities interaction term is insignificant for either the GSCI or the WTI variable and therefore excluded, while the GSCI alone (without the EPU effect) is a significant determinant of OSE realized volatility (Table 3). Moreover, the Danish index remains without any commodity effect in any specification, benchmark or asymmetric power, with or without the EPU multiplier. Overall, we demonstrate that the European stock market volatilities are consistently exacerbated by economic policy uncertainty generated in the UK, besides the global commodity and credit market conditions. Our empirical leading-edge results should urge policymakers to consider and closely investigate the side effects for the whole European financial system of a probable UK turbulence on the way towards Brexit.

[Table 9 here]

All in all, our major contribution to the EPU literature consists of the new empirical evidence we provide on the positive link between daily EPU and realized volatility and the UK EPU spillovers across 
Europe. Within the HEAVY framework, we firstly prove the UK EPU destabilizing impact on European stock markets with financial volatility investigated on a daily frequency. Secondly, we show that the leverage and heavy effects on realized variance are state-dependent, not only based on the realized measure structural changes (see Section 4.4), but they are also considerably magnified under higher prevailing uncertainty conditions. Thirdly and most interestingly from an economic perspective, the increased volatility in credit conditions (or higher cost of debt if the Moody's corporate bond yields and spreads are applied) and the rising prices in commodities, both phenomena associated with economic downturns, exacerbate realized volatility to a degree intensified by elevated UK EPU. Finally, we complement the literature on EPU spillovers (see, for example, Gabauer and Gupta, 2018, Balli et al., 2017, and Klößner and Sekkel, 2014) by providing evidence of the daily uncertainty spillover effects from the UK to Europe's intra-daily stock market volatility. We have proved that policy uncertainty in a specific country is not confined to the country's borders but is propagated across the whole continent immediately (only the first EPU lag is examined in this study).

\section{Policy Implications}

Over the decade following the global turmoil that sharply sparked the interest in the role of uncertainty and the relevant research increasingly gained momentum following an accelerating pace, the most widespread metrics documented, or proxies used, have referred to macroeconomic, financial and policy uncertainty. They all share a common and highly plausible stylized fact: their guiding significance with a detrimental impact on the health of the economy and financial markets, which is stage-contingent (dampening economic activity with higher magnitude in shakier times). Therefore, we extend our empirical analysis by focusing more specifically on the first volatility macro-determinant of the m-DAP-HEAVY- $R$ equation, that is the UK uncertainty impact on European indices realized variance. It is generally acknowledged that both financial markets and the real economy are at the mercy of feelings of uncertainty. On the one hand, macroeconomic uncertainty measures concern the macroeconomic variables fluctuations and the associated 'lack of confidence' about their predictability (Knight, 1921, Bloom, 2014), while financial uncertainty pertains to financial indicators setting the tone for the dynamics of every asset class behavior. On the other hand, economic policy uncertainty, as established by Baker et al. (2016), focuses on the uncertainty surrounding policy implementation and future policy changes by governments, central banks, and other regulatory authorities since they cannot be presumed as certain by economic agents. Policy risk concerns play a decisive role in every perspective of the economic behavior of all agents with a highly unpredictable outcome, no matter the postulated degree of regulators' benevolence (Pastor and Veronesi, 2012). Besides the policy environment in agents' minds, in the advent of the recent crisis, we 
also witnessed the apparent and striking ineffectiveness of policies implemented to stabilize the economy in-crisis and boost post-crisis (monetary- and fiscal-stimulus policies undoubtedly failed to deal with the 2008 financial turmoil). Consequently, we consider policy-generated uncertainty as a broader measure, embracing both macroeconomic and financial uncertainty, as well as capturing proxies of risk aversion attitudes, economic sentiment and confidence indicators and even political ingredients of country risk (such as political stability, polarization or partisan conflict).

Nowadays, regulatory authorities in the UK and the European Union, who design policies to deal with Brexit and partly contribute to the policy uncertainty generated in the economic agents' minds, should consider the shocks they exert in financial markets fluctuations during their lengthy negotiations apart from just dealing with the Brexit processes. Turning to the policy implications of the proposed macro-augmented high-frequency volatility model, our findings suggest that policymakers and authorities supervising and regulating the financial system should take into account reliable volatility forecasts in designing macro- and micro-prudential policy responses. The risk management of the financial system is structured as follows: i) identification of risk sources (both endogenous - financial markets volatility and exogenous - the macroeconomy), ii) assessment of the nature of risk factors, iii) risk measurement (micro-prudential metrics in the financial institution level and macro-prudential metrics in the system and markets level), and, iv) risk mitigation with proactive regulation and crisis preparedness plans and strategies. Thereupon, regulators should employ the macro-informed financial volatility forecasts of the m-DAP-HEAVY model across the whole risk management process and the financial stability oversight tools, such as the early warning systems, the macro stress tests on financial institutions and the bank capital and risk frameworks.

For example, the macro stress test scenario inputs, which include, among others, stock market volatility predictions for the financial institutions' trading books, should consider macro-informed volatility estimates to account for the macro-effects on financial markets. Economic uncertainty in one major country is proved to play a decisive role across the whole region's equities. Accordingly, it is essential for the European Banking Authority (EBA) to add the UK uncertainty factor in the EU-wide stress tests while facing the Brexit fears over the European banking system. Furthermore, complying with the capital and risk frameworks set by supervisors (Basel committee and central banks), financial institutions measure their trading portfolio's market risk (beyond the credit risk of their loan portfolio). They mostly use internal models with the daily Value-at-Risk (VaR) metric in order to estimate the potential trading losses over a pre-defined holding period for a given confidence level and define the corresponding capital charges. The most important input in the VaR calculation is the one-day volatility forecast of the risk factor relevant to the financial instruments under scope. Stock index price volatilities are widely used in the VaR computation of stock portfolios. Thus, reliable macro-informed volatility forecasts, provided by 
our superior modeling framework, improve the VaR estimates considerably. The potential trading loss in the lower quantile of the return distribution defined by the VaR number should be large enough to cover the losses to be realized in the future. The higher number of exceptions in the VaR's backtesting exercise means higher market risk capital requirements for financial institutions since regulators heavily penalize a bank's internal models that fail to cover trading losses (Basel traffic light approach). At the same time, the VaR-predicted loss should be low (in absolute value) enough in order to prevent supervisors from increasing the capital charges. Given that the market risk capital requirement is calculated on the trading portfolio total $99 \%$ VaR (absolute value, 60-day average) adjusted by the penalty of the backtesting exceptions (higher than 4 in the 250-day sample), supervisors should encourage banks to improve their market risk internal models with more accurate macro-informed volatility forecasts that better capture the loss distribution without inflating the capital charges.

Beyond our results' implications for policymakers, the volatility forecasts produced by the m-DAPHEAVY model are directly applicable to a wide range of business finance operations. Alongside the well-established risk management practice of the trading VaR estimation, portfolio managers should rely on the proposed framework to predict future volatility in asset allocation and minimum-variance portfolio selection complying with their clients' risk appetite. Risk averse investors' mandates specify low volatility boundaries on their portfolio positions, while risk lovers allow for higher volatilities on the risk-return trade-off of their investments. Accurate volatility predictions can also be used in a forward-looking performance evaluation context, through the risk-adjusted metrics, i.e. the Sharpe or the Treynor riskadjusted return ratios. Traders and risk managers focus on the volatility trajectory in derivatives pricing, volatility targeting strategies and macro-informed trading decisions. Trading and hedging in financial markets depend on risk factors whose predicted volatilities are the main input of any pricing function applied. Lastly, financial chiefs consider volatility forecasts when they decide on investment projects or funding choices (bond and equity valuation defining the cost of capital) given that expected future cash-flow variation is a critical factor in business analytics.

\section{Conclusions}

Our study has examined the HEAVY model and extended it by taking into consideration leverage, power transformations, and macro-characteristics. For the realized measure our empirical results favor the most general macro-augmented double asymmetric power specification, where the lags of both powered variables - squared negative returns, and realized variance - move the dynamics of the power transformed conditional variance of the latter. Similarly, modeling the returns with a double asymmetric power process, we found that not only the powered realized measure asymmetry but the power transformed 
squared negative returns, as well, help to forecast the conditional variance of the latter. The macroaugmentation of the asymmetric power model ensures the superiority of our contribution, which can be implemented in the areas of asset allocation and portfolio selection, as well as in several risk management practices. We proved the forecasting dominance of our extensions over the benchmark HEAVY model through the out-of-sample forecasting across multiple short- and long-term horizons. Moreover, the detection of structural breaks and the inclusion of break dummies in the asymmetric power formulation capture the time-varying pattern of the parameters, as the break corresponding to the financial crisis of 2007/08, in particular, increases the values of the parameters intensifying the destabilizing effect from asymmetries and macro-factors on stock markets.

Moreover, we demarcate our study from previous literature by estimating the significant UK uncertainty effect on the power of leverage (Heavy and Arch), global credit, and commodity determinants of European markets realized variance. The UK-generated uncertainty spillovers shed light on new evidence for i) volatility modeling and ii) the macro-financial linkages literature. Our findings' novelty is twofold: Given higher (lower) daily UK uncertainty levels, mostly associated with economic downturns (upturns), i) heavy and leverage effects become more (less) acute in realized variance modeling, and ii) credit and commodity market conditions' impact on financial volatility increases (decreases). The latter conclusion proves, interestingly, that the positive effect of tighter credit conditions (proxied either by higher Treasury bonds volatility or higher corporate yields and spreads) and higher commodity prices (captured either in the commodity benchmark GSCI index or the crude oil WTI prices) on European stock market volatility is amplified given higher UK economic policy uncertainty during a weaker economic stance.

Our empirical findings on the nexus between low-frequency daily squared returns, high-frequency intra-daily realized measures and daily macro-proxies provide a volatility forecasting framework with important implications for policymakers and market practitioners, from investors, risk and portfolio managers up to financial chiefs, leaving ample room for future research on further HEAVY model extensions. Thereupon, policymakers and market players may use our more general framework to closely track and forecast financial volatility patterns in the process of devising drastic policies, enforcing the financial system's regulations to preserve financial stability, deciding on asset allocation, hedging strategies, and investment projects. This UK-led uncertainty spillover phenomenon, in particular, should be immediately recognized, monitored and mitigated by regulators amid the Brexit fears and the associated highly probable impairments for Europe's financial system. As part of future research, it would be interesting to extend our study to exchange rate market volatility and several other asset classes using alternative macro-proxies for each asset volatility. In this vein, it is crucial to develop daily EPU indices also for other countries, beyond the US and the UK. A further interesting line of future research could be the extension of the multivariate HEAVY formulation of Noureldin et al. (2012) with leverage, power transformations 
and macro-effects, starting from the recent study of Dark (2018), who has applied the Dynamic Conditional Correlations multivariate GARCH models (Engle, 2002a) to the multivariate HEAVY, or Opschoor et al. (2018) within the Generalized Autoregressive Score (GAS) process of Creal et al. (2013).

\section{References}

[1] Aastveit, K.A., Natvik, G.J., Sola, S., 2017. Economic uncertainty and the influence of monetary policy. Journal of International Money and Finance 76, 50-67.

[2] Alessandri, P., Mumtaz, H., 2019. Financial regimes and uncertainty shocks. Journal of Monetary Economics 101, 31-46.

[3] Aloui, R., Gupta, R., Miller, S.M., 2016. Uncertainty and crude oil returns. Energy Economics 55, $92-100$.

[4] Andersen, T.G., Bollerslev, T., 1998. Answering the skeptics: Yes, standard volatility models do provide accurate forecasts. International Economic Review 39, 885-905.

[5] Andersen, T.G., Bollerslev, T., Diebold, F.X., Labys, P., 2001. The distribution of exchange rate volatility. Journal of the American Statistical Association 96, 42-55.

[6] Andreasson, P., Bekiros, S., Nguyen, D.K., Uddin, G.S., 2016. Impact of speculation and economic uncertainty on commodity markets. International Review of Financial Analysis 43, 115-127.

[7] Antonakakis, N., Chatziantoniou, I., Filis, G., 2013. Dynamic co-movements of stock market returns, implied volatility and policy uncertainty. Economics Letters 120, 87-92.

[8] Antonakakis, N., Chatziantoniou, I., Filis, G., 2014. Dynamic spillovers of oil price shocks and economic policy uncertainty. Energy Economics 44, 433-447.

[9] Antonakakis, N., Chatziantoniou, I., Filis, G., 2017. Oil shocks and stock markets: Dynamic connectedness under the prism of recent geopolitical and economic unrest. International Review of Financial Analysis 50, 1-26.

[10] Aruoba, S.B., Diebold, F.X., Scotti, C., 2009. Real-time measurement of business conditions. Journal of Business and Economic Statistics 27, 417-427.

[11] Asgharian, H., Hou, A.J., Javed, F., 2013. The importance of the macroeconomic variables in forecasting stock return variance: a GARCH-MIDAS approach. Journal of Forecasting 32, 600-612. 
[12] Bai, J., Perron, P., 1998. Estimating and testing linear models with multiple structural changes. Econometrica 66, 47-78.

[13] Bai, J., Perron, P., 2003a. Computation and analysis of multiple structural change models. Journal of Applied Econometrics 18, 1-22.

[14] Bai, J., Perron, P., 2003b. Critical values for multiple structural change tests. Econometrics Journal $6,72-78$.

[15] Bakas, D., Triantafyllou, A., 2019. Volatility forecasting in commodity markets using macro uncertainty. Energy Economics 81, 79-94.

[16] Baker, S.R., Bloom, N., Davis, S.J., 2016. Measuring economic policy uncertainty. The Quarterly Journal of Economics 131, 1593-1636.

[17] Balli, F., Uddin, G.S., Mudassar, H., Yoon, S.M., 2017. Cross-country determinants of economic policy uncertainty spillovers. Economics Letters 156, 179-183.

[18] Barsky, R.B., Kilian, L., 2004. Oil and the macroeconomy since the 1970s. Journal of Economic Perspectives 18, 115-134.

[19] Barndorff-Nielsen, O.E., Hansen, P.R., Lunde, A., Shephard, N., 2008. Designing realized kernels to measure the ex-post variation of equity prices in the presence of noise. Econometrica 76, 1481-1536.

[20] Barndorff-Nielsen, O.E., Hansen, P.R., Lunde, A., Shephard, N., 2009. Realized kernels in practice: trades and quotes. Econometrics Journal 12, C1-C32.

[21] Barndorff-Nielsen, O.E., Shephard, N., 2002. Econometric analysis of realized volatility and its use in estimating stochastic volatility models. Journal of the Royal Statistical Society, Series B 64, 253-280.

[22] Bekaert, G., Hoerova, M., Lo Duca, M., 2013. Risk, uncertainty and monetary policy. Journal of Monetary Economics 60, 771-788.

[23] Ben-David, I., Fermand, E., Kuhnen, C.M., Li, G., 2018. Expectations uncertainty and household economic behavior. National Bureau of Economic Research, No. w25336.

[24] Benamar, H., Foucault, T., Vega, C., 2018. Demand for information, macroeconomic uncertainty, and the response of US treasury securities to news. HEC Paris Research Paper No. FIN-2018-1263.

[25] Bernal, O., Gnabo, J.Y., Guilmin, G., 2016. Economic policy uncertainty and risk spillovers in the Eurozone. Journal of International Money and Finance 65, 24-45. 
[26] Bernanke, B.S., 1983. Irreversibility, uncertainty, and cyclical investment. The Quarterly Journal of Economics 98, 85-106.

[27] Bloom, N., 2009. The Impact of uncertainty shocks. Econometrica 77, 623-685.

[28] Bloom, N., 2014. Fluctuations in uncertainty. The Journal of Economic Perspectives 28, 153-175.

[29] Bordo, M.D., Duca, J.V., Koch, C., 2016. Economic policy uncertainty and the credit channel: Aggregate and bank level US evidence over several decades. Journal of Financial Stability 26, 90106.

[30] Borovkova, S., Mahakena, D., 2015. News, volatility and jumps: the case of natural gas futures. Quantitative Finance 15, 1217-1242.

[31] Boumparis, P., Milas, C., Panagiotidis, T., 2017. Economic policy uncertainty and sovereign credit rating decisions: Panel quantile evidence for the Eurozone. Journal of International Money and Finance 79, 39-71.

[32] Brogaard, D., Detzel, A., 2015. The asset-pricing Implications of government economic policy uncertainty. Management Science 61, 3-18.

[33] Brooks, R.D., Faff, R.W., McKenzie, M.D., Mitchell, H., 2000. A multi-country study of power ARCH models and national stock market returns. Journal of International Money and Finance 19, 377-397.

[34] Caggiano, G., Castelnuovo, E., Figueres, J.M., 2017. Economic policy uncertainty and unemployment in the United States: A nonlinear approach. Economics Letters 151, 31-34.

[35] Caliendo, F.N., Guo, N.L., Smith, J.M., 2018. Policy uncertainty and bank bailouts. Journal of Financial Markets 39, 111-125.

[36] Caporale, G.M., Spagnolo, F., Spagnolo, N., 2018. Macro news and bond yield spreads in the euro area. The European Journal of Finance 24, 114-134.

[37] Carriero, A., Clark, T.E., Marcellino, M., 2018. Measuring uncertainty and its impact on the economy. The Review of Economics and Statistics 100, 799-815.

[38] Castelnuovo, E., Tran, T.D., 2017. Google It Up! A Google trends-based Uncertainty index for the United States and Australia. Economics Letters 161, 149-153.

[39] Cho, D., Han, H., Lee, N.K., 2018. Carry trades and endogenous regime switches in exchange rate volatility. Journal of International Financial Markets, Institutions and Money 58, 255-268. 
[40] Christou, C., Gupta, R., Hassapis, C., 2017. Does economic policy uncertainty forecast real housing returns in a panel of OECD countries? A Bayesian approach. The Quarterly Review of Economics and Finance 65, 50-60.

[41] Colombo, V., 2013. Economic policy uncertainty in the US: Does it matter for the Euro area? Economics Letters 121, 39-42.

[42] Connolly, R., Dubofsky, D., Stivers, C., 2018. Macroeconomic uncertainty and the distant forwardrate slope. Journal of Empirical Finance 48, 140-161.

[43] Conrad, C., Karanasos, M., 2010. Negative volatility spillovers in the unrestricted ECCC-GARCH model. Econometric Theory 26, 838-862.

[44] Conrad, C., Loch, K., 2015. Anticipating long-term stock market volatility. Journal of Applied Econometrics 30, 1090-1114.

[45] Corradi, V., Distaso, W., Mele, A., 2013. Macroeconomic determinants of stock volatility and volatility premiums. Journal of Monetary Economics 60, 203-220.

[46] Corsi, F., Mittnik, S., Pigorsch, C., Pigorsch, U., 2008. The volatility of realized volatility. Econometric Reviews 27, 46-78.

[47] Creal, D.D., Koopman, S.J., Lucas, A., 2013. Generalized autoregressive score models with applications. Journal of Applied Econometrics 28, 777-795.

[48] Dakhlaoui, I., Aloui, C., 2016. The interactive relationship between the US economic policy uncertainty and BRIC stock markets. International Economics 146, 141-157.

[49] Dark, J.G., 2018. Multivariate models with long memory dependence in conditional correlation and volatility. Journal of Empirical Finance 48, 162-180.

[50] Diebold, F.X., Yilmaz, K., 2009. Measuring financial asset return and volatility spillovers, with application to global equity markets. Economic Journal 119, 158-171.

[51] Ding, Z., Granger, C.W.J., Engle, R.F., 1993. A long memory property of stock market returns and a new model. Journal of Empirical Finance 1, 83-106.

[52] Dixit, A.K, Pindyck, R.S., 1994. Investment under uncertainty. Princeton, NJ: Princeton University Press. 
[53] Engle, R.F., 2002a. Dynamic conditional correlation: A simple class of multivariate generalized autoregressive conditional heteroskedasticity models. Journal of Business and Economic Statistics 20, 339-350.

[54] Engle, R.F., 2002b. New frontiers for ARCH models. Journal of Applied Econometrics 17, 425-446.

[55] Engle, R.F., Ghysels, E., Sohn, B., 2013. Stock market volatility and macroeconomic fundamentals. Review of Economics and Statistics 95, 776-797.

[56] Engle, R.F., Ng, V.K., 1993. Measuring and testing the impact of news on volatility. The Journal of Finance 48, 1749-1778.

[57] Engle, R.F., Rangel, J.G., 2008. The spline-GARCH model for low-frequency volatility and its global macroeconomic causes. Review of Financial Studies 21, 1187-1222.

[58] Estrella, A., Hardouvelis, G.A., 1991. The term structure as a predictor of real economic activity. The Journal of Finance 46, 555-576.

[59] Fang, L., Bouri, E., Gupta, R., Roubaud, D., 2019. Does global economic uncertainty matter for the volatility and hedging effectiveness of Bitcoin? International Review of Financial Analysis 61, 29-36.

[60] Fang, L., Chen, B., Yu, H., Qian, Y., 2018. The importance of global economic policy uncertainty in predicting gold futures market volatility: A GARCH-MIDAS approach. Journal of Futures Markets $38,413-422$.

[61] Fountas, S., Karanasos, M., 2007. Inflation, output growth, and nominal and real uncertainty: empirical evidence for the G7. Journal of International Money and Finance 26, 229-250.

[62] Gabauer, D., Gupta, R., 2018. On the transmission mechanism of country-specific and international economic uncertainty spillovers: Evidence from a TVP-VAR connectedness decomposition approach. Economics Letters 171, 63-71.

[63] Glosten, L.R., Jagannathan R., Runkle, D.E., 1993. On the relation between the expected value and the volatility of the nominal excess return on stocks. The Journal of Finance 48, 1779-1801.

[64] Gulen, H., Ion, M., 2015. Policy uncertainty and corporate investment. The Review of Financial Studies 29, 523-564.

[65] Halunga, A.G., Orme, C. D., 2009. First-order asymptotic theory for parametric misspecification tests of GARCH models. Econometric Theory 25, 364-410. 
[66] Hamilton, J., Lin, G., 1996. Stock market volatility and the business cycle. Journal of Applied Econometrics 5, 573-593.

[67] Han, H., 2015. Asymptotic properties of GARCH-X processes. Journal of Financial Econometrics $13,188-221$.

[68] Han, H., Kristensen, D., 2014. Asymptotic theory for the QMLE in GARCH-X models with stationary and nonstationary covariates. Journal of Business and Economic Statistics 32, 416-429.

[69] Hansen, P.R., Huang, Z., Shek, H., 2012. Realized GARCH: A joint model for returns and realized measures of volatility. Journal of Applied Econometrics 27, 877-906.

[70] He, C., Teräsvirta, T., 1999. Statistical properties of the asymmetric power ARCH model. In: Engle, R.F., White, H. (Eds.), Cointegration, Causality, and Forecasting. Festschrift in Honour of Clive W.J. Granger. Oxford University Press, Oxford, 462-474.

[71] Heber, G., Lunde, A., Shephard, N., Sheppard, K., 2009. Oxford-Man Institute's (OMI's) realized library, Version 0.3. Oxford-Man Institute: University of Oxford.

[72] Huang, Z., Liu, H., Wang, T., 2016. Modeling long memory volatility using realized measures of volatility: A realized HAR GARCH model. Economic Modelling 52, 812-821.

[73] Jo, S., Sekkel, R., 2017. Macroeconomic uncertainty through the lens of professional forecasters. Journal of Business and Economic Statistics 37, 436-446.

[74] Jones, P.M., Olson, E., 2013. The time-varying correlation between uncertainty, output, and inflation: Evidence from a DCC-GARCH model. Economics Letters 118, 33-37.

[75] Jurado, K., Ludvigson, S. D., Ng, S. 2015. Measuring uncertainty. American Economic Review 105, 1177-1216.

[76] Karaman, K.K., Yildirim-Karaman, S., 2019. How does financial development alter the impact of uncertainty? Journal of Banking and Finance 102, 33-42.

[77] Karanasos, M., Kim, J., 2006. A re-examination of the asymmetric power ARCH model. Journal of Empirical Finance 13, 113-128.

[78] Kelly, B., Pastor, L., Veronesi, P., 2016. The price of political uncertainty: Theory and evidence from the option market. The Journal of Finance 71, 2417-2480.

[79] Kido, Y., 2016. On the link between the US economic policy uncertainty and exchange rates. Economics Letters 144, 49-52. 
[80] Klößner, S., Sekkel, R., 2014. International spillovers of policy uncertainty. Economics Letters 124, 508-512.

[81] Knight, F.H., 1921. Risk, uncertainty, and profit. Boston, MA: Hart, Schaffner \& Marx; Houghton Mifflin Company.

[82] Larsen, V.H., Thorsrud, L.A., 2018. The value of news for economic developments. Journal of Econometrics 210, 203-218.

[83] Laurent, S., 2004. Analytical derivates of the APARCH model. Computational Economics 24, 51-57.

[84] Li, X.M., Zhang, B., Gao, R., 2015. Economic policy uncertainty shocks and stock-bond correlations: Evidence from the US market. Economics Letters 132, 91-96.

[85] Ling, S., McAleer, M., 2003. Asymptotic theory for a vector ARMA-GARCH model. Econometric Theory 19, 280-310.

[86] Mumtaz, H., Theodoridis, K., 2018. The changing transmission of uncertainty shocks in the U.S. Journal of Business and Economic Statistics 36, 239-252.

[87] Nagar, V., Schoenfeld, J., Wellman, L., 2018. The effect of economic policy uncertainty on investor information asymmetry and management disclosures. Journal of Accounting and Economics 67, $36-57$.

[88] Nakatani, T., Teräsvirta, T., 2009. Testing for volatility interactions in the constant conditional correlation GARCH model. Econometrics Journal 12, 147-163.

[89] Noureldin, D., Shephard, N., Sheppard, K., 2012. Multivariate high-frequency-based volatility (HEAVY) models. Journal of Applied Econometrics 27, 907-933.

[90] Opschoor, A., Janus, P., Lucas, A., Van Dijk, D., 2018. New HEAVY models for fat-tailed realized covariances and returns. Journal of Business and Economic Statistics 36, 643-657.

[91] Pastor, L., Veronesi, P., 2012. Uncertainty about government policy and stock prices. The Journal of Finance 67, 1219-1264.

[92] Pastor, L., Veronesi, P., 2013. Political uncertainty and risk premia. Journal of Financial Economics $110,520-545$.

[93] Patton, A.J., 2011. Volatility forecast comparison using imperfect volatility proxies. Journal of Econometrics 160, 246-256. 
[94] Pedersen, R.S., 2017. Inference and testing on the boundary in extended constant conditional correlation GARCH models. Journal of Econometrics 196, 23-36.

[95] Pedersen, R.S., Rahbek, A., 2019. Testing GARCH-X type models. Econometric Theory 35, 10121047.

[96] Pérez, A., Ruiz, E., Veiga, H., 2009. A note on the properties of power-transformed returns in long-memory stochastic volatility models with leverage effect. Computational Statistics and Data Analysis 53, 3593-3600.

[97] Pham, A.V., 2019. Political risk and cost of equity: The mediating role of political connections. Journal of Corporate Finance 56, 64-87.

[98] Rossi, B., Sekhposyan, T., 2015. Uncertainty indices based on nowcast and forecast error distributions. American Economic Review 105, 650-655.

[99] Scheffel, E.M., 2016. Accounting for the political uncertainty factor. Journal of Applied Econometrics $31,1048-1064$.

[100] Schwert, G.W., 1989. Why does stock market volatility change over time? The Journal of Finance $44,1115-1153$.

[101] Scotti, C., 2016. Surprise and uncertainty indexes: Real-time aggregation of real-activity macrosurprises. Journal of Monetary Economics 82, 1-19.

[102] Shephard, N., Sheppard, K., 2010. Realising the future: forecasting with high-frequency-based volatility (HEAVY) models. Journal of Applied Econometrics 25, 197-231.

[103] Tarassow, A., 2019. Forecasting US money growth using economic uncertainty measures and regularisation techniques. International Journal of Forecasting 35, 443-457.

[104] Vlastakis, N., Markellos, R. N., 2012. Information demand and stock market volatility. Journal of Banking and Finance 36, 1808-1821.

[105] Wisniewski, T.P., Lambe, B.J., 2015. Does economic policy uncertainty drive CDS spreads? International Review of Financial Analysis 42, 447-458.

[106] Zhong, W., Lin, Y., Gao, D., Yang, H., 2019. Does politician turnover affect foreign subsidiary performance? Evidence in China. Journal of International Business Studies 50, 1184-1212. 


\section{A APPENDIX}

\section{A.1 Realized Measure Equation Analysis}

[Table A.1 here]

[Table A.2 here]

[Table A.3 here]

\section{A.2 Stock Index and Macro-variables Graphs}

[Figure A.1 here] [Figure A.2 here]

[Figure A.3 here]

[Figure A.4 here] [Figure A.5 here]

[Figure A.6 here][Figure A.7 here]

[Figure A.8 here][Figure A.9 here]

[Figure A.10 here]

Table 1: Data Description

\begin{tabular}{lccccccc}
\hline \hline & \multicolumn{2}{c}{ Total Sample period } & & \multicolumn{2}{c}{$r_{t}^{2}$} & \multicolumn{2}{c}{$R V_{t}$} \\
\hline Index & Start date & End date & Obs. & Avol & sd & Avol & sd \\
\hline FTSE & $02 / 01 / 2001$ & $01 / 03 / 2019$ & 4581 & 0.182 & 0.039 & 0.172 & 0.028 \\
EU & $02 / 01 / 2001$ & $01 / 03 / 2019$ & 4631 & 0.227 & 0.055 & 0.201 & 0.032 \\
DAX & $02 / 01 / 2001$ & $01 / 03 / 2019$ & 4609 & 0.232 & 0.060 & 0.203 & 0.030 \\
CAC & $02 / 01 / 2001$ & $01 / 03 / 2019$ & 4635 & 0.223 & 0.053 & 0.183 & 0.023 \\
AEX & $02 / 01 / 2001$ & $01 / 03 / 2019$ & 4635 & 0.221 & 0.057 & 0.171 & 0.020 \\
BELL & $02 / 01 / 2001$ & $01 / 03 / 2019$ & 4633 & 0.193 & 0.043 & 0.147 & 0.014 \\
IBEX & $02 / 01 / 2001$ & $01 / 03 / 2019$ & 4604 & 0.229 & 0.059 & 0.189 & 0.021 \\
SSMI & $03 / 01 / 2001$ & $01 / 03 / 2019$ & 4552 & 0.187 & 0.043 & 0.147 & 0.016 \\
OMXC & $04 / 10 / 2005$ & $01 / 03 / 2019$ & 3338 & 0.206 & 0.048 & 0.181 & 0.038 \\
OMXS & $04 / 10 / 2005$ & $01 / 03 / 2019$ & 3367 & 0.209 & 0.051 & 0.161 & 0.030 \\
OSE & $04 / 09 / 2001$ & $01 / 03 / 2019$ & 4363 & 0.219 & 0.055 & 0.180 & 0.027 \\
\hline
\end{tabular}

Notes: Avol is the annualized volatility and sd is the standard deviation. 
Table 2: The Benchmark HEAVY model.

\begin{tabular}{|c|c|c|c|c|c|c|c|c|}
\hline & \multicolumn{4}{|c|}{$\begin{array}{l}\text { Panel A. Stock Returns: HEAVY- } r \\
\left(1-\beta_{r} L\right) \sigma_{r t}^{2}=\omega_{r}+\alpha_{r R} L\left(R M_{t}\right)\end{array}$} & \multicolumn{4}{|c|}{$\begin{array}{l}\text { Panel B. Realized Measure: HEAVY- } R \\
\qquad\left(1-\beta_{R} L\right) \sigma_{R t}^{2}=\omega_{R}+\alpha_{R R} L\left(R M_{t}\right)\end{array}$} \\
\hline & $\beta_{r}$ & $\alpha_{r R}$ & SBT & $\ln L$ & $\beta_{R}$ & $\alpha_{R R}$ & SBT & $\ln L$ \\
\hline FTSE & $\begin{array}{c}0.64 \\
(0.045)^{* * *}\end{array}$ & $\begin{array}{c}0.38 \\
(0.053)^{* * *}\end{array}$ & $\begin{array}{l}2.57 \\
{[0.01]}\end{array}$ & -6067.59 & $\begin{array}{c}0.62 \\
(0.039)^{* * *}\end{array}$ & $\begin{array}{c}0.37 \\
(0.041)^{* * *}\end{array}$ & $\begin{array}{l}2.68 \\
{[0.01]}\end{array}$ & -5858.93 \\
\hline $\mathrm{EU}$ & $\begin{array}{c}0.64 \\
(0.046)^{* * *}\end{array}$ & $\begin{array}{c}0.45 \\
(0.061)^{* * *}\end{array}$ & $\begin{array}{l}3.32 \\
{[0.00]}\end{array}$ & -7205.94 & $\begin{array}{c}0.57 \\
(0.036)^{* * *}\end{array}$ & $\begin{array}{c}0.41 \\
(0.036)^{* * *}\end{array}$ & $\begin{array}{l}2.83 \\
{[0.00]}\end{array}$ & -6653.53 \\
\hline DAX & $\begin{array}{c}0.63 \\
(0.050)^{* * *}\end{array}$ & $\begin{array}{c}0.46 \\
(0.067)^{* * *}\end{array}$ & $\begin{array}{l}3.85 \\
{[0.00]}\end{array}$ & -7271.24 & $\begin{array}{c}0.58 \\
(0.031)^{* * *}\end{array}$ & $\begin{array}{c}0.40 \\
(0.031)^{* * *}\end{array}$ & $\begin{array}{l}3.10 \\
{[0.00]}\end{array}$ & -6553.32 \\
\hline CAC & $\begin{array}{c}0.43 \\
(0.057)^{* * *}\end{array}$ & $\begin{array}{c}0.83 \\
(0.092)^{* * *}\end{array}$ & $\begin{array}{l}2.31 \\
{[0.02]}\end{array}$ & -7133.23 & $\begin{array}{c}0.55 \\
(0.035)^{* * *}\end{array}$ & $\begin{array}{c}0.43 \\
(0.036)^{* * *}\end{array}$ & $\begin{array}{l}2.29 \\
{[0.02]}\end{array}$ & -6257.72 \\
\hline AEX & $\begin{array}{c}0.54 \\
(0.056)^{* * *}\end{array}$ & $\begin{array}{c}0.75 \\
(0.094)^{* * *}\end{array}$ & $\begin{array}{l}2.32 \\
{[0.02]}\end{array}$ & -6797.87 & $\begin{array}{c}0.53 \\
(0.034)^{* * *}\end{array}$ & $\begin{array}{c}0.45 \\
(0.036)^{* * *}\end{array}$ & $\begin{array}{l}2.90 \\
{[0.00]}\end{array}$ & -5780.19 \\
\hline BELL & $\begin{array}{c}0.46 \\
(0.057)^{* * *}\end{array}$ & $\begin{array}{c}0.86 \\
(0.102)^{* * *}\end{array}$ & $\begin{array}{l}2.41 \\
{[0.02]}\end{array}$ & -6410.59 & $\begin{array}{c}0.54 \\
(0.032)^{* * *}\end{array}$ & $\begin{array}{c}0.45 \\
(0.034)^{* * *}\end{array}$ & $\begin{array}{l}2.50 \\
{[0.01]}\end{array}$ & -5320.22 \\
\hline IBEX & $\begin{array}{c}0.49 \\
(0.082)^{* * *}\end{array}$ & $\begin{array}{c}0.71 \\
(0.128)^{* * *}\end{array}$ & $\begin{array}{l}1.69 \\
{[0.09]}\end{array}$ & & $\begin{array}{c}0.54 \\
(0.041)^{* * *}\end{array}$ & $\begin{array}{c}0.45 \\
(0.043)^{* * *}\end{array}$ & $\begin{array}{l}2.01 \\
{[0.04]}\end{array}$ & -6531.19 \\
\hline SSMI & $\begin{array}{c}0.47 \\
(0.062)^{* * *}\end{array}$ & $\begin{array}{c}0.87 \\
(0.112)^{* * *}\end{array}$ & $\begin{array}{l}2.09 \\
{[0.04]}\end{array}$ & -6133.67 & $\begin{array}{c}0.47 \\
(0.053)^{* * *}\end{array}$ & $\begin{array}{c}0.52 \\
(0.062)^{* * *}\end{array}$ & $\begin{array}{l}2.88 \\
{[0.00]}\end{array}$ & -5108.27 \\
\hline OMXC & $\begin{array}{c}0.52 \\
(0.121)^{* * *}\end{array}$ & $\begin{array}{c}0.57 \\
(0.156)^{* * *}\end{array}$ & $\begin{array}{l}2.67 \\
{[0.01]}\end{array}$ & -5085.39 & $\begin{array}{c}0.66 \\
(0.204)^{* * *}\end{array}$ & $\begin{array}{c}0.35 \\
(0.199)^{*}\end{array}$ & $\begin{array}{l}2.99 \\
{[0.00]}\end{array}$ & -4547.20 \\
\hline OMXS & $\begin{array}{c}0.39 \\
(0.100)^{* * *}\end{array}$ & ${ }_{(0.218)^{* * *}}$ & $\begin{array}{l}3.57 \\
{[0.00]}\end{array}$ & -4967.65 & $\begin{array}{c}0.52 \\
(0.085)^{* * *}\end{array}$ & $\begin{array}{c}0.51 \\
(0.107)^{* * *}\end{array}$ & $\begin{array}{l}2.69 \\
{[0.01]}\end{array}$ & -3899.14 \\
\hline OSE & $\begin{array}{c}0.75 \\
(0.040)^{* * *}\end{array}$ & $\begin{array}{c}0.36 \\
(0.058)^{* * *}\end{array}$ & $\begin{array}{l}3.20 \\
{[0.00]}\end{array}$ & -6694.12 & $\begin{array}{c}0.65 \\
(0.047)^{* * *}\end{array}$ & $\begin{array}{c}0.33 \\
(0.046)^{* * *}\end{array}$ & $\begin{array}{l}2.49 \\
{[0.02]}\end{array}$ & -5914.80 \\
\hline
\end{tabular}

Notes: The numbers in parentheses are robust standard errors. ${ }^{* * *},{ }^{* *},{ }^{*}$ denote significance at the 0.01, 0.05, 0.10 level respectively. SBT denotes the Sign Bias test of Engle and $\mathrm{Ng}$ (1993). The numbers in square brackets are p-values. $\ln L$ denotes the log-likelihood value for each specification. 
Table 3: The m-DAP-HEAVY model.

\begin{tabular}{|c|c|c|c|c|c|c|c|}
\hline \multicolumn{8}{|c|}{$\begin{array}{l}\text { Panel A. Stock Returns: m-DAP-HEAVY- } r^{4} \\
\left(1-\beta_{r} L\right)\left(\sigma_{r t}^{2}\right)^{\frac{\delta_{r}}{2}}=\omega_{r}+\gamma_{r r} s_{t-1} L\left(r_{t}^{2}\right)^{\frac{\delta_{r}}{2}}+\gamma_{r R} s_{t-1} L\left(R M_{t}\right)^{\frac{\delta_{R}}{2}}\end{array}$} \\
\hline & $\beta_{r}$ & $\gamma_{r r}$ & $\gamma_{r R}$ & $\delta_{r}$ & $\delta_{R}$ & SBT & $\ln L$ \\
\hline FTSE & $\begin{array}{c}0.87 \\
(0.013)^{* * *}\end{array}$ & $\begin{array}{c}0.10 \\
(0.014)^{* * *}\end{array}$ & $\begin{array}{c}0.11 \\
(0.019)^{* * *}\end{array}$ & 1.50 & 1.30 & $\begin{array}{l}0.70 \\
{[0.49]}\end{array}$ & -5746.51 \\
\hline $\mathrm{EU}$ & $\begin{array}{c}0.88 \\
(0.013)^{* * *}\end{array}$ & $\begin{array}{c}0.09 \\
(0.015)^{* * *}\end{array}$ & $\begin{array}{c}0.14 \\
(0.027)^{* * *}\end{array}$ & 1.50 & 1.30 & $\begin{array}{l}1.39 \\
{[0.16]}\end{array}$ & -6620.78 \\
\hline DAX & $\begin{array}{c}0.89 \\
(0.013)^{* * *}\end{array}$ & $\begin{array}{c}0.07 \\
(0.013)^{* * *}\end{array}$ & $\begin{array}{c}0.12 \\
(0.025)^{* * *}\end{array}$ & 1.40 & 1.40 & $\begin{array}{l}1.02 \\
{[0.31]}\end{array}$ & -6585.29 \\
\hline $\mathrm{CAC}$ & $\begin{array}{c}0.88 \\
(0.012)^{* * *}\end{array}$ & $\begin{array}{c}0.09 \\
(0.013)^{* * *}\end{array}$ & $\begin{array}{c}0.15 \\
(0.026)^{* * *}\end{array}$ & 1.40 & 1.10 & $\begin{array}{l}0.67 \\
{[0.50]}\end{array}$ & -6519.87 \\
\hline AEX & $\begin{array}{c}0.89 \\
(0.011)^{* * *}\end{array}$ & $\begin{array}{c}0.09 \\
(0.012)^{* * *}\end{array}$ & $\begin{array}{c}0.12 \\
(0.022)^{* * *}\end{array}$ & 1.40 & 1.20 & $\begin{array}{l}1.27 \\
{[0.20]}\end{array}$ & -6277.56 \\
\hline BELL & $\begin{array}{c}0.87 \\
(0.013)^{* * *}\end{array}$ & $\begin{array}{c}0.11 \\
(0.014)^{* * *}\end{array}$ & $\begin{array}{c}0.12 \\
(0.023)^{* * *}\end{array}$ & 1.40 & 1.20 & $\begin{array}{l}0.48 \\
{[0.63]}\end{array}$ & -6001.13 \\
\hline IBEX & $\begin{array}{c}0.88 \\
(0.017)^{* * *}\end{array}$ & $\begin{array}{c}0.09 \\
(0.015)^{* * *}\end{array}$ & $\begin{array}{c}0.17 \\
(0.049)^{* * *}\end{array}$ & 1.70 & 1.20 & $\begin{array}{l}0.06 \\
{[0.95]}\end{array}$ & -6959.82 \\
\hline SSMI & $\begin{array}{c}0.86 \\
(0.011)^{* * *}\end{array}$ & $\begin{array}{c}0.10 \\
(0.014)^{* * *}\end{array}$ & $\begin{array}{c}0.18 \\
(0.027)^{* * *}\end{array}$ & 1.50 & 1.20 & $\begin{array}{l}1.00 \\
{[0.32]}\end{array}$ & -5802.58 \\
\hline OMXC & $\begin{array}{c}0.86 \\
(0.017)^{* * *}\end{array}$ & $\begin{array}{c}0.09 \\
(0.018)^{* * *}\end{array}$ & $\begin{array}{c}0.15 \\
(0.031)^{* * *}\end{array}$ & 1.60 & 1.00 & $\begin{array}{l}0.11 \\
{[0.91]}\end{array}$ & -4759.62 \\
\hline OMXS & $\begin{array}{c}0.87 \\
(0.016)^{* * *}\end{array}$ & $\begin{array}{c}0.12 \\
(0.020)^{* * *}\end{array}$ & $\begin{array}{c}0.16 \\
(0.035)^{* * *}\end{array}$ & 1.60 & 1.00 & $\begin{array}{l}0.12 \\
{[0.91]}\end{array}$ & -4672.02 \\
\hline OSE & $\begin{array}{c}0.90 \\
(0.014)^{* * *}\end{array}$ & $\begin{array}{c}0.10 \\
(0.015)^{* * *}\end{array}$ & $\begin{array}{c}0.09 \\
(0.025)^{* * *}\end{array}$ & 1.60 & 1.00 & $\begin{array}{c}0.59 \\
{[0.56]}\end{array}$ & -6271.82 \\
\hline
\end{tabular}

Notes: See Notes in Table 2.

\footnotetext{
${ }^{4}$ The returns equation is also estimated with the direct Heavy effect from the power transformed realized measure, $\alpha_{r}$, instead of the Heavy asymmetry, $\gamma_{r R}$ (These results are available in Appendix Table A.4).
} 
Table 3: The m-DAP-HEAVY model.

\begin{tabular}{|c|c|c|c|c|c|c|c|c|c|c|c|}
\hline \multicolumn{12}{|c|}{$\begin{array}{c}\text { Panel B. Realized Measure: m-DAP-HEAVY- } R \\
\left(1-\beta_{R} L\right)\left(\sigma_{R t}^{2}\right)^{\frac{\delta_{R}}{2}}=\omega_{R}+\left(\alpha_{R R}+\gamma_{R R} s_{t-1}\right) L\left(R M_{t}\right)^{\frac{\delta_{R}}{2}} \\
+\gamma_{R r} s_{t-1} L\left(r_{t}^{2}\right)^{\frac{\delta_{r}}{2}}+\phi_{R} E P U_{t-1}+\zeta_{R} B O_{t-1}+\vartheta_{R} C O_{t-1}\end{array}$} \\
\hline & $\beta_{R}$ & $\alpha_{R R}$ & $\gamma_{R R}$ & $\gamma_{R r}$ & $\phi_{R}$ & $\zeta_{R}$ & $\vartheta_{R}$ & $\delta_{r}$ & $\delta_{R}$ & $\mathrm{SBT}$ & $\ln L$ \\
\hline FTSE & $\begin{array}{c}0.77 \\
(0.022)^{* * *}\end{array}$ & $\begin{array}{c}0.13 \\
(0.022)^{* * *}\end{array}$ & $\begin{array}{c}0.04 \\
(0.014)^{* * *}\end{array}$ & $\begin{array}{c}0.09 \\
(0.008)^{* * *}\end{array}$ & $\begin{array}{c}0.02 \\
(0.005)^{* * *}\end{array}$ & $\begin{array}{c}0.06 \\
(0.011)^{* * *} \\
M O V E\end{array}$ & $\begin{array}{c}0.01 \\
(0.006)^{* *} \\
W T I\end{array}$ & 1.50 & 1.30 & $\begin{array}{l}1.04 \\
{[0.30]}\end{array}$ & -5744.36 \\
\hline $\mathrm{EU}$ & $\begin{array}{c}0.72 \\
(0.025)^{* * *}\end{array}$ & $\begin{array}{c}0.17 \\
(0.023)^{* * *}\end{array}$ & $\begin{array}{c}0.04 \\
(0.013)^{* * *}\end{array}$ & $\begin{array}{c}0.08 \\
(0.007)^{* * *}\end{array}$ & $\begin{array}{c}0.01 \\
(0.006)^{* *}\end{array}$ & $\begin{array}{c}0.07 \\
(0.015)^{* * *} \\
M O V E\end{array}$ & $\begin{array}{c}0.02^{\circledast} \\
(0.009)^{*} \\
G S C I\end{array}$ & 1.50 & 1.30 & $\begin{array}{l}1.40 \\
{[0.16]}\end{array}$ & -6509.33 \\
\hline DAX & $\begin{array}{c}0.72 \\
(0.023)^{* * *}\end{array}$ & $\begin{array}{c}0.20 \\
(0.021)^{* * *}\end{array}$ & $\begin{array}{c}0.03 \\
(0.010)^{* * *}\end{array}$ & $\begin{array}{c}0.07 \\
(0.007)^{* * *}\end{array}$ & $\begin{array}{c}0.01 \\
(0.006)^{*}\end{array}$ & $\begin{array}{c}0.06 \\
(0.019)^{* * *} \\
A A A\end{array}$ & $\begin{array}{c}0.02^{\circledast} \\
(0.008)^{* * *} \\
G S C I\end{array}$ & 1.40 & 1.40 & $\begin{array}{l}0.90 \\
{[0.37]}\end{array}$ & -6460.71 \\
\hline CAC & $\begin{array}{c}0.69 \\
(0.023)^{* * *}\end{array}$ & $\begin{array}{c}0.21 \\
(0.020)^{* * *}\end{array}$ & $\begin{array}{c}0.03 \\
(0.008)^{* * *}\end{array}$ & $\begin{array}{c}0.06 \\
(0.005)^{* * *}\end{array}$ & $\begin{array}{c}0.02 \\
(0.005)^{* * *}\end{array}$ & $\begin{array}{c}0.06 \\
(0.012)^{* * *} \\
M O V E\end{array}$ & $\begin{array}{c}0.01 \\
(0.004)^{*} \\
W T I\end{array}$ & 1.40 & 1.10 & $\begin{array}{l}0.54 \\
{[0.59]}\end{array}$ & -6110.21 \\
\hline AEX & $\begin{array}{c}0.67 \\
(0.024)^{* * *}\end{array}$ & $\begin{array}{c}0.22 \\
(0.022)^{* * *}\end{array}$ & $\begin{array}{c}0.02 \\
(0.010)^{* * *}\end{array}$ & $\begin{array}{c}0.07 \\
(0.006)^{* * *}\end{array}$ & $\begin{array}{c}0.01 \\
(0.004)^{* * *}\end{array}$ & $\begin{array}{c}0.06 \\
(0.011)^{* * *} \\
\text { MOVE }\end{array}$ & $\begin{array}{c}0.01^{\circledast} \\
(0.007)^{*} \\
G S C I\end{array}$ & 1.40 & 1.20 & $\begin{array}{l}0.96 \\
{[0.34]}\end{array}$ & -5706.58 \\
\hline BELL & $\begin{array}{c}0.65 \\
(0.024)^{* * *}\end{array}$ & $\begin{array}{c}0.26 \\
(0.022)^{* * *}\end{array}$ & $\begin{array}{c}0.02 \\
(0.009)^{* *}\end{array}$ & $\begin{array}{c}0.06 \\
(0.006)^{* * *}\end{array}$ & $\begin{array}{c}0.02 \\
(0.004)^{* * *}\end{array}$ & $\begin{array}{c}0.04 \\
(0.009)^{* * *} \\
\text { MOVE }\end{array}$ & & 1.40 & 1.20 & $\begin{array}{l}0.20 \\
{[0.84]}\end{array}$ & -5242.64 \\
\hline IBEX & $\begin{array}{c}0.66 \\
(0.027)^{* * *}\end{array}$ & $\begin{array}{c}0.26 \\
(0.025)^{* * *}\end{array}$ & $\begin{array}{c}0.02 \\
(0.011)^{* *}\end{array}$ & $\begin{array}{c}0.04 \\
(0.004)^{* * *}\end{array}$ & $\begin{array}{c}0.03 \\
(0.007)^{* * *}\end{array}$ & $\begin{array}{c}0.03 \\
(0.013)^{* * *} \\
\text { MOVE }\end{array}$ & $\begin{array}{c}0.02 \\
(0.008)^{* *} \\
W T I\end{array}$ & 1.70 & 1.20 & $\begin{array}{l}0.68 \\
{[0.50]}\end{array}$ & -6441.87 \\
\hline SSMI & $\begin{array}{c}0.64 \\
(0.033)^{* * *}\end{array}$ & $\begin{array}{c}0.27 \\
(0.031)^{* * *}\end{array}$ & $\begin{array}{c}0.02 \\
(0.008)^{* * *}\end{array}$ & $\begin{array}{c}0.05 \\
(0.005)^{* * *}\end{array}$ & $\begin{array}{c}0.01 \\
(0.003) *\end{array}$ & $\begin{array}{c}0.05 \\
(0.010)^{* * *} \\
\text { MOVE }\end{array}$ & $\begin{array}{c}0.01^{\circledast} \\
(0.003)^{* *} \\
G S C I\end{array}$ & 1.50 & 1.20 & $\begin{array}{l}0.41 \\
{[0.68]}\end{array}$ & -5073.07 \\
\hline OMXC & $\begin{array}{c}0.73 \\
(0.044)^{* * *}\end{array}$ & $\begin{array}{c}0.20 \\
(0.033)^{* * *}\end{array}$ & & $\begin{array}{c}0.04 \\
(0.006)^{* * *}\end{array}$ & $\begin{array}{c}0.01 \\
(0.006)^{*}\end{array}$ & $\begin{array}{c}0.04 \\
(0.017)^{* *} \\
A A A\end{array}$ & & 1.60 & 1.00 & $\begin{array}{l}1.06 \\
{[0.29]}\end{array}$ & -4492.10 \\
\hline OMXS & $\begin{array}{c}0.69 \\
(0.040)^{* * *}\end{array}$ & $\begin{array}{c}0.20 \\
(0.033)^{* * *}\end{array}$ & $\begin{array}{c}0.03 \\
(0.010)^{* * *}\end{array}$ & $\begin{array}{c}0.05 \\
(0.005)^{* * *}\end{array}$ & $\begin{array}{c}0.01 \\
(0.007)^{* *}\end{array}$ & $\begin{array}{c}0.15 \\
(0.028)^{* * *} \\
B A A\end{array}$ & $\begin{array}{c}0.02^{\circledast} \\
(0.008)^{* * *} \\
G S C I\end{array}$ & 1.60 & 1.00 & $\begin{array}{l}0.84 \\
{[0.40]}\end{array}$ & -3732.41 \\
\hline OSE & $\begin{array}{c}0.72 \\
(0.022)^{* * *}\end{array}$ & $\begin{array}{c}0.17 \\
(0.015)^{* * *}\end{array}$ & $\begin{array}{c}0.04 \\
(0.009)^{* * *}\end{array}$ & $\begin{array}{c}0.04 \\
(0.004)^{* * *}\end{array}$ & & $\begin{array}{c}0.03 \\
(0.006)^{* * *} \\
B A A_{-} A A A\end{array}$ & $\begin{array}{c}0.02 \\
(0.007)^{* * *} \\
G S C I\end{array}$ & 1.60 & 1.00 & $\begin{array}{l}0.87 \\
{[0.39]}\end{array}$ & -5813.53 \\
\hline
\end{tabular}

Notes: See Notes in Table 2. $\circledast$ signifies that the Commodity coefficient is not jointly significant with the Bonds parameter. 
Table 4: Mean Square Error (MSE) and QLIKE of m-step-ahead out-of-sample forecasts for FTSE as a Ratio of the benchmark model.

\begin{tabular}{|c|c|c|c|c|c|c|c|c|}
\hline \multirow[b]{2}{*}{ Specifications $\downarrow$ m-steps $\rightarrow$} & \multicolumn{4}{|c|}{ MSE } & \multicolumn{4}{|c|}{ QLIKE } \\
\hline & 1 & 5 & 10 & 20 & 1 & 5 & 10 & 20 \\
\hline \multicolumn{9}{|c|}{ Panel A: Stock Returns (HEAVY-r) } \\
\hline Benchmark & 1.000 & 1.000 & 1.000 & 1.000 & 1.000 & 1.000 & 1.000 & 1.000 \\
\hline m-DAP & 0.777 & 0.793 & 0.824 & 0.902 & 0.751 & 0.782 & 0.816 & 0.929 \\
\hline \multicolumn{9}{|c|}{ Panel B: Realized Measure (HEAVY-R) } \\
\hline Benchmark & 1.000 & 1.000 & 1.000 & 1.000 & 1.000 & 1.000 & 1.000 & 1.000 \\
\hline DAP & 0.851 & 0.896 & 0.933 & 0.967 & 0.762 & 0.801 & 0.794 & 0.831 \\
\hline m-DAP (EPU only) & 0.813 & 0.877 & 0.901 & 0.915 & 0.719 & 0.750 & 0.787 & 0.766 \\
\hline $\mathrm{m}-\mathrm{DAP} \oplus$ & 0.836 & 0.854 & 0.873 & 0.902 & 0.747 & 0.738 & 0.781 & 0.759 \\
\hline
\end{tabular}

Notes: Bold numbers indicate minimum values across the different specifications.

$\oplus$ The m-DAP-HEAVY- $R$ specification includes all three macro-factors: EPU, Bonds \& Commodities.

Table 5: The break dates for FTSE.

\begin{tabular}{crrc}
\hline \hline & $1^{\text {st }}$ Break & $2^{\text {nd }}$ Break & $3^{\text {rd }}$ Break \\
\cline { 2 - 4 }$r$ & $03 / 10 / 2003$ & $23 / 07 / 2007$ & $27 / 05 / 2010$ \\
$R$ & $\mathbf{0 1 / 1 0 / 2 0 0 3}$ & $\mathbf{2 4 / 0 7 / 2 0 0 7}$ & $\mathbf{2 1 / 0 7 / 2 0 1 0}$ \\
\hline
\end{tabular}

Notes: Bai \& Perron breaks identification: Results selected

from the repartition procedure for $1 \%$ significance level

with 5 maximum number of breaks and 0.15 trimming

parameter. Dates in bold indicate that the corresponding

dummy coefficient is used in the HEAVY models. 
Table 6: The m-DAP-HEAVY model for FTSE

with the crisis period break.

\begin{tabular}{|c|c|c|c|c|}
\hline \multicolumn{5}{|c|}{$\begin{array}{c}\text { Panel A. Stock Returns: m-DAP-HEAVY- } r \\
\left(1-\beta_{r} L\right)\left(\sigma_{r t}^{2}\right)^{\frac{\delta_{r}}{2}}=\omega_{r}+\left(\gamma_{r r}+\gamma_{r r}^{(2)} D_{2, t-1}\right) s_{t-1} L\left(r_{t}^{2}\right)^{\frac{\delta_{r}}{2}} \\
+\left(\gamma_{r R}+\gamma_{r R}^{(2)} D_{2, t-1}\right) s_{t-1} L\left(R M_{t}\right)^{\frac{\delta_{R}}{2}}\end{array}$} \\
\hline \multirow[t]{2}{*}{$I$} & $\beta_{r}$ & $\gamma_{r r}$ & $\gamma_{r r}^{(2)}$ & $\gamma_{r R}$ \\
\hline & $\begin{array}{c}0.87 \\
(0.013)^{* * *}\end{array}$ & $\begin{array}{c}0.10 \\
(0.013)^{* * *}\end{array}$ & $\begin{array}{c}0.04 \\
(0.014)^{* * *}\end{array}$ & $\begin{array}{c}0.10 \\
(0.019)^{* * *}\end{array}$ \\
\hline \multirow[t]{2}{*}{$I I$} & $\beta_{r}$ & $\gamma_{r r}$ & $\gamma_{r R}$ & $\gamma_{r R}^{(2)}$ \\
\hline & $\begin{array}{c}0.87 \\
(0.013)^{* * *}\end{array}$ & $\begin{array}{c}0.11 \\
(0.014)^{* * *}\end{array}$ & $\begin{array}{c}0.10 \\
(0.019)^{* * *}\end{array}$ & $\begin{array}{c}0.04 \\
(0.013)^{* * *}\end{array}$ \\
\hline
\end{tabular}

Panel B. Realized Measure: m-DAP-HEAVY- $R$

with EPU, Bonds \& Commodities

\begin{tabular}{|c|c|c|c|c|c|c|}
\hline \multicolumn{7}{|c|}{$\begin{array}{c}\left(1-\beta_{R} L\right)\left(\sigma_{R t}^{2}\right)^{\frac{\delta_{R}}{2}}=\omega_{R}+\left[\alpha_{R R}+\alpha_{R R}^{(2)} D_{2, t-1}\right. \\
\left.+\left(\gamma_{R R}+\gamma_{R R}^{(2)} D_{2, t-1}\right) s_{t-1}\right] L\left(R M_{t}\right)^{\frac{\delta_{R}}{2}} \\
+\left(\gamma_{R r}+\gamma_{R r}^{(2)} D_{2, t-1}\right) s_{t-1} L\left(r_{t}^{2}\right)^{\frac{\delta_{r}}{2}}+\left(\phi_{R}+\phi_{R}^{(2)} D_{2, t-1}\right) E P U_{t-1} \\
+\left(\zeta_{R}+\zeta_{R}^{(2)} D_{2, t-1}\right) B O_{t-1}+\left(\vartheta_{R}+\vartheta_{R}^{(2)} D_{2, t-1}\right) C O_{t-1}\end{array}$} \\
\hline \multirow[t]{2}{*}{$I$} & $\beta_{R}$ & $\alpha_{R R}$ & $\alpha_{R R}^{(2)}$ & $\gamma_{R R}$ & $\gamma_{R r}$ & \\
\hline & $\begin{array}{c}0.77 \\
(0.021)^{* * *}\end{array}$ & $\begin{array}{c}0.13 \\
(0.023)^{* * *}\end{array}$ & $\begin{array}{c}0.02 \\
(0.004)^{* * *} \\
\end{array}$ & $\begin{array}{c}0.04 \\
(0.015)^{* * *}\end{array}$ & $\begin{array}{c}0.08 \\
(0.008)^{* * *}\end{array}$ & \\
\hline \multirow[t]{2}{*}{$I I$} & $\beta_{R}$ & $\alpha_{R R}$ & $\gamma_{R R}$ & $\gamma_{R R}^{(2)}$ & $\gamma_{R r}$ & \\
\hline & $\begin{array}{c}0.78 \\
(0.021)^{* * *} \\
\end{array}$ & $\begin{array}{c}0.13 \\
(0.023)^{* * *} \\
\end{array}$ & $\begin{array}{c}0.04 \\
(0.0174)^{* * *}\end{array}$ & $\begin{array}{c}0.03 \\
(0.008)^{* * *}\end{array}$ & $\begin{array}{c}0.08 \\
(0.008)^{* * *}\end{array}$ & \\
\hline \multirow[t]{2}{*}{$I I I$} & $\beta_{R}$ & $\alpha_{R R}$ & $\gamma_{R R}$ & $\gamma_{R r}$ & $\gamma_{R r}^{(2)}$ & \\
\hline & $\begin{array}{c}0.77 \\
(0.021)^{* * *} \\
\end{array}$ & $\begin{array}{c}0.13 \\
(0.023)^{* * *}\end{array}$ & $\begin{array}{c}0.04 \\
(0.015)^{* * *}\end{array}$ & $\begin{array}{c}0.08 \\
(0.008)^{* * *}\end{array}$ & $\begin{array}{c}0.03 \\
(0.009)^{* * *} \\
\end{array}$ & \\
\hline \multirow[t]{2}{*}{$I V$} & $\beta_{R}$ & $\alpha_{R R}$ & $\gamma_{R R}$ & $\gamma_{R r}$ & $\phi_{R}$ & $\phi_{R}^{(2)}$ \\
\hline & $\begin{array}{c}0.78 \\
(0.022)^{* * *} \\
\end{array}$ & $\begin{array}{c}0.12 \\
(0.023)^{* * *}\end{array}$ & $\begin{array}{c}0.05 \\
(0.015)^{* * *} \\
\end{array}$ & $\begin{array}{c}0.09 \\
(0.008)^{* * *} \\
\end{array}$ & $\begin{array}{c}0.01 \\
(0.004)^{*}\end{array}$ & $\begin{array}{c}0.01 \\
(0.002)^{* * *} \\
\end{array}$ \\
\hline \multirow[t]{2}{*}{$V$} & $\beta_{R}$ & $\alpha_{R R}$ & $\gamma_{R R}$ & $\gamma_{R r}$ & $\zeta_{R}$ & $\zeta_{R}^{(2)}$ \\
\hline & $\begin{array}{c}0.77 \\
(0.022)^{* * *}\end{array}$ & $\begin{array}{c}0.12 \\
(0.024)^{* * *}\end{array}$ & $\begin{array}{c}0.04 \\
(0.015)^{* * *}\end{array}$ & $\begin{array}{c}0.09 \\
(0.008)^{* * *}\end{array}$ & $\begin{array}{c}0.02 \\
(0.009)^{* * *} \\
M O V E\end{array}$ & $\begin{array}{c}0.01 \\
(0.002)^{* * *} \\
M O V E\end{array}$ \\
\hline \multirow[t]{2}{*}{$V I$} & $\beta_{R}$ & $\alpha_{R R}$ & $\gamma_{R R}$ & $\gamma_{R r}$ & $\vartheta_{R}$ & $\vartheta_{R}^{(2)}$ \\
\hline & $\begin{array}{c}0.78 \\
(0.021)^{* * *}\end{array}$ & $\begin{array}{c}0.12 \\
(0.023)^{* * *}\end{array}$ & $\begin{array}{c}0.05 \\
(0.015)^{* * *}\end{array}$ & $\begin{array}{c}0.09 \\
(0.008)^{* * *}\end{array}$ & $\begin{array}{c}0.01 \\
(0.005)^{*} \\
G S C I\end{array}$ & $\begin{array}{c}0.01 \\
(0.001)^{* * *} \\
G S C I\end{array}$ \\
\hline \multicolumn{7}{|c|}{ Powers $\delta_{i}$} \\
\hline$\delta_{r}$ & $\delta_{R}$ & & & & & \\
\hline 1.50 & 1.30 & & & & & \\
\hline
\end{tabular}

Notes: See notes in Table 2.

Superscripts in parentheses indicate the crisis break date. 
Table 7: The Benchmark HEAVY- $R$ equation for FTSE with the EPU effect on Heavy, Bonds and Commodities parameters.

\begin{tabular}{|c|c|c|c|c|c|c|c|c|c|c|}
\hline & (1) & (2) & (3) & (4) & $(5)$ & (6) & $(7)$ & (8) & (9) & (10) \\
\hline \multicolumn{11}{|c|}{$\begin{array}{c}\left(1-\beta_{R} L\right) \sigma_{R t}^{2}=\omega_{R}+\left(\alpha_{R R}+\alpha_{R R}^{e p u} E P U_{t-1}\right) L\left(R M_{t}\right)+ \\
\left(\zeta_{R}+\zeta_{R}^{e p u} E P U_{t-1}\right) B O_{t-1}+\left(\vartheta_{R}+\vartheta_{R}^{e p u} E P U_{t-1}\right) C O_{t-1}\end{array}$} \\
\hline$\beta_{R}$ & $\begin{array}{c}0.61 \\
(0.041)^{* * *}\end{array}$ & $\begin{array}{c}0.60 \\
(0.042)^{* * *}\end{array}$ & $\begin{array}{c}0.60 \\
(0.041)^{* * *}\end{array}$ & $\begin{array}{c}0.58 \\
(0.043)^{* * *}\end{array}$ & $\begin{array}{c}0.60 \\
(0.042)^{* * *}\end{array}$ & $\begin{array}{c}0.60 \\
(0.041)^{* * *}\end{array}$ & ${ }_{(0.041)^{* * *}}^{0.61}$ & $\begin{array}{c}0.61 \\
(0.040)^{* * *}\end{array}$ & $\begin{array}{c}0.61 \\
(0.040)^{* * *}\end{array}$ & $\begin{array}{c}0.59 \\
(0.043)^{* * *}\end{array}$ \\
\hline$\alpha_{R R}$ & $\begin{array}{c}0.23 \\
(0.083)^{* * *}\end{array}$ & $\begin{array}{c}0.19 \\
(0.088)^{* *}\end{array}$ & $\begin{array}{c}0.17 \\
(0.094)^{*}\end{array}$ & $\begin{array}{c}0.21 \\
(0.084)^{* * *}\end{array}$ & $\begin{array}{c}0.37 \\
(0.041)^{* * *}\end{array}$ & $\begin{array}{c}0.37 \\
(0.041)^{* * *}\end{array}$ & $\begin{array}{c}0.37 \\
(0.041)^{* * *}\end{array}$ & $\begin{array}{c}0.37 \\
(0.042)^{* * *}\end{array}$ & $\begin{array}{c}0.37 \\
(0.042)^{* * *}\end{array}$ & $\begin{array}{c}0.37 \\
(0.042)^{* * *}\end{array}$ \\
\hline$\alpha_{R R}^{e p u}$ & $\begin{array}{c}0.06 \\
(0.038)^{*}\end{array}$ & $\begin{array}{c}0.08 \\
(0.040)^{* *}\end{array}$ & $\begin{array}{c}0.09 \\
(0.042)^{* *}\end{array}$ & $\begin{array}{c}0.07 \\
(0.038)^{*}\end{array}$ & & & & & & \\
\hline$\zeta_{R}$ & & $\begin{array}{l}0.06 \\
(0.028)^{* *} \\
M O V E\end{array}$ & $\begin{array}{c}0.08 \\
(0.041)^{*} \\
B A A\end{array}$ & $\begin{array}{c}0.06 \\
(0.018)^{* * *} \\
B A A_{-} A A A\end{array}$ & $\begin{array}{l}0.04 \\
(0.024)^{\circ} \\
M O V E\end{array}$ & $\begin{array}{l}0.08 \\
(0.032)^{* * *} \\
M O V E\end{array}$ & $\begin{array}{l}0.06 \\
(0.027)^{* *} \\
M O V E\end{array}$ & & & \\
\hline$\zeta_{R}^{e p u}$ & & & & & $\begin{array}{l}0.02 \\
(0.006)^{* * *} \\
M O V E\end{array}$ & & & $\begin{array}{c}0.03 \\
(0.017)^{*} \\
A A A\end{array}$ & $\begin{array}{l}0.04 \\
(0.017)^{* * *} \\
B A A\end{array}$ & $\begin{array}{c}0.02 \\
(0.007)^{* * *} \\
B A A_{-} A A A\end{array}$ \\
\hline \multicolumn{11}{|l|}{$\vartheta_{R}$} \\
\hline$\vartheta_{R}^{e p u}$ & & & & & & $\begin{array}{c}0.01 \\
(0.005)^{* * *} \\
W T I\end{array}$ & $\begin{array}{c}0.01 \\
(0.004)^{* *} \\
G S C I\end{array}$ & & & \\
\hline
\end{tabular}

Notes: See notes in Table 2. Superscripts indicate the EPU effect on the respective parameter. o denotes marginal significance at the 0.15 level $\left(\zeta_{R}\right.$ in specification $\left.(5)\right)$. 
Table 8: The m-DAP-HEAVY- $R$ equation for FTSE with the EPU effect on Heavy, Arch, Bonds and

Commodities parameters.

\begin{tabular}{|c|c|c|c|c|c|c|c|c|c|c|}
\hline & (1) & (2) & (3) & (4) & $(5)$ & (6) & (7) & (8) & (9) & (10) \\
\hline \multicolumn{11}{|c|}{$\begin{array}{l}\quad\left(1-\beta_{R} L\right)\left(\sigma_{R t}^{2}\right)^{\frac{\delta_{R}}{2}}=\omega_{R}+\left[\alpha_{R R}+\alpha_{R R}^{e p u} E P U_{t-1}+\right. \\
\left.\left.{ }_{R}^{u} E P U_{t-1}\right) s_{t-1}\right] L\left(R M_{t}\right)^{\frac{\delta_{R}}{2}}+\left(\gamma_{R r}+\gamma_{R r}^{e p u} E P U_{t-1}\right) s_{t-1} L\left(r_{t}^{2}\right)^{\frac{\delta_{r}}{2}}+ \\
\left.{ }_{R}+\zeta_{R}^{e p u} E P U_{t-1}\right) B O_{t-1}+\left(\vartheta_{R}+\vartheta_{R}^{e p u} E P U_{t-1}\right) C O_{t-1}\end{array}$} \\
\hline$\beta_{R}$ & $\begin{array}{c}0.76 \\
(0.023)^{* * *}\end{array}$ & $\begin{array}{c}0.77 \\
(0.021)^{* * *}\end{array}$ & $\begin{array}{c}0.77 \\
(0.020)^{* * *}\end{array}$ & $\begin{array}{c}0.77 \\
(0.020)^{* * *}\end{array}$ & $\begin{array}{c}0.77 \\
(0.022)^{* * *}\end{array}$ & $\begin{array}{c}0.77 \\
(0.021)^{* * *}\end{array}$ & $\begin{array}{c}0.77 \\
(0.021)^{* * *}\end{array}$ & $\begin{array}{c}0.77 \\
(0.021)^{* * *}\end{array}$ & $\begin{array}{c}0.77 \\
(0.021)^{* * *}\end{array}$ & $\begin{array}{c}0.76 \\
(0.021)^{* * *}\end{array}$ \\
\hline$\alpha_{R R}$ & $\begin{array}{c}0.05 \\
(0.022)^{* *}\end{array}$ & $\begin{array}{c}0.13 \\
(0.023)^{* * *}\end{array}$ & $\begin{array}{c}0.13 \\
(0.022)^{* * *}\end{array}$ & $\begin{array}{c}0.13 \\
(0.021)^{* * *}\end{array}$ & $\begin{array}{c}0.13 \\
(0.022)^{* * *}\end{array}$ & $\begin{array}{c}0.13 \\
(0.022)^{* * *}\end{array}$ & $\begin{array}{c}0.13 \\
(0.022)^{* * *}\end{array}$ & $\begin{array}{c}0.13 \\
(0.022)^{* * *}\end{array}$ & $\begin{array}{c}0.13 \\
(0.023)^{* * *}\end{array}$ & $\begin{array}{c}0.12 \\
(0.021)^{* * *}\end{array}$ \\
\hline$\alpha_{R R}^{e p u}$ & $\begin{array}{c}0.03 \\
(0.012)^{* * *}\end{array}$ & & & & & & & & & \\
\hline$\gamma_{R R}$ & $\begin{array}{c}0.04 \\
(0.014)^{* * *}\end{array}$ & & $\begin{array}{c}0.04 \\
(0.015)^{* * *}\end{array}$ & & $\begin{array}{c}0.04 \\
(0.014)^{* * *}\end{array}$ & $\begin{array}{c}0.04 \\
(0.015)^{* * *}\end{array}$ & $\begin{array}{c}0.04 \\
(0.014)^{* * *}\end{array}$ & $\begin{array}{c}0.04 \\
(0.014)^{* * *}\end{array}$ & $\begin{array}{c}0.04 \\
(0.015)^{* * *}\end{array}$ & $\begin{array}{c}0.04 \\
(0.014)^{* * *}\end{array}$ \\
\hline$\gamma_{R R}^{e p u}$ & & $\begin{array}{c}0.02 \\
(0.006)^{* * *}\end{array}$ & & $\begin{array}{c}0.02 \\
(0.005)^{* * *}\end{array}$ & & & & & & \\
\hline$\gamma_{R r}$ & $\begin{array}{c}0.09 \\
(0.008)^{* * *}\end{array}$ & $\begin{array}{c}0.08 \\
(0.008)^{* * *}\end{array}$ & & & $\begin{array}{c}0.09 \\
(0.008)^{* * *}\end{array}$ & $\begin{array}{c}0.09 \\
(0.008)^{* * *}\end{array}$ & $\begin{array}{c}0.09 \\
(0.008)^{* * *}\end{array}$ & $\begin{array}{c}0.08 \\
(0.008)^{* * *}\end{array}$ & $\begin{array}{c}0.09 \\
(0.008)^{* * *}\end{array}$ & $\begin{array}{c}0.09 \\
(0.008)^{* * *}\end{array}$ \\
\hline$\gamma_{R r}^{e p u}$ & & & $\begin{array}{c}0.04 \\
(0.003)^{* * *}\end{array}$ & $\begin{array}{c}0.04 \\
(0.003)^{* * *}\end{array}$ & & & & & & \\
\hline$\zeta_{R}$ & $\begin{array}{c}0.05 \\
(0.011)^{* * *} \\
M O V E\end{array}$ & $\begin{array}{c}0.04 \\
(0.011)^{* * *} \\
M O V E\end{array}$ & $\begin{array}{c}0.05 \\
(0.011)^{* * *} \\
M O V E\end{array}$ & $\begin{array}{c}0.05 \\
(0.011)^{* * *} \\
M O V E\end{array}$ & $\begin{array}{c}0.03 \\
(0.011)^{* * *} \\
M O V E\end{array}$ & $\begin{array}{c}0.05 \\
(0.011)^{* * *} \\
M O V E\end{array}$ & $\begin{array}{c}0.05 \\
(0.010)^{* * *} \\
M O V E\end{array}$ & $\begin{array}{c}0.04 \\
(0.015)^{* * *} \\
A A A\end{array}$ & $\begin{array}{c}0.07 \\
(0.019)^{* * *} \\
B A A\end{array}$ & $\begin{array}{c}0.03 \\
(0.006)^{* * *} \\
B A A_{-} A A A\end{array}$ \\
\hline$\zeta_{R}^{e p u}$ & & & & & $\begin{array}{c}0.01 \\
(0.003)^{* * *} \\
M O V E\end{array}$ & & & & & \\
\hline$\vartheta_{R}$ & $\begin{array}{c}0.01 \\
(0.006)^{*} \\
W T I\end{array}$ & $\begin{array}{c}0.01 \\
(0.006)^{* * *} \\
W T I\end{array}$ & $\begin{array}{c}0.01 \\
(0.006)^{* *} \\
W T I\end{array}$ & $\begin{array}{c}0.01 \\
(0.006)^{* *} \\
W T I\end{array}$ & $\begin{array}{c}0.01 \\
(0.006)^{* *} \\
W T I\end{array}$ & & & & & \\
\hline$\vartheta_{R}^{e p u}$ & & & & & & $\begin{array}{c}0.01 \\
(0.002)^{* * *} \\
W T I\end{array}$ & $\begin{array}{c}0.01 \\
(0.001)^{* * *} \\
G S C I\end{array}$ & $\begin{array}{c}0.01 \\
(0.002)^{* * *} \\
W T I \\
\end{array}$ & $\begin{array}{c}0.01 \\
(0.002)^{* * *} \\
W T I \\
\end{array}$ & $\begin{array}{c}0.004 \\
(0.001)^{* * *} \\
G S C I\end{array}$ \\
\hline$\delta_{r}$ & & & & & & & & & & \\
\hline$\delta_{R}$ & & & & & & & & & & \\
\hline
\end{tabular}

Notes: See notes in Table 2. Superscripts indicate the EPU effect on the respective parameter. 
Table 9: The EPU effect on Heavy, Bonds and Commodities parameters in the m-DAP-HEAVY- $R$ equation.

\begin{tabular}{|c|c|c|c|c|c|c|c|c|c|}
\hline & $\alpha_{R R}^{e p u}$ & $\gamma_{R R}^{e p u}$ & $\gamma_{R r}^{e p u}$ & $\begin{array}{c}\zeta_{R}^{e p u} \\
M O V E\end{array}$ & $\begin{array}{l}\zeta_{R}^{e p u} \\
A A A\end{array}$ & $\begin{array}{l}\zeta_{R}^{e p u} \\
B A A\end{array}$ & $\begin{array}{c}\zeta_{R}^{e p u} \\
B A A_{-} A A A\end{array}$ & $\begin{array}{c}\vartheta_{R}^{e p u} \\
G S C I \\
\end{array}$ & $\begin{array}{l}\vartheta_{R}^{e p u} \\
W T I\end{array}$ \\
\hline $\mathrm{EU}$ & $\begin{array}{c}0.03 \\
(0.011)^{* * *}\end{array}$ & $\begin{array}{c}0.02 \\
(0.005)^{* * *}\end{array}$ & $\begin{array}{c}0.03 \\
(0.003)^{* * *}\end{array}$ & $\begin{array}{c}0.01 \\
(0.003)^{* * *}\end{array}$ & $\begin{array}{c}0.02 \\
(0.008)^{* * *}\end{array}$ & $\begin{array}{c}0.03 \\
(0.008)^{* * *}\end{array}$ & $\begin{array}{c}0.02 \\
(0.003)^{* * *}\end{array}$ & $\begin{array}{c}0.01 \\
(0.002)^{* * *}\end{array}$ & \\
\hline DAX & $\begin{array}{c}0.02 \\
(0.009)^{* *}\end{array}$ & $\begin{array}{c}0.02 \\
(0.004)^{* * *}\end{array}$ & $\begin{array}{c}0.03 \\
(0.003)^{* * *}\end{array}$ & $\begin{array}{c}0.01 \\
(0.003)^{* * *}\end{array}$ & $\begin{array}{c}0.02 \\
(0.007)^{* * *}\end{array}$ & $\begin{array}{c}0.03 \\
(0.008)^{* * *}\end{array}$ & $\begin{array}{c}0.01 \\
(0.003)^{* * *}\end{array}$ & $\begin{array}{c}0.003 \\
(0.002)^{* *}\end{array}$ & \\
\hline $\mathrm{CAC}$ & $\begin{array}{c}0.04 \\
(0.008)^{* * *}\end{array}$ & $\begin{array}{c}0.01 \\
(0.003)^{* * *}\end{array}$ & $\begin{array}{c}0.02 \\
(0.002)^{* * *}\end{array}$ & $\begin{array}{c}0.01 \\
(0.003)^{* * *}\end{array}$ & $\begin{array}{c}0.03 \\
(0.006)^{* * *}\end{array}$ & $\begin{array}{c}0.04 \\
(0.007)^{* * *}\end{array}$ & $\begin{array}{c}0.02 \\
(0.002)^{* * *}\end{array}$ & $\begin{array}{c}0.01 \\
(0.001)^{* * *}\end{array}$ & $\begin{array}{c}0.01 \\
(0.002)^{* * *}\end{array}$ \\
\hline AEX & $\begin{array}{c}0.03 \\
(0.008)^{* * *}\end{array}$ & $\begin{array}{c}0.01 \\
(0.004)^{* *}\end{array}$ & $\begin{array}{c}0.03 \\
(0.002)^{* * *}\end{array}$ & $\begin{array}{c}0.01 \\
(0.002)^{* * *}\end{array}$ & $\begin{array}{c}0.02 \\
(0.006)^{* * *}\end{array}$ & $\begin{array}{c}0.03 \\
(0.006)^{* * *}\end{array}$ & $\begin{array}{c}0.01 \\
(0.002)^{* * *}\end{array}$ & $\begin{array}{c}0.004 \\
(0.001)^{* * *}\end{array}$ & $\begin{array}{c}0.01 \\
(0.002)^{* * *}\end{array}$ \\
\hline BELL & $\begin{array}{c}0.03 \\
(0.009)^{* * *}\end{array}$ & $\begin{array}{c}0.01 \\
(0.004)^{* *}\end{array}$ & $\begin{array}{c}0.02 \\
(0.002)^{* * *}\end{array}$ & $\begin{array}{c}0.01 \\
(0.002)^{* * *}\end{array}$ & $\begin{array}{c}0.01 \\
(0.005)^{* * *}\end{array}$ & $\begin{array}{c}0.02 \\
(0.004)^{* * *}\end{array}$ & $\begin{array}{c}0.01 \\
(0.002)^{* * *}\end{array}$ & $\begin{array}{c}0.004 \\
(0.001)^{* * *}\end{array}$ & $\begin{array}{c}0.01 \\
(0.002)^{* * *}\end{array}$ \\
\hline IBEX & $\begin{array}{c}0.04 \\
(0.011)^{* * *}\end{array}$ & $\begin{array}{c}0.01 \\
(0.004)^{* *}\end{array}$ & $\begin{array}{c}0.02 \\
(0.002)^{* * *}\end{array}$ & $\begin{array}{c}0.02 \\
(0.004)^{* * *}\end{array}$ & $\begin{array}{c}0.01 \\
(0.007)^{* *}\end{array}$ & $\begin{array}{c}0.03 \\
(0.008)^{* * *}\end{array}$ & $\begin{array}{c}0.01 \\
(0.003)^{* * *}\end{array}$ & $\begin{array}{c}0.01 \\
(0.002)^{* * *}\end{array}$ & $\begin{array}{c}0.01 \\
(0.003)^{* * *}\end{array}$ \\
\hline SSMI & $\begin{array}{c}0.03 \\
(0.009)^{* * *}\end{array}$ & $\begin{array}{c}0.01 \\
(0.003)^{* * *}\end{array}$ & $\begin{array}{c}0.02 \\
(0.002)^{* * *}\end{array}$ & $\begin{array}{c}0.01 \\
(0.002)^{* * *}\end{array}$ & $\begin{array}{c}0.02 \\
(0.006)^{* * *}\end{array}$ & $\begin{array}{c}0.02 \\
(0.006)^{* * *}\end{array}$ & $\begin{array}{c}0.01 \\
(0.002)^{* * *}\end{array}$ & $\begin{array}{c}0.003 \\
(0.001)^{* *}\end{array}$ & $\begin{array}{c}0.003 \\
(0.002)^{* *}\end{array}$ \\
\hline OMXC & $\begin{array}{c}0.02 \\
(0.012)^{\circ}\end{array}$ & & $\begin{array}{c}0.02 \\
(0.003)^{* * *}\end{array}$ & $\begin{array}{c}0.01 \\
(0.003)^{* *}\end{array}$ & $\begin{array}{c}0.02 \\
(0.008)^{* *}\end{array}$ & $\begin{array}{c}0.03 \\
(0.009)^{* * *}\end{array}$ & $\begin{array}{c}0.01 \\
(0.004)^{* * *}\end{array}$ & & \\
\hline OMXS & $\begin{array}{c}0.03 \\
(0.012)^{* * *}\end{array}$ & $\begin{array}{c}0.01 \\
(0.004)^{* * *}\end{array}$ & $\begin{array}{c}0.02 \\
(0.002)^{* * *}\end{array}$ & $\begin{array}{c}0.01 \\
(0.002)^{* * *}\end{array}$ & $\begin{array}{c}0.03 \\
(0.009)^{* * *}\end{array}$ & $\begin{array}{c}0.03 \\
(0.009)^{* * *}\end{array}$ & $\begin{array}{c}0.01 \\
(0.003)^{* * *}\end{array}$ & $\begin{array}{c}0.003 \\
(0.002)^{*}\end{array}$ & \\
\hline OSE & & $\begin{array}{c}0.01 \\
(0.003)^{* * *} \\
\end{array}$ & $\begin{array}{c}0.02 \\
(0.002)^{* * *} \\
\end{array}$ & $\begin{array}{c}0.004 \\
(0.002)^{\circ} \\
\end{array}$ & $\begin{array}{c}0.02 \\
(0.006)^{* * *}\end{array}$ & $\begin{array}{c}0.02 \\
(0.006)^{* * *} \\
\end{array}$ & $\begin{array}{c}0.01 \\
(0.002)^{* * *} \\
\end{array}$ & & \\
\hline
\end{tabular}

Notes: See notes in Table 2. Superscripts indicate the EPU effect on the respective parameter.

o denotes marginal significance at the 0.15 level $\left(\alpha_{R R}^{e p u}\right.$ for OMXC, $\zeta_{M O V E}^{e p u}$ for OSE). 
Table A.1: The DAP-HEAVY- $R$ equation. (without macro-factors)

\begin{tabular}{|c|c|c|c|c|c|c|}
\hline \multicolumn{7}{|c|}{$\begin{array}{c}\left(1-\beta_{R} L\right)\left(\sigma_{R t}^{2}\right)^{\frac{\delta_{R}}{2}}=\omega_{R}+ \\
+\left(\alpha_{R R}+\gamma_{R R} s_{t-1}\right) L\left(R M_{t}\right)^{\frac{\delta_{R}}{2}}+\gamma_{R r} s_{t-1} L\left(r_{t}^{2}\right)^{\frac{\delta_{r}}{2}}\end{array}$} \\
\hline & $\beta_{R}$ & $\alpha_{R R}$ & $\gamma_{R R}$ & $\gamma_{R r}$ & $\delta_{r}$ & $\delta_{R}$ \\
\hline FTSE & $\begin{array}{c}0.77 \\
(0.020)^{* * *}\end{array}$ & $\begin{array}{c}0.14 \\
(0.022)^{* * *}\end{array}$ & $\begin{array}{c}0.04 \\
(0.014)^{* * *}\end{array}$ & $\begin{array}{c}0.08 \\
(0.008)^{* * *}\end{array}$ & 1.50 & 1.30 \\
\hline $\mathrm{EU}$ & $\begin{array}{c}0.73 \\
(0.023)^{* * *}\end{array}$ & $\begin{array}{c}0.18 \\
(0.023)^{* * *}\end{array}$ & $\begin{array}{c}0.04 \\
(0.012)^{* * *}\end{array}$ & $\begin{array}{c}0.08 \\
(0.007)^{* * *}\end{array}$ & 1.50 & 1.30 \\
\hline DAX & $\begin{array}{c}0.72 \\
(0.022)^{* * *}\end{array}$ & $\begin{array}{c}0.21 \\
(0.021)^{* * *}\end{array}$ & $\begin{array}{c}0.03 \\
(0.010)^{* * *}\end{array}$ & $\begin{array}{c}0.07 \\
(0.007)^{* * *}\end{array}$ & 1.40 & 1.40 \\
\hline CAC & $\begin{array}{c}0.70 \\
(0.022)^{* * *}\end{array}$ & $\begin{array}{c}0.22 \\
(0.020)^{* * *}\end{array}$ & $\begin{array}{c}0.03 \\
(0.008)^{* * *}\end{array}$ & $\begin{array}{c}0.05 \\
(0.005)^{* * *}\end{array}$ & 1.40 & 1.10 \\
\hline AEX & $\begin{array}{c}0.69 \\
(0.023)^{* * *}\end{array}$ & $\begin{array}{c}0.23 \\
(0.022)^{* * *}\end{array}$ & $\begin{array}{c}0.03 \\
(0.010)^{* * *}\end{array}$ & $\begin{array}{c}0.06 \\
(0.006)^{* * *}\end{array}$ & 1.40 & 1.20 \\
\hline BELL & $\begin{array}{c}0.66 \\
(0.023)^{* * *}\end{array}$ & $\begin{array}{c}0.26 \\
(0.023)^{* * *}\end{array}$ & $\begin{array}{c}0.02 \\
(0.009)^{* *}\end{array}$ & $\begin{array}{c}0.05 \\
(0.006)^{* * *}\end{array}$ & 1.40 & 1.20 \\
\hline IBEX & $\begin{array}{c}0.67 \\
(0.026)^{* * *}\end{array}$ & $\begin{array}{c}0.27 \\
(0.026)^{* * *}\end{array}$ & $\begin{array}{c}0.02 \\
(0.011)^{* *}\end{array}$ & $\begin{array}{c}0.04 \\
(0.004)^{* * *}\end{array}$ & 1.70 & 1.20 \\
\hline SSMI & $\begin{array}{c}0.65 \\
(0.031)^{* * *}\end{array}$ & $\begin{array}{c}0.27 \\
(0.030)^{* * *}\end{array}$ & $\begin{array}{c}0.03 \\
(0.008)^{* * *}\end{array}$ & $\begin{array}{c}0.05 \\
(0.005)^{* * *}\end{array}$ & 1.50 & 1.20 \\
\hline OMXC & $\begin{array}{c}0.73 \\
(0.045)^{* * *}\end{array}$ & $\begin{array}{c}0.20 \\
(0.033)^{* * *}\end{array}$ & & $\begin{array}{c}0.04 \\
(0.006)^{* * *}\end{array}$ & 1.60 & 1.00 \\
\hline OMXS & $\begin{array}{c}0.69 \\
(0.037)^{* * *}\end{array}$ & $\begin{array}{c}0.22 \\
(0.033)^{* * *}\end{array}$ & $\begin{array}{c}0.03 \\
(0.010)^{* * *}\end{array}$ & $\begin{array}{c}0.04 \\
(0.005)^{* * *}\end{array}$ & 1.60 & 1.00 \\
\hline OSE & $\begin{array}{c}0.74 \\
(0.021)^{* * *}\end{array}$ & $\begin{array}{c}0.17 \\
(0.016)^{* * *}\end{array}$ & $\begin{array}{c}0.03 \\
(0.008)^{* * *}\end{array}$ & $\begin{array}{c}0.04 \\
(0.004)^{* * *}\end{array}$ & 1.60 & 1.00 \\
\hline
\end{tabular}

Notes: See Notes in Table 2. 
Table A.2: The m-DAP-HEAVY- $R$ equation for FTSE with EPU, Bonds \& Commodities.

(stepwise procedure)

\begin{tabular}{|c|c|c|c|c|c|c|c|c|c|}
\hline & (1) & $(2)$ & $(3)$ & (4) & (5) & (6) & (7) & (8) & $(9)$ \\
\hline \multicolumn{10}{|c|}{$\begin{array}{l}\left(1-\beta_{R} L\right)\left(\sigma_{R t}^{2}\right)^{\frac{\delta_{R}}{2}}=\omega_{R}+\left(\alpha_{R R}+\gamma_{R R} s_{t-1}\right) L\left(R M_{t}\right)^{\frac{\delta_{R}}{2}} \\
+\gamma_{R r} s_{t-1} L\left(r_{t}^{2}\right)^{\frac{\delta_{r}}{2}}+\phi_{R} E P U_{t-1}+\zeta_{R} B O_{t-1}+\vartheta_{R} C O_{t-1}\end{array}$} \\
\hline$\beta_{R}$ & $\begin{array}{c}0.77 \\
(0.020)^{* * *}\end{array}$ & $\begin{array}{c}0.76 \\
(0.021)^{* * *}\end{array}$ & $\begin{array}{c}0.77 \\
(0.021)^{* * *}\end{array}$ & $\begin{array}{c}0.77 \\
(0.021)^{* * *}\end{array}$ & $\begin{array}{c}0.77 \\
(0.021)^{* * *}\end{array}$ & $\begin{array}{c}0.76 \\
(0.021)^{* * *}\end{array}$ & $\begin{array}{c}0.77 \\
(0.022)^{* * *}\end{array}$ & $\begin{array}{c}0.77 \\
(0.021)^{* * *}\end{array}$ & $\begin{array}{c}0.76 \\
(0.021)^{* * *}\end{array}$ \\
\hline$\alpha_{R R}$ & $\begin{array}{c}0.14 \\
(0.021)^{* * *}\end{array}$ & $\begin{array}{c}0.13 \\
(0.021)^{* * *}\end{array}$ & $\begin{array}{c}0.13 \\
(0.021)^{* * *}\end{array}$ & $\begin{array}{c}0.13 \\
(0.022)^{* * *}\end{array}$ & $\begin{array}{c}0.13 \\
(0.022)^{* * *}\end{array}$ & $\begin{array}{c}0.12 \\
(0.021)^{* * *}\end{array}$ & $\begin{array}{c}0.13 \\
(0.022)^{* * *}\end{array}$ & $\begin{array}{c}0.13 \\
(0.022)^{* * *}\end{array}$ & $\begin{array}{c}0.12 \\
(0.022)^{* * *}\end{array}$ \\
\hline$\gamma_{R R}$ & $\begin{array}{c}0.04 \\
(0.014)^{* * *}\end{array}$ & $\begin{array}{c}0.04 \\
(0.014)^{* * *}\end{array}$ & $\begin{array}{c}0.04 \\
(0.014)^{* * *}\end{array}$ & $\begin{array}{c}0.04 \\
(0.014)^{* * *}\end{array}$ & $\begin{array}{c}0.04 \\
(0.014)^{* * *}\end{array}$ & $\begin{array}{c}0.04 \\
(0.014)^{* * *}\end{array}$ & $\begin{array}{c}0.04 \\
(0.014)^{* * *}\end{array}$ & $\begin{array}{c}0.04 \\
(0.014)^{* * *}\end{array}$ & $\begin{array}{c}0.04 \\
(0.014)^{* * *}\end{array}$ \\
\hline$\gamma_{R r}$ & $\begin{array}{c}0.08 \\
(0.008)^{* * *}\end{array}$ & $\begin{array}{c}0.09 \\
(0.008)^{* * *}\end{array}$ & $\begin{array}{c}0.08 \\
(0.008)^{* * *}\end{array}$ & $\begin{array}{c}0.08 \\
(0.008)^{* * *}\end{array}$ & $\begin{array}{c}0.09 \\
(0.008)^{* * *}\end{array}$ & $\begin{array}{c}0.09 \\
(0.008)^{* * *}\end{array}$ & $\begin{array}{c}0.09 \\
(0.008)^{* * *}\end{array}$ & $\begin{array}{c}0.09 \\
(0.008)^{* * *}\end{array}$ & $\begin{array}{c}0.09 \\
(0.008)^{* * *}\end{array}$ \\
\hline$\phi_{R}$ & $\begin{array}{c}0.01 \\
(0.004)^{* * *}\end{array}$ & $\begin{array}{c}0.02 \\
(0.005)^{* * *}\end{array}$ & $\begin{array}{c}0.01 \\
(0.005)^{* * *}\end{array}$ & $\begin{array}{c}0.02 \\
(0.005)^{* * *}\end{array}$ & $\begin{array}{c}0.03 \\
(0.005)^{* * *}\end{array}$ & $\begin{array}{c}0.01 \\
(0.004)^{* *}\end{array}$ & $\begin{array}{c}0.02 \\
(0.005)^{* * *}\end{array}$ & $\begin{array}{c}0.02 \\
(0.005)^{* * *}\end{array}$ & $\begin{array}{c}0.01 \\
(0.005)^{* * *}\end{array}$ \\
\hline$\zeta_{R}$ & & $\begin{array}{c}0.05 \\
(0.011)^{* * *} \\
\text { MOVE }\end{array}$ & & $\begin{array}{c}0.04 \\
(0.014)^{* * *} \\
A A A\end{array}$ & $\begin{array}{c}0.07 \\
(0.018)^{* * *} \\
B A A\end{array}$ & $\begin{array}{c}0.03 \\
(0.006)^{* * *} \\
B A A_{-} A A A\end{array}$ & $\begin{array}{c}0.06 \\
(0.011)^{* * *} \\
M O V E\end{array}$ & $\begin{array}{c}0.08 \\
(0.019)^{* * *} \\
B A A\end{array}$ & $\begin{array}{c}0.03 \\
(0.006)^{* * *} \\
B A A_{-} A A A\end{array}$ \\
\hline$\vartheta_{R}$ & & & $\begin{array}{c}0.01 \\
(0.007)^{*} \\
G S C I \\
\end{array}$ & & & & $\begin{array}{c}0.01 \\
(0.006)^{* *} \\
W T I \\
\end{array}$ & $\begin{array}{c}0.01 \\
(0.006)^{*} \\
W T I \\
\end{array}$ & $\begin{array}{c}0.01 \\
(0.007)^{\circ} \\
G S C I \\
\end{array}$ \\
\hline$\delta_{r}$ & & & & & 1.50 & & & & \\
\hline$\delta_{R}$ & & & & & 1.30 & & & & \\
\hline $\mathrm{AIC}$ & 2.59901 & 2.59895 & 2.59936 & 2.59926 & 2.59903 & 2.59859 & 2.59829 & 2.59940 & 2.59898 \\
\hline
\end{tabular}

Notes: See notes in Table 2. o denotes marginal significance at the 0.15 level $\left(\vartheta_{R}\right.$ in specification $\left.(9)\right)$. 
Table A.3: The EPU effect on Heavy, Bonds and Commodities parameters in the Benchmark HEAVY- $R$ equation.

\begin{tabular}{|c|c|c|c|c|c|c|c|}
\hline \multicolumn{8}{|c|}{$\begin{array}{c}\left(1-\beta_{R} L\right) \sigma_{R t}^{2}=\omega_{R}+\left(\alpha_{R R}+\alpha_{R R}^{e p u} E P U_{t-1}\right) L\left(R M_{t}\right)+ \\
\left(\zeta_{R}+\zeta_{R}^{e p u} E P U_{t-1}\right) B O_{t-1}+\left(\vartheta_{R}+\vartheta_{R}^{e p u} E P U_{t-1}\right) C O_{t-1}\end{array}$} \\
\hline & $\alpha_{R R}^{e p u}$ & $\begin{array}{c}\zeta_{R}^{e p u} \\
M O V E\end{array}$ & $\begin{array}{l}\zeta_{R}^{e p u} \\
A A A\end{array}$ & $\begin{array}{l}\zeta_{R}^{e p u} \\
B A A\end{array}$ & $\begin{array}{c}\zeta_{R}^{e p u} \\
B A A_{-} A A A\end{array}$ & $\begin{array}{c}\vartheta_{R}^{e p u} \\
G S C I \\
\end{array}$ & $\begin{array}{l}\vartheta_{R}^{e p u} \\
W T I\end{array}$ \\
\hline $\mathrm{EU}$ & $\begin{array}{c}0.08 \\
(0.033)^{* *}\end{array}$ & $\begin{array}{c}0.02 \\
(0.007)^{* *}\end{array}$ & & $\begin{array}{c}0.05 \\
(0.019)^{* * *}\end{array}$ & $\begin{array}{c}0.04 \\
(0.009)^{* * *}\end{array}$ & $\begin{array}{c}0.004 \\
(0.002)^{* *}\end{array}$ & \\
\hline DAX & & $\begin{array}{c}0.01 \\
(0.005)^{*}\end{array}$ & $\begin{array}{c}0.02 \\
(0.016)^{\circ}\end{array}$ & $\begin{array}{c}0.03 \\
(0.014)^{* *}\end{array}$ & $\begin{array}{c}0.02 \\
(0.007)^{* * *}\end{array}$ & $\begin{array}{c}0.03 \\
(0.016)^{*}\end{array}$ & \\
\hline CAC & $\begin{array}{c}0.09 \\
(0.028)^{* * *}\end{array}$ & $\begin{array}{c}0.02 \\
(0.006)^{* * *}\end{array}$ & $\begin{array}{c}0.04 \\
(0.016)^{* * *}\end{array}$ & $\begin{array}{c}0.06 \\
(0.016)^{* * *}\end{array}$ & $\begin{array}{c}0.04 \\
(0.008)^{* * *}\end{array}$ & $\begin{array}{c}0.01 \\
(0.003)^{* * *}\end{array}$ & $\begin{array}{c}0.02 \\
(0.005)^{* * *}\end{array}$ \\
\hline AEX & $\begin{array}{c}0.09 \\
(0.024)^{* * *}\end{array}$ & $\begin{array}{c}0.02 \\
(0.004)^{* * *}\end{array}$ & $\begin{array}{c}0.04 \\
(0.012)^{* * *}\end{array}$ & $\begin{array}{c}0.04 \\
(0.011)^{* * *}\end{array}$ & $\begin{array}{c}0.02 \\
(0.006)^{* * *}\end{array}$ & $\begin{array}{c}0.01 \\
(0.002)^{* * *}\end{array}$ & $\begin{array}{c}0.01 \\
(0.004)^{* *}\end{array}$ \\
\hline BELL & $\begin{array}{c}0.07 \\
(0.025)^{* * *}\end{array}$ & $\begin{array}{c}0.01 \\
(0.003)^{* * *}\end{array}$ & $\begin{array}{c}0.02 \\
(0.008)^{* *}\end{array}$ & $\begin{array}{c}0.03 \\
(0.008)^{* * *}\end{array}$ & $\begin{array}{c}0.02 \\
(0.004)^{* * *}\end{array}$ & $\begin{array}{c}0.01 \\
(0.002)^{* * *}\end{array}$ & $\begin{array}{c}0.01 \\
(0.003)^{* * *}\end{array}$ \\
\hline IBEX & $\begin{array}{c}0.09 \\
(0.037)^{* * *}\end{array}$ & $\begin{array}{c}0.03 \\
(0.010)^{* * *}\end{array}$ & $\begin{array}{c}0.03 \\
(0.020)^{*}\end{array}$ & $\begin{array}{c}0.05 \\
(0.022)^{* *}\end{array}$ & $\begin{array}{c}0.03 \\
(0.011)^{* * *}\end{array}$ & $\begin{array}{c}0.01 \\
(0.005)^{* * *}\end{array}$ & $\begin{array}{c}0.03 \\
(0.009)^{* * *}\end{array}$ \\
\hline SSMI & & $\begin{array}{c}0.01 \\
(0.007)^{*}\end{array}$ & $\begin{array}{c}0.02 \\
(0.014)^{\circ}\end{array}$ & $\begin{array}{c}0.02 \\
(0.013)^{*}\end{array}$ & $\begin{array}{c}0.01 \\
(0.003)^{* * *}\end{array}$ & & \\
\hline \multicolumn{8}{|l|}{ OMXC } \\
\hline OMXS & $\begin{array}{c}0.10 \\
(0.066)^{\circ}\end{array}$ & & $\begin{array}{c}0.05 \\
(0.020)^{* *}\end{array}$ & $\begin{array}{c}0.04 \\
(0.018)^{* *}\end{array}$ & & & \\
\hline OSE & & & & & $\begin{array}{c}0.01 \\
(0.006)^{*}\end{array}$ & & \\
\hline
\end{tabular}

Notes: See notes in Table 2. Superscripts indicate the EPU effect on the respective parameter. $\circ$ denotes marginal significance at the 0.15 level ( $\zeta_{R}^{e p u}$ for DAX and SSMI, $\alpha_{R R}^{e p u}$ for OMXS). $A A A$ 
Table A.4: The m-OAP-HEAVY- $r$ equation.

\begin{tabular}{|c|c|c|c|c|c|c|}
\hline \multicolumn{7}{|c|}{$\left(1-\beta_{r} L\right)\left(\sigma_{r t}^{2}\right)^{\frac{\delta_{r}}{2}}=\omega_{r}+\gamma_{r r} s_{t-1} L\left(r_{t}^{2}\right)^{\frac{\delta_{r}}{2}}+\alpha_{r R} L\left(R M_{t}\right)^{\frac{\delta_{R}}{2}}$} \\
\hline & $\beta_{r}$ & $\gamma_{r r}$ & $\alpha_{r R}$ & $\delta_{r}$ & $\delta_{R}$ & $\ln L$ \\
\hline FTSE & $\begin{array}{c}0.81 \\
(0.025)^{* * *}\end{array}$ & $\begin{array}{l}0.15 \\
(0.015)^{* * *}\end{array}$ & $\begin{array}{c}0.10 \\
(0.023)^{* * *}\end{array}$ & 1.50 & 1.30 & -5747.63 \\
\hline $\mathrm{EU}$ & $\begin{array}{c}0.82 \\
(0.029)^{* * *}\end{array}$ & $\begin{array}{c}0.13 \\
(0.016)^{* * *}\end{array}$ & $\begin{array}{c}0.13 \\
(0.036)^{* * *}\end{array}$ & 1.50 & 1.30 & -6623.97 \\
\hline DAX & $\begin{array}{c}0.78 \\
(0.035)^{* * *}\end{array}$ & $\begin{array}{c}0.11 \\
(0.016)^{* * *}\end{array}$ & $\begin{array}{c}0.15 \\
(0.037)^{* * *}\end{array}$ & 1.40 & 1.40 & -6578.93 \\
\hline CAC & $\begin{array}{c}0.67 \\
(0.089)^{* * *}\end{array}$ & $\begin{array}{c}0.13 \\
(0.024)^{* * *}\end{array}$ & $\begin{array}{c}0.36 \\
(0.132)^{* * *}\end{array}$ & 1.40 & 1.10 & -6521.71 \\
\hline AEX & $\begin{array}{c}0.75 \\
(0.054)^{* * *}\end{array}$ & $\begin{array}{c}0.13 \\
(0.016)^{* * *}\end{array}$ & $\begin{array}{c}0.24 \\
(0.075)^{* * *}\end{array}$ & 1.40 & 1.20 & -6287.84 \\
\hline BELL & $\begin{array}{c}0.73 \\
(0.040)^{* * *}\end{array}$ & $\begin{array}{c}0.12 \\
(0.013)^{* * *}\end{array}$ & $\begin{array}{c}0.20 \\
(0.045)^{* * *}\end{array}$ & 1.40 & 1.20 & -6004.52 \\
\hline IBEX & $\begin{array}{c}0.75 \\
(0.075)^{* * *}\end{array}$ & $\begin{array}{c}0.14 \\
(0.019)^{* * *}\end{array}$ & $\begin{array}{c}0.27 \\
(0.125)^{* * *}\end{array}$ & 1.70 & 1.20 & -6961.27 \\
\hline SSMI & $\begin{array}{c}0.66 \\
(0.060)^{* * *}\end{array}$ & $\begin{array}{c}0.16 \\
(0.020)^{* * *}\end{array}$ & $\begin{array}{c}0.35 \\
(0.095)^{* * *}\end{array}$ & 1.50 & 1.20 & -5807.50 \\
\hline OMXC & $\begin{array}{c}0.73 \\
(0.044)^{* * *}\end{array}$ & $\begin{array}{c}0.13 \\
(0.023)^{* * *}\end{array}$ & $\begin{array}{c}0.29 \\
(0.071)^{* * *}\end{array}$ & 1.60 & 1.00 & -4761.04 \\
\hline OMXS & $\begin{array}{c}0.74 \\
(0.059)^{* * *}\end{array}$ & $\begin{array}{c}0.16 \\
(0.023)^{* * *}\end{array}$ & $\begin{array}{c}0.32 \\
(0.105)^{* * *}\end{array}$ & 1.60 & 1.00 & -4673.32 \\
\hline OSE & $\begin{array}{c}0.82 \\
(0.025)^{* * *} \\
\end{array}$ & $\begin{array}{c}0.13 \\
(0.017)^{* * *} \\
\end{array}$ & $\begin{array}{c}0.18 \\
(0.037)^{* * *} \\
\end{array}$ & 1.60 & 1.00 & -6277.02 \\
\hline
\end{tabular}

Notes: See Notes in Table 2. 


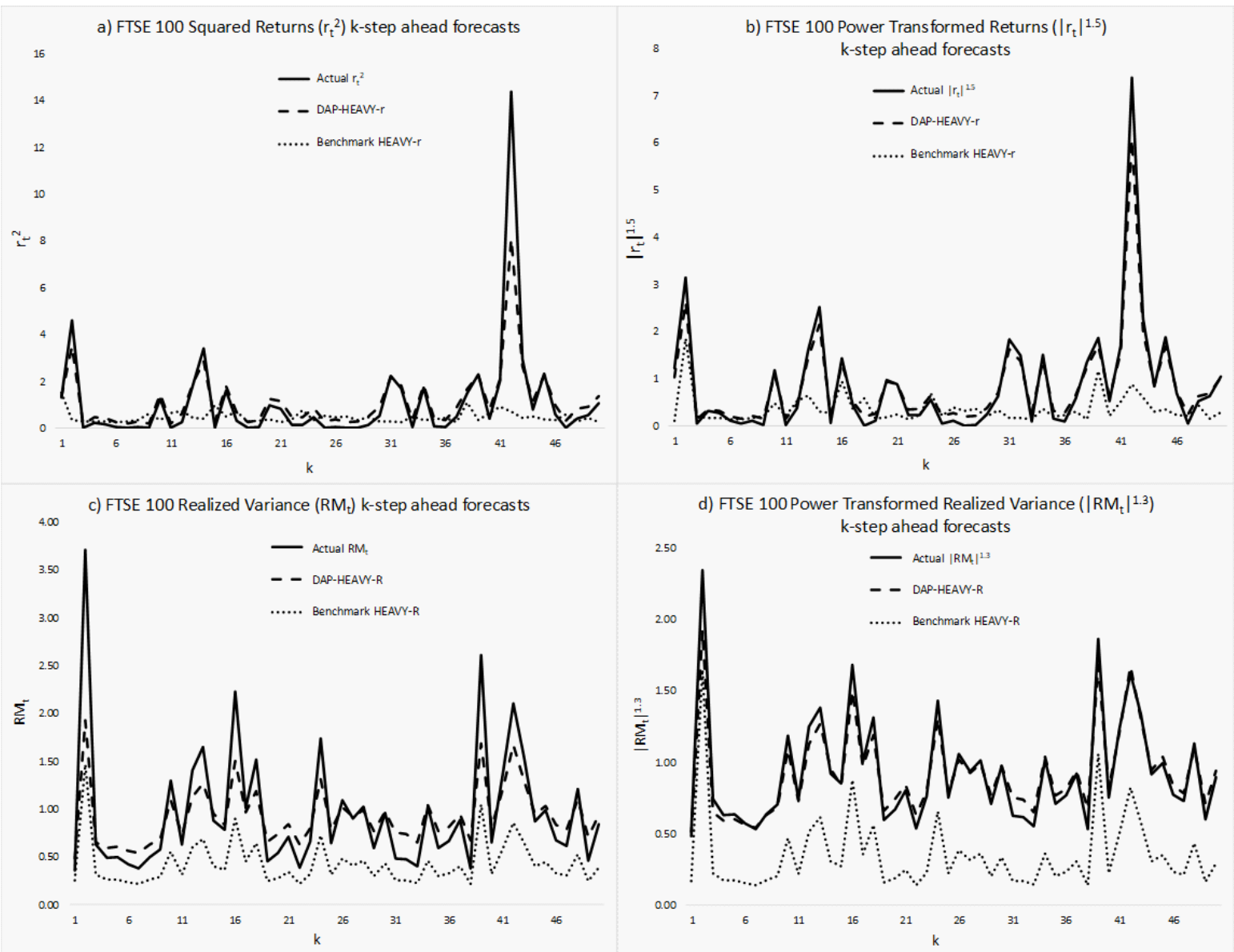

Figure 1. FTSE 100 Returns and Realized Variance k-step ahead forecasts

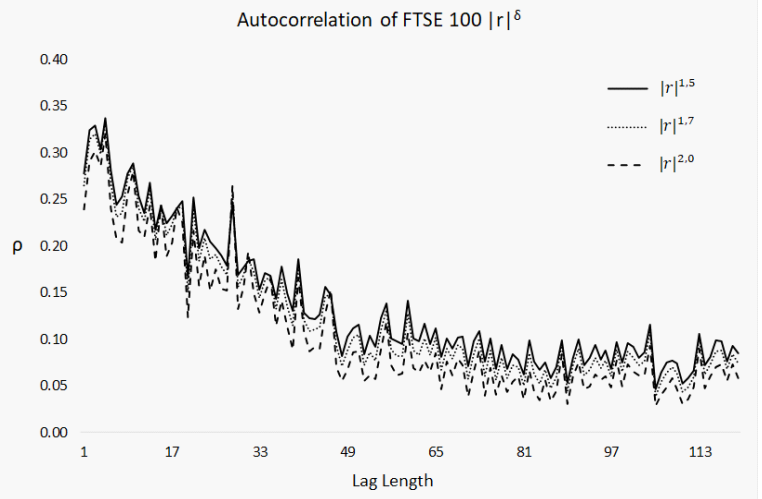

Figure 2. Autocorrelation of FTSE $100\left|r_{t}\right|^{\delta_{r}}$ for

$$
\delta_{r}=1.5,1.7,2.0
$$

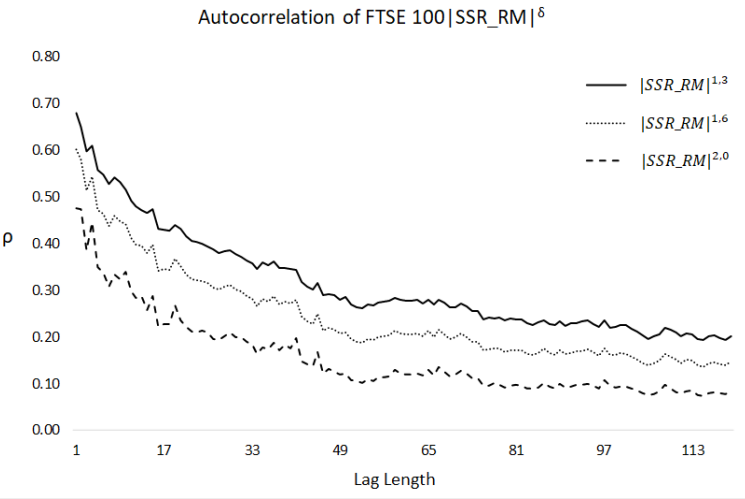

Figure 3. Autocorrelation of FTSE 100

$\left|S S R \_R M_{t}\right|^{\delta_{R}}$ for $\delta_{R}=1.3,1.6,2.0$ 


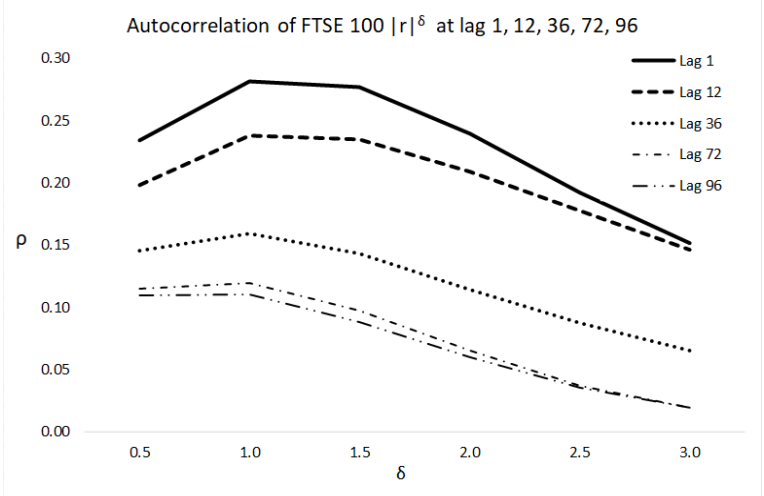

Figure 4. Autocorrelation of FTSE $100\left|r_{t}\right|^{\delta_{r}}$ at lags $1,12,36,72,96$

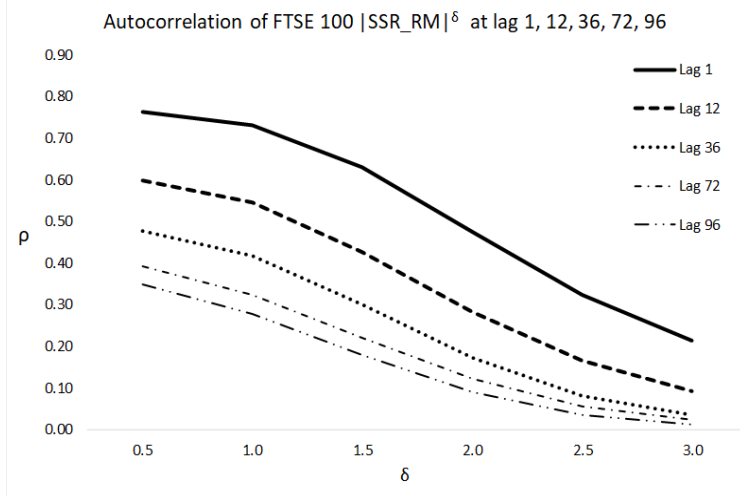

Figure 5. Autocorrelation of FTSE 100 $\left|S S R \_R M_{t}\right|^{\delta_{R}}$ at lags $1,12,36,72,96$

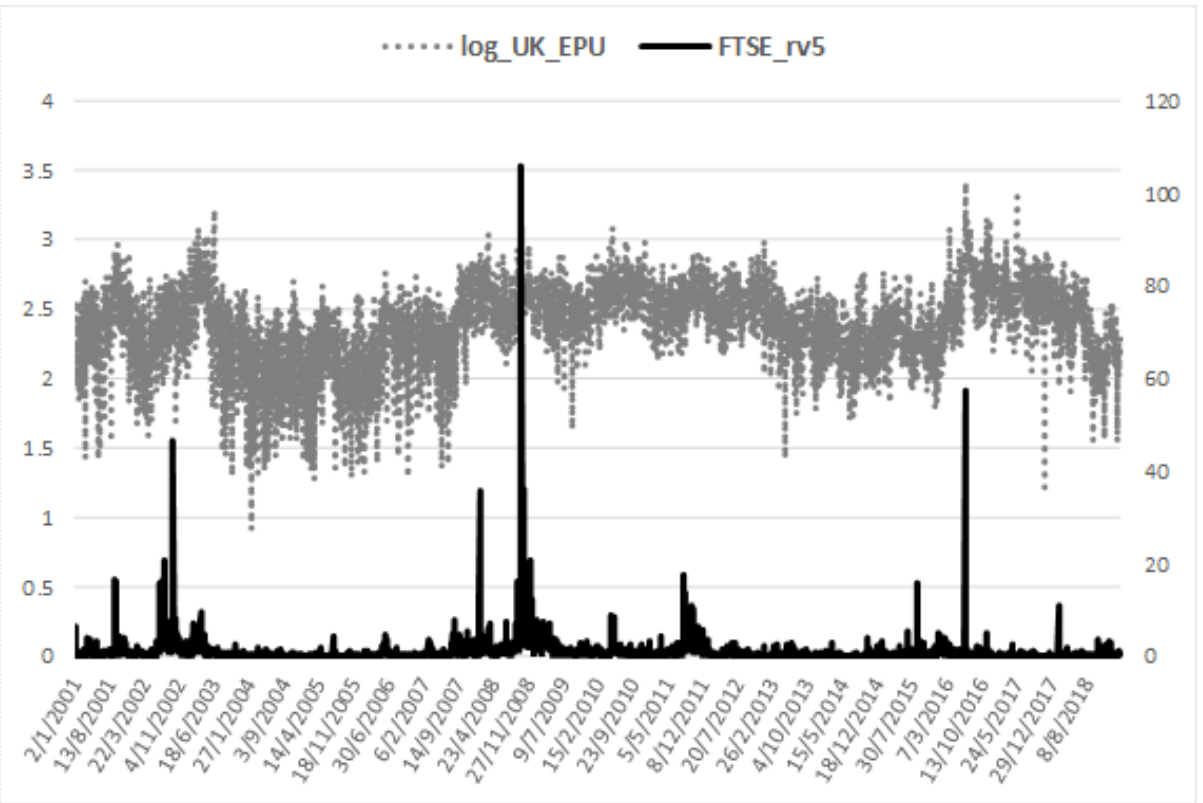

Figure 6. UK EPU and FTSE 100 Realized Variance 


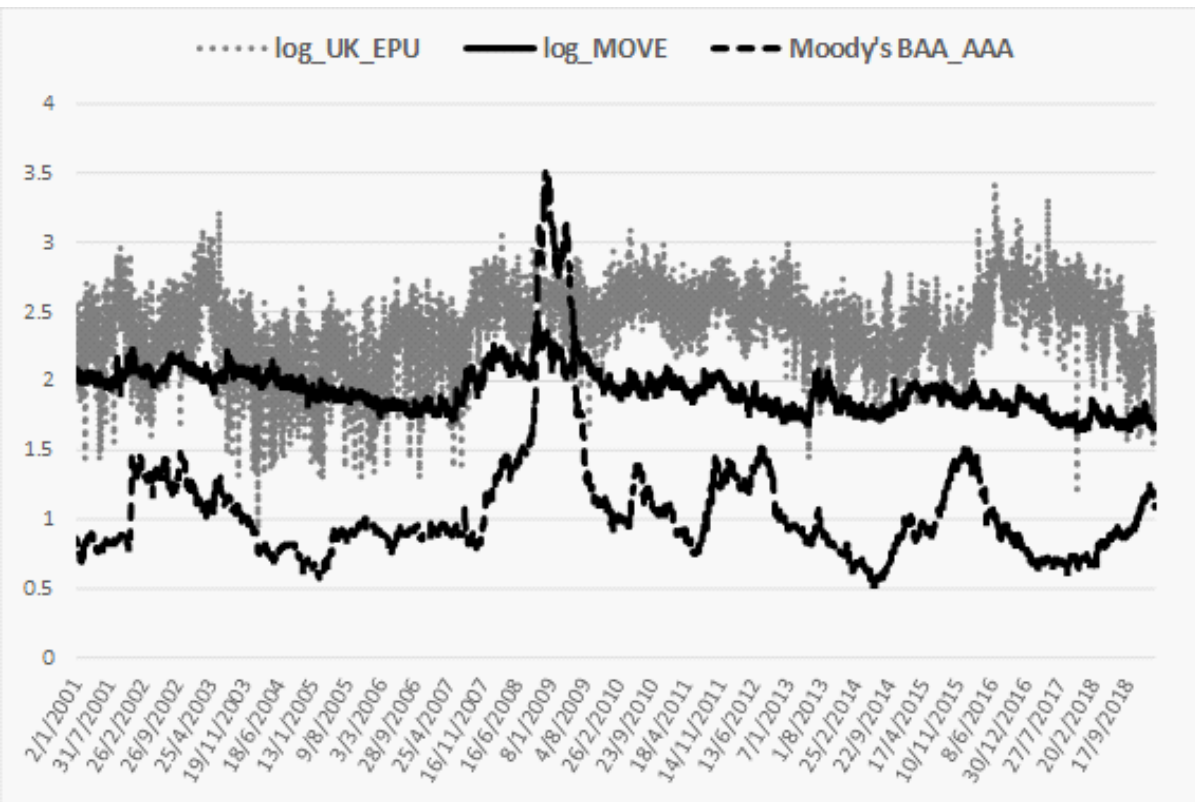

Figure 7. UK EPU and the Credit market proxies

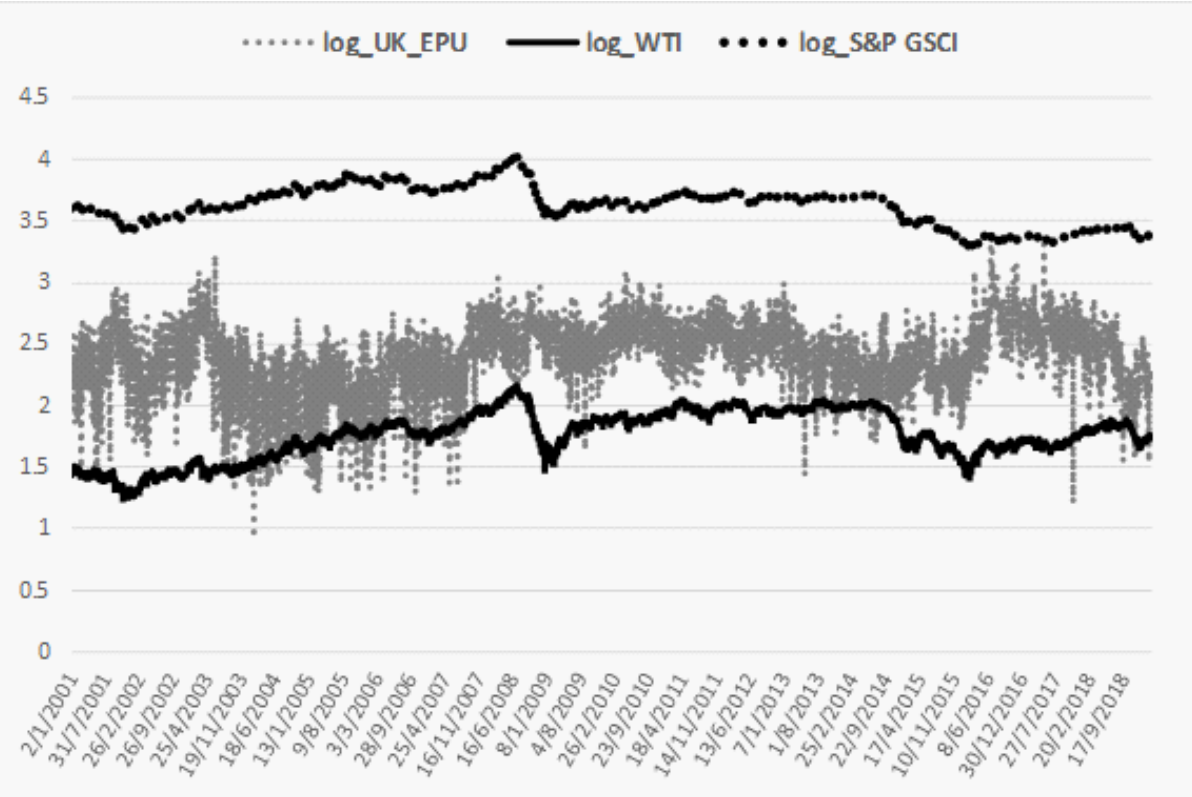

Figure 8. UK EPU and the Commodity market proxies 


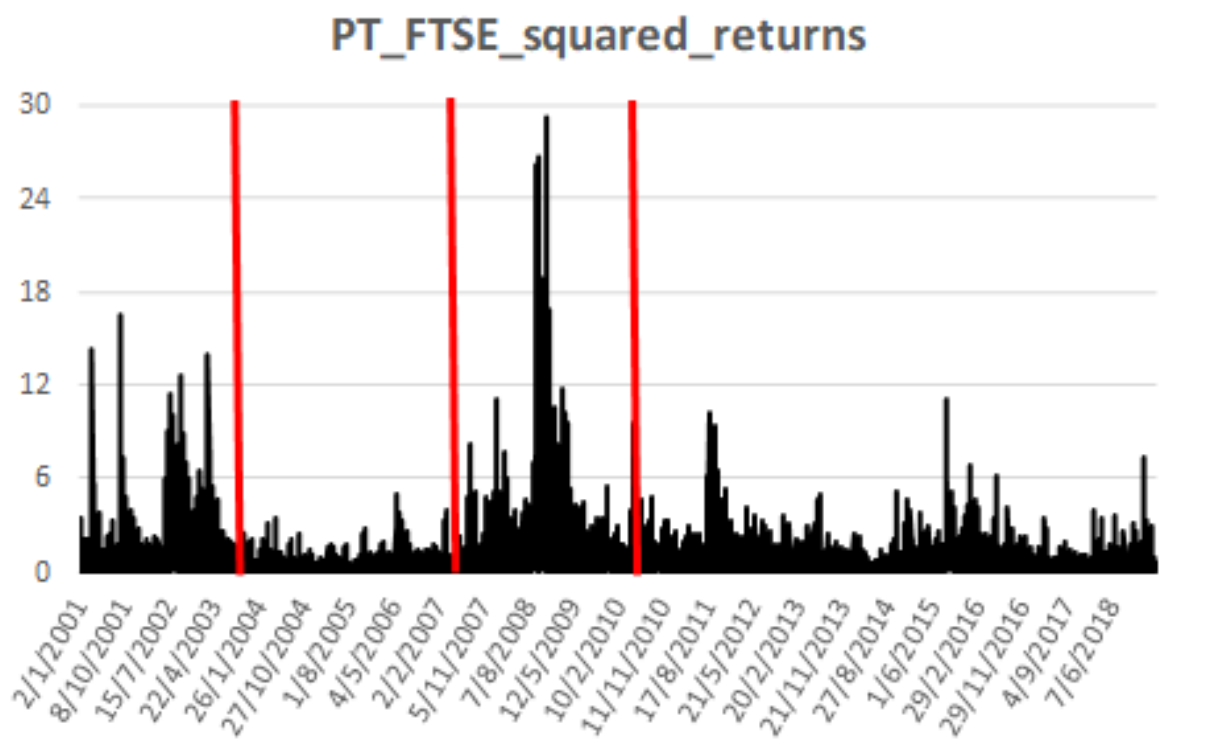

Figure 9. Power transformed FTSE Squared Returns with breaks

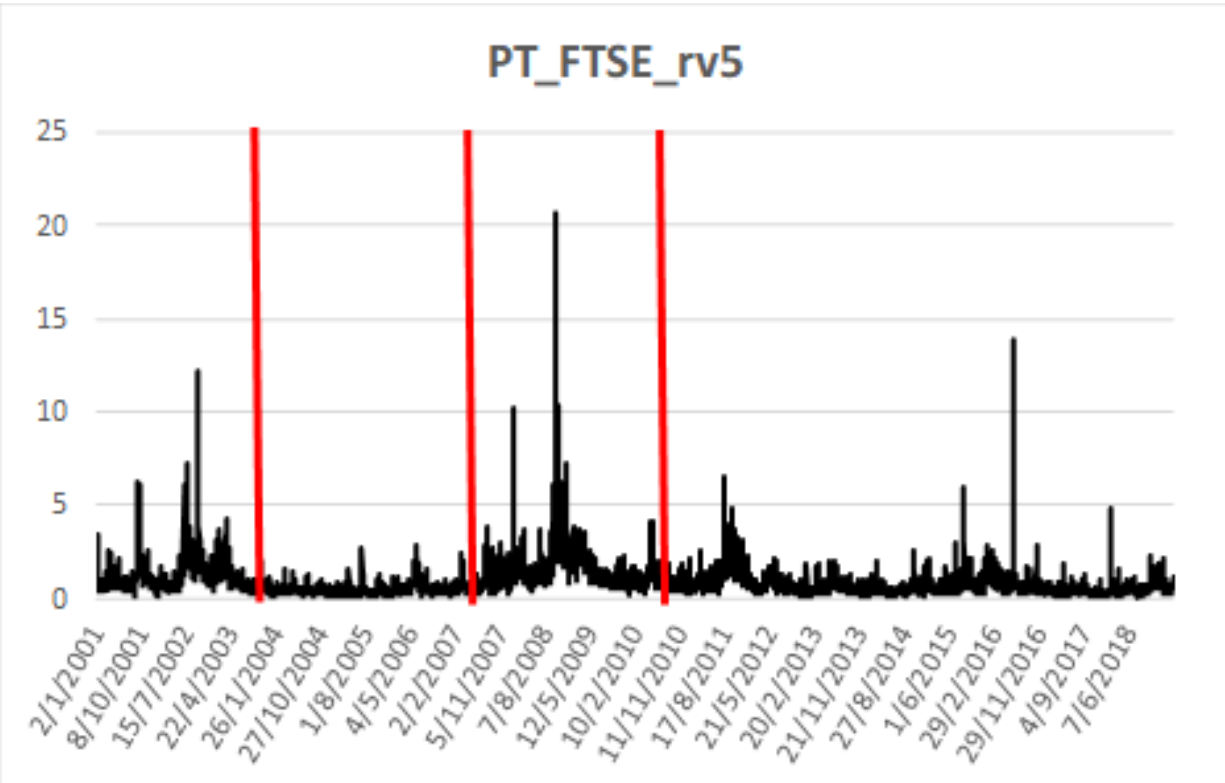

Figure 10. Power transformed FTSE Realized Variance with breaks 
FTSE_rv5

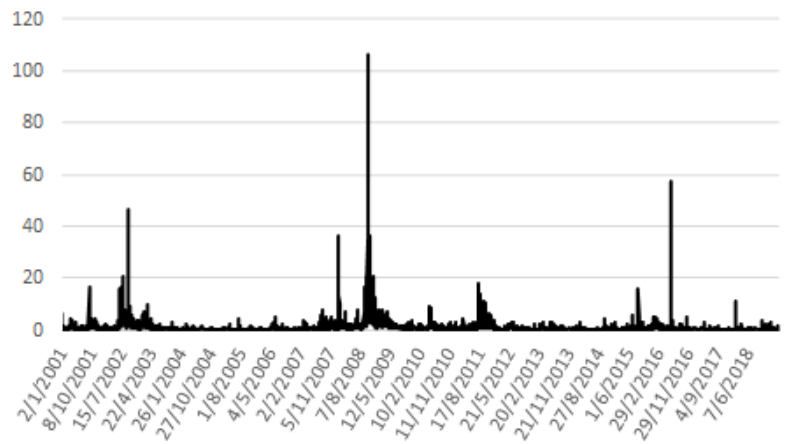

Figure A.1. FTSE 100 Realized Variance

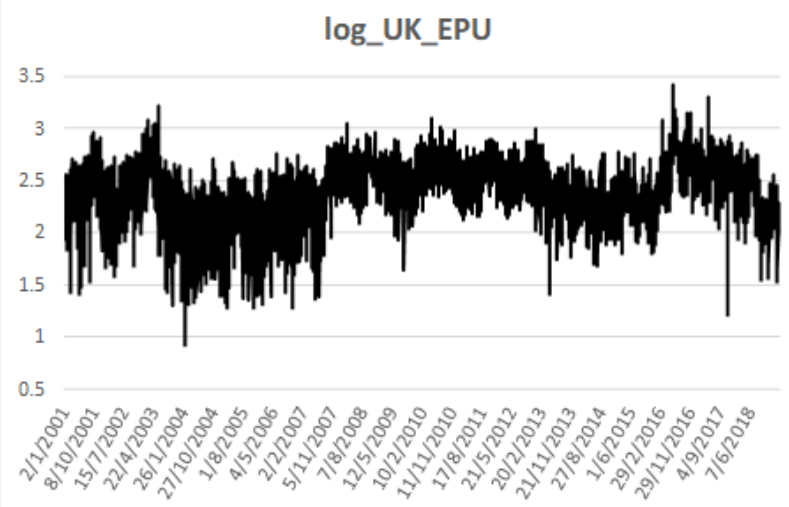

Figure A.3. UK Economic Policy Uncertainty

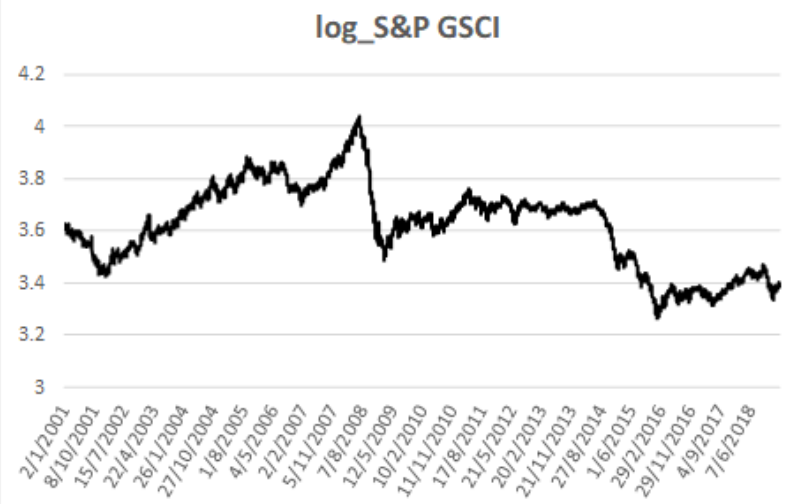

Figure A.4. S\&P GSCI
FTSE_squared_returns

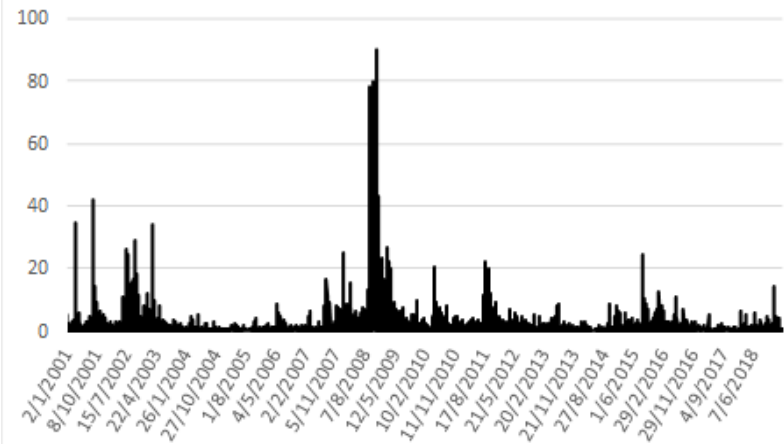

Figure A.2. FTSE 100 Squared Returns

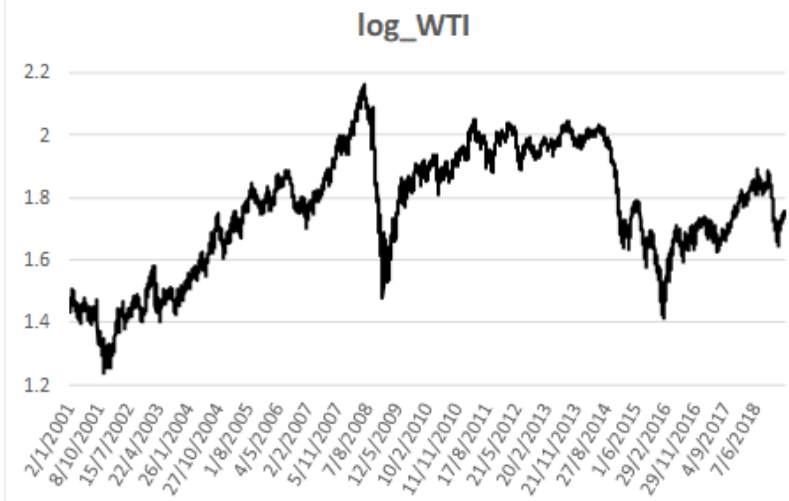

Figure A.5. Crude oil WTI 


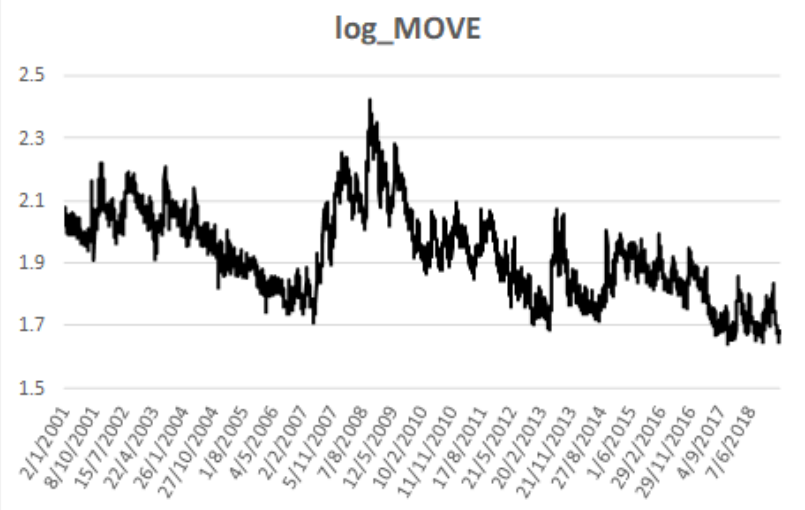

Figure A.6. Merrill Lynch MOVE 1 Month

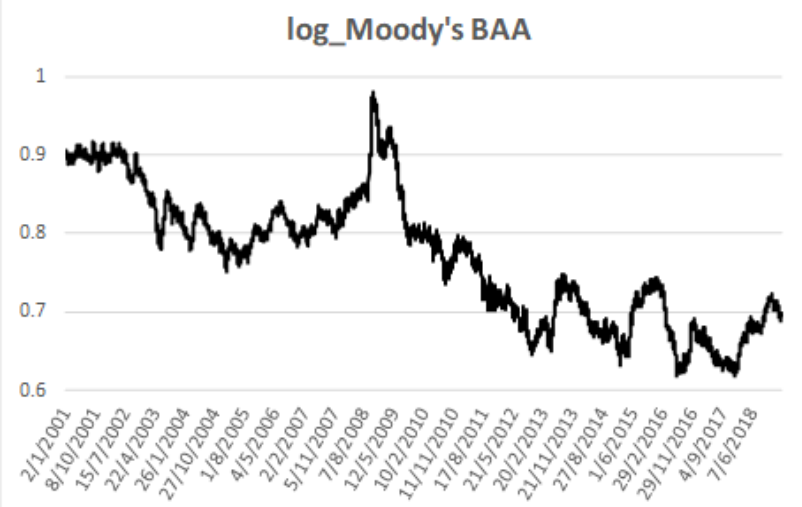

Figure A.8. Moody's BAA corporate bonds yield

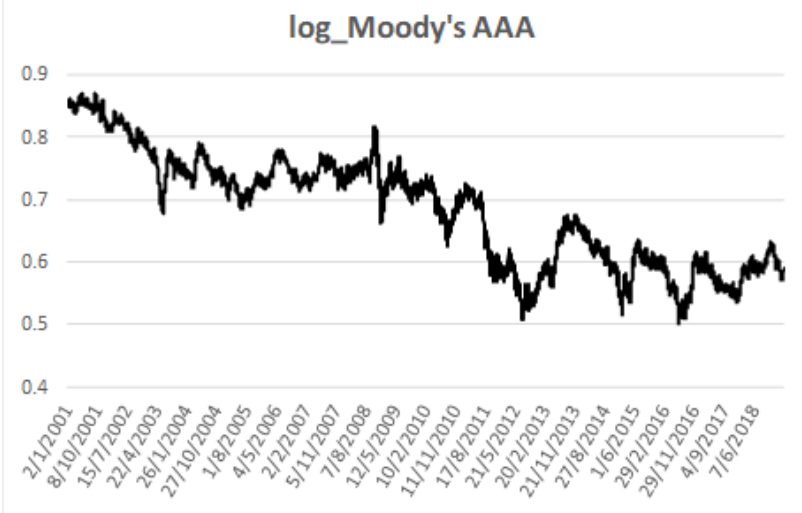

Figure A.7. Moody's AAA corporate bonds yield

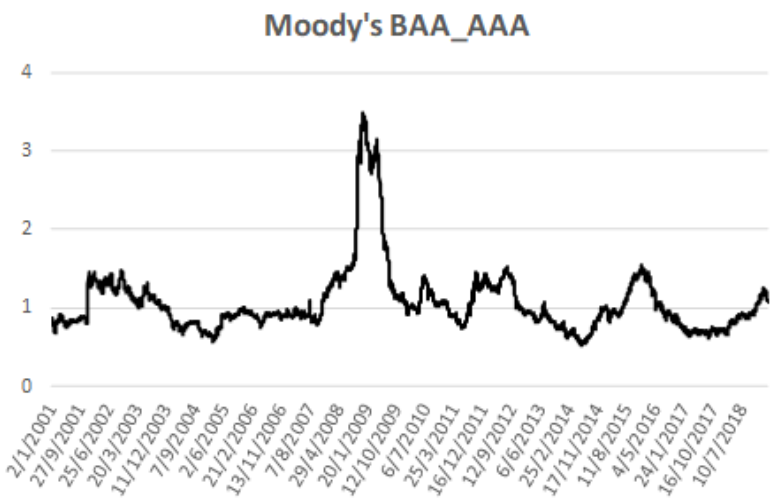

Figure A.9. BAA-AAA corporate bonds spread 

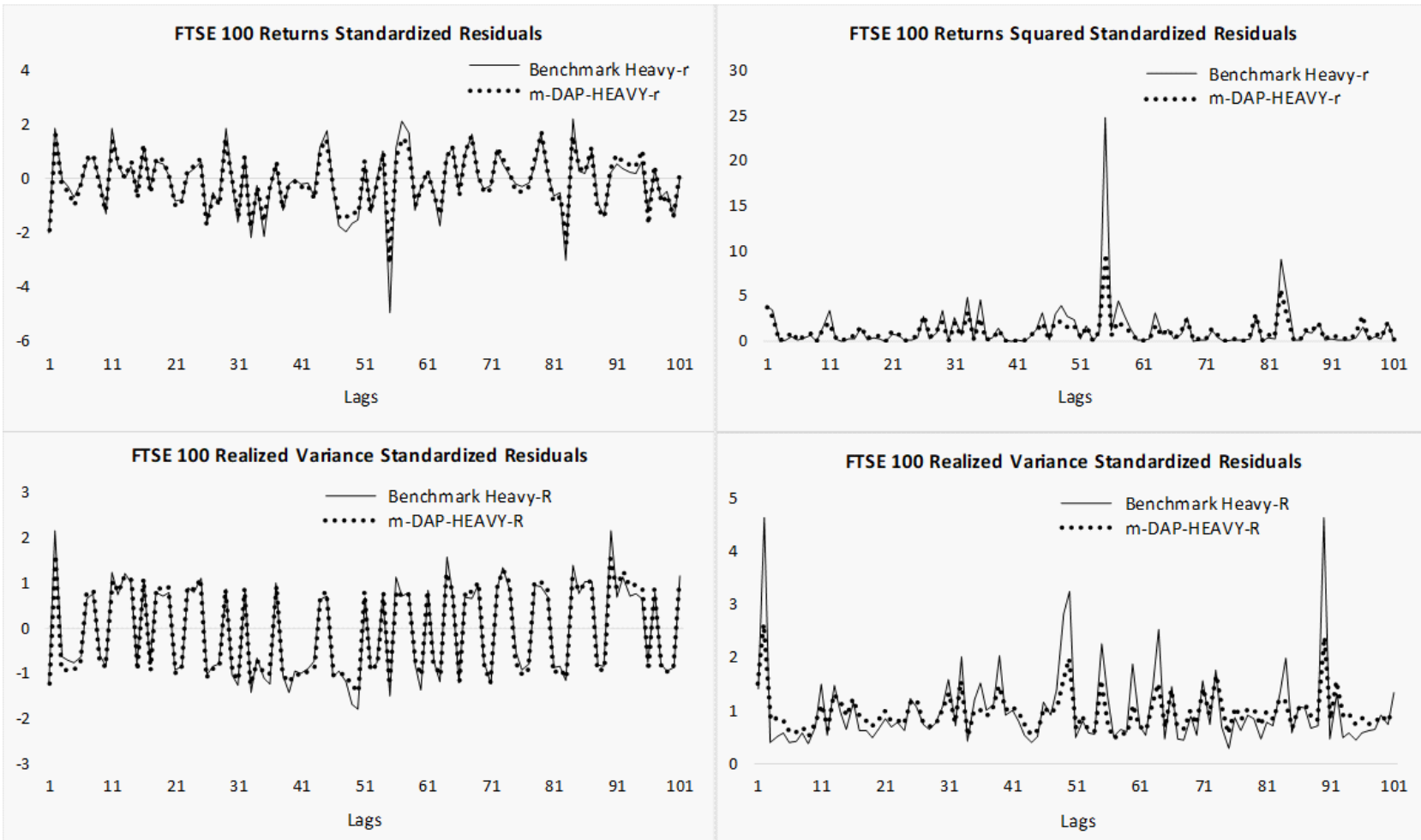

Figure A.10. FTSE 100 Standardized Residuals (Benchmark HEAVY and m-DAP-HEAVY models) 